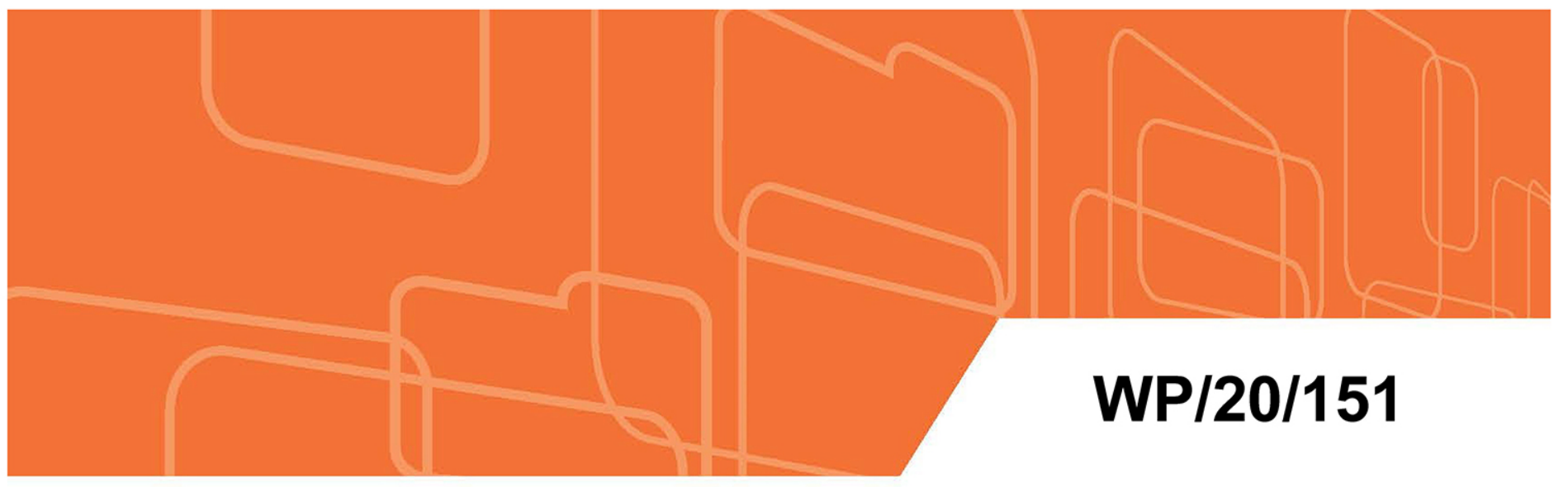

\title{
Managing Macrofinancial Risk
}

by Tobias Adrian and Francis Vitek

IMF Working Papers describe research in progress by the author(s) and are published to elicit comments and to encourage debate. The views expressed in IMF Working Papers are those of the author(s) and do not necessarily represent the views of the IMF, its Executive Board, or IMF management. 


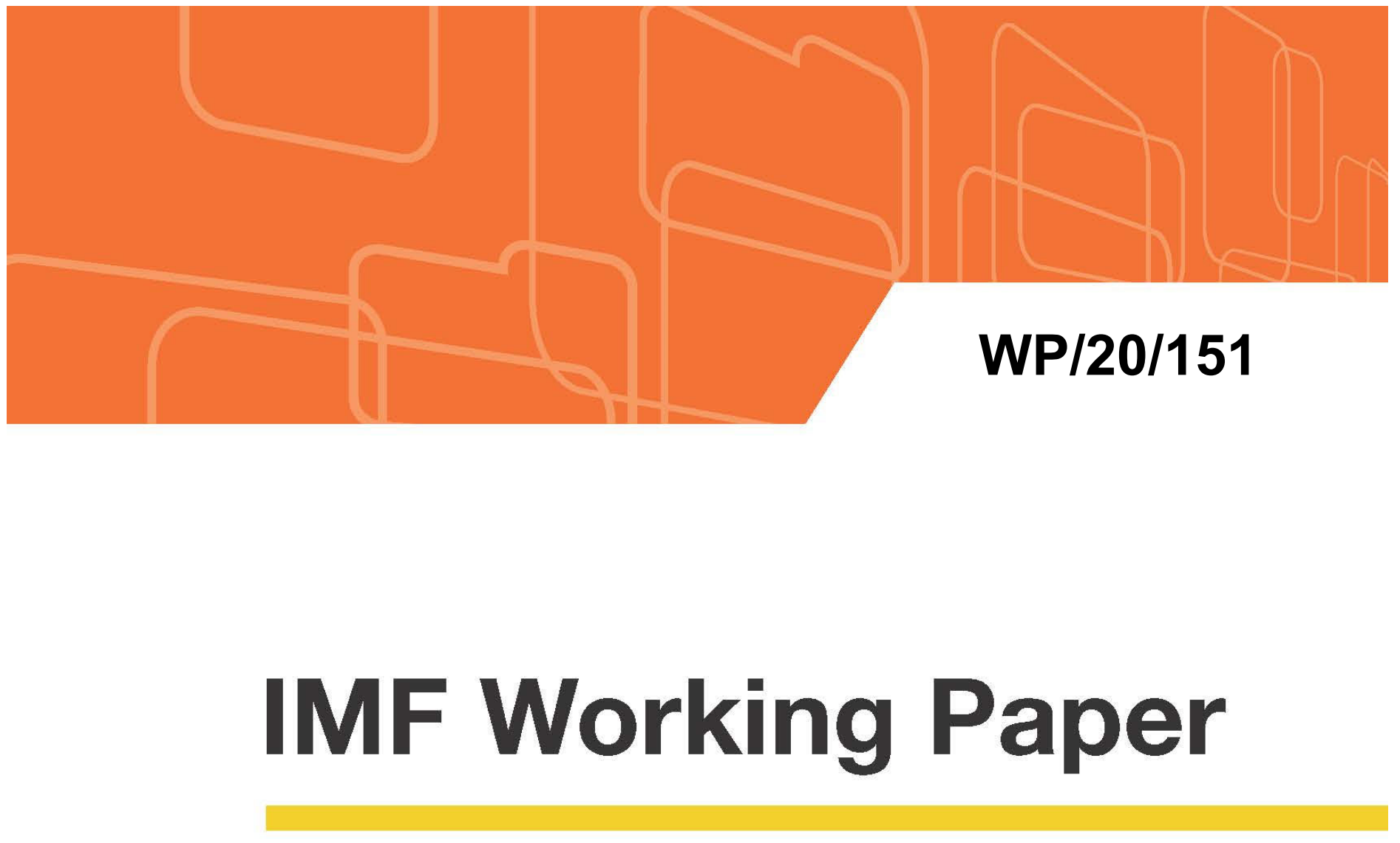

\section{Managing Macrofinancial Risk}

by Tobias Adrian and Francis Vitek

IMF Working Papers describe research in progress by the author(s) and are published to elicit comments and to encourage debate. The views expressed in IMF Working Papers are those of the author(s) and do not necessarily represent the views of the IMF, its Executive Board, or IMF management. 


\title{
IMF Working Paper
}

Monetary and Capital Markets Department

\section{Managing Macrofinancial Risk}

Prepared by Tobias Adrian and Francis Vitek ${ }^{1}$

Authorized for distribution by Tobias Adrian

August 2020

\section{IMF Working Papers describe research in progress by the author(s) and are published to} elicit comments and to encourage debate. The views expressed in IMF Working Papers are those of the author(s) and do not necessarily represent the views of the IMF, its Executive Board, or IMF management.

\begin{abstract}
We augment a linearized dynamic stochastic general equilibrium (DSGE) model with a tractable endogenous risk mechanism, to support the joint analysis of monetary and macroprudential policy. This state dependent conditional heteroskedasticity mechanism specifies the conditional variances of structural shocks as functions of the business or financial cycle. The resultant heteroskedastic linearized DSGE model preserves the satisfactory simulation and forecasting performance of its nested homoskedastic counterpart for the conditional means of endogenous variables, while substantially improving its goodness of fit to their conditional distributions. In particular, the model matches the key stylized facts of growth at risk. Accounting for state dependent conditional heteroskedasticity makes it optimal for monetary policy to respond more aggressively to the business cycle, and for macroprudential policy to manage the resilience of the banking sector more actively over the financial cycle.
\end{abstract}

JEL Classification Numbers: E3; E5

Keywords: Monetary policy; Macroprudential policy; Endogenous risk; Business cycle; Financial cycle; Growth at risk; Dynamic stochastic general equilibrium model; State dependent conditional heteroskedasticity

Author's E-Mail Addresses: TAdrian@IMF.org; FVitek@IMF.org

\footnotetext{
${ }^{1}$ The authors gratefully acknowledge comments and suggestions from Christopher Erceg and Jesper Lindé, as well as from seminar participants at the International Monetary Fund and the Bank of Japan.
} 


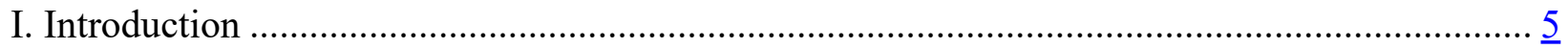

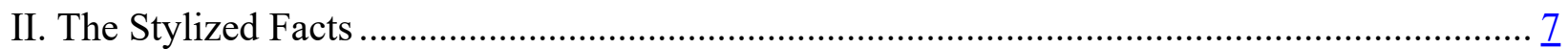

III. The Theoretical Framework ........................................................................................ 12

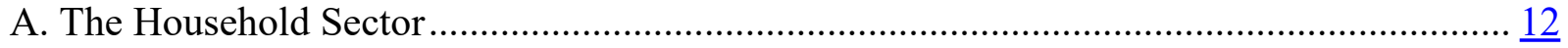

Consumption, Saving, and Residential Investment ................................................. 12

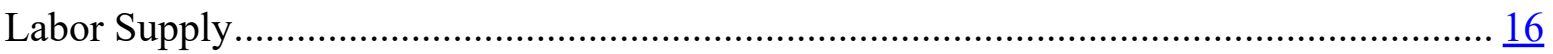

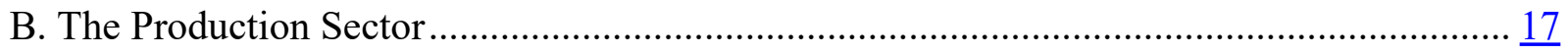

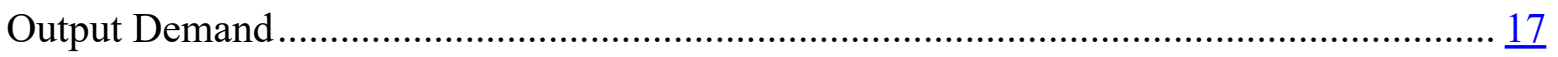

Labor Demand and Business Investment.................................................................. 18

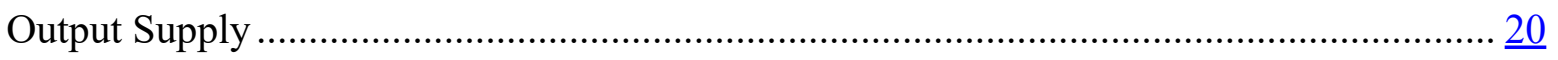

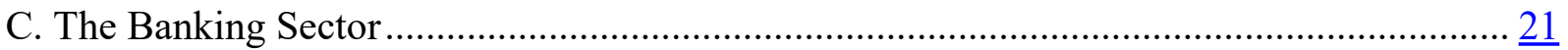

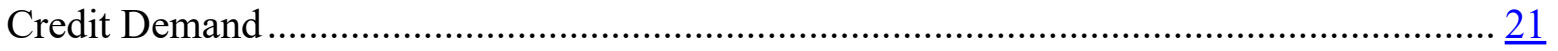

Funding Demand and Bank Capital Accumulation ................................................... 22

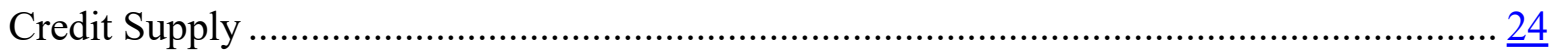

D. Monetary, Fiscal, and Macroprudential Policy .......................................................... 25

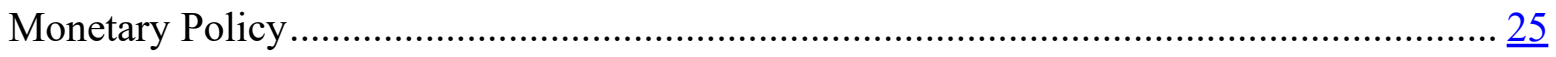

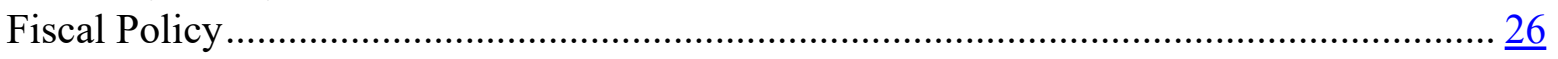

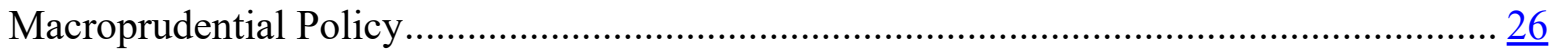

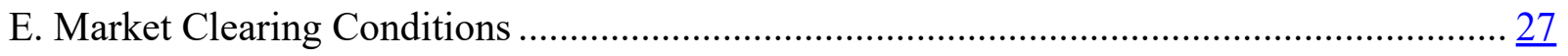

IV. The Empirical Framework .......................................................................................... 27

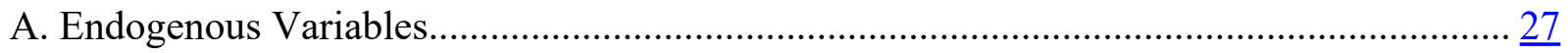

Cyclical Components ........................................................................................ 28

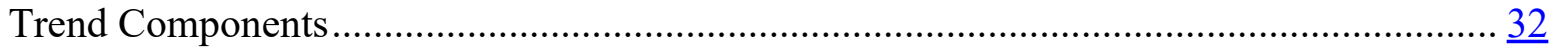

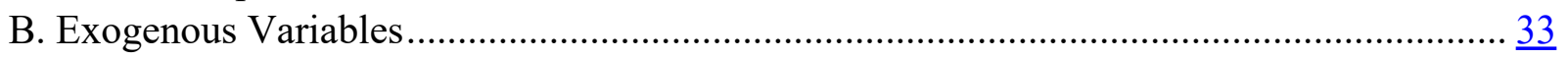

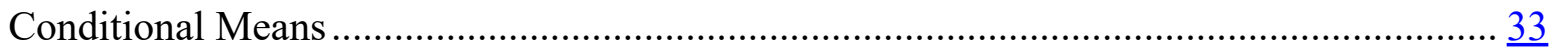

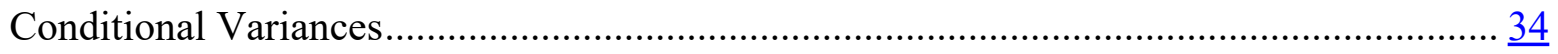

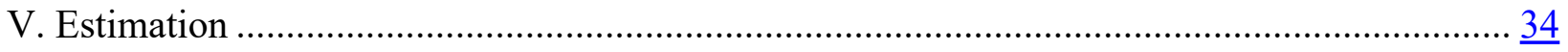

A. Estimation Procedure ....................................................................................... $\underline{35}$

B. Estimation Results.......................................................................................... $\underline{38}$

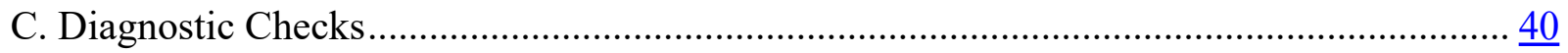

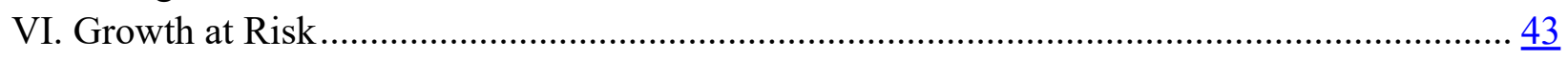

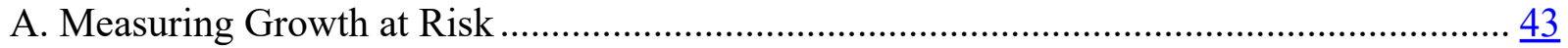

B. Explaining Growth at Risk ................................................................................ 45

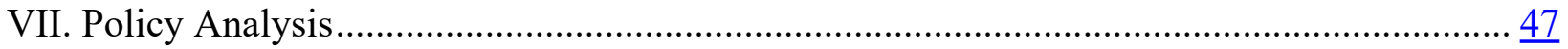

A. Transmission Mechanisms .................................................................................... 47

B. Counterfactual Distributions ............................................................................... $\frac{51}{53}$

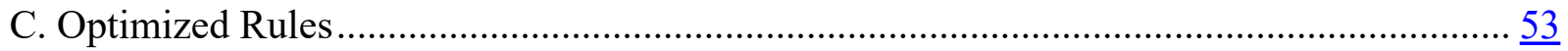

VIII. Conclusion ....................................................................................................... 55

Appendix. Estimation Results......................................................................................... 57

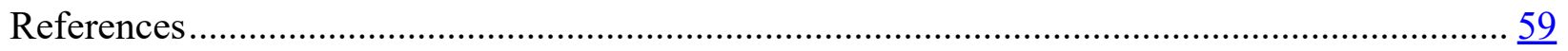




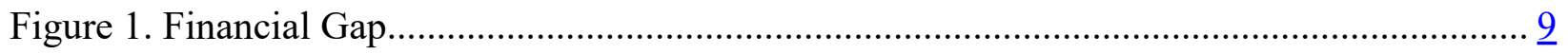

Figure 2. Conditional Quantiles of Output Growth ........................................................ 10

Figure 3. Conditional Mean versus Variance of Output Growth............................................. 11

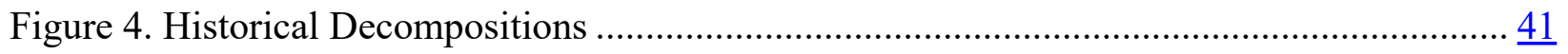

Figure 5. Sequential Dynamic Forecasts .................................................................. 42

Figure 6. Dynamic Forecast Comparison .................................................................... 43

Figure 7. Conditional Distribution of Output Growth ..................................................... 44

Figure 8. Conditional Quantiles of Output Growth ........................................................... 45

Figure 9. Decomposition of Growth at Risk .................................................................... 46

Figure 10. Conditional Mean versus Variance of Output Growth........................................... 47

Figure 11. Quantile Impulse Responses to a Monetary Policy Shock .................................... 49

Figure 12. Quantile Impulse Responses to a Macroprudential Policy Shock ........................... $\underline{50}$

Figure 13. Distribution of Output Growth Conditional on a Monetary Policy Shock................ $\underline{52}$

Figure 14. Distribution of Output Growth Conditional on a Macroprudential Policy Shock....... $\underline{53}$

Table 1. Optimized Rules ........................................................................................ 55

Table 2. Conditional Mean Function Parameters …........................................................ $\underline{57}$

Table 3. Conditional Variance Function Parameters .............................................................. $\underline{58}$ 


\section{INTRODUCTION}

Loose monetary policy stimulates the economy via the intertemporal substitution channel, boosting the conditional mean of output growth in the short run. But sustained loose monetary policy can also cause the buildup of financial vulnerabilities via the risk taking channel identified by Borio and Zhu (2012) and Adrian and Shin (2010), elevating the conditional variance of output growth over the medium term. Tight macroprudential policy can limit the potential decline in the conditional lower quantile of output growth over the medium term - mitigating medium run growth at risk - by making the banking sector more resilient to systemic risk arising from financial vulnerabilities - while leaning against their buildup. Based on the seminal contributions of Christiano, Eichenbaum and Evans (2005) and Smets and Wouters (2003), the linearized dynamic stochastic general equilibrium (DSGE) models currently in use at many central banks deliver simulation and forecasting performance on par with restricted vector autoregressions for the conditional means of their observed endogenous variables. But they are not well suited to analyzing such macrofinancial risk based interactions between monetary and macroprudential policy, because they lack endogenous variation in conditional second moments.

This paper augments a linearized DSGE model similar to those in use at central banks with a tractable endogenous risk mechanism, to support the joint analysis of monetary and macroprudential policy. This state dependent conditional heteroskedasticity mechanism specifies the conditional variances of structural shocks as loglinear functions of the predetermined phase and position of the business or financial cycle, as measured by the lagged change in and level of the output or financial gap. This specification choice is motivated by the empirical finding documented in Vitek (2018) that macrofinancial volatility tends to be low during business cycle expansions - which are associated with financial cycle upturns - and high during business cycle contractions - particularly when they coincide with financial cycle downturns. Our objective is to enhance the macrofinancial risk management capabilities of the linearized DSGE models that are widely used to help inform the conduct of monetary policy, so they can better support the joint analysis of monetary and macroprudential policy. We propose a tractable interim solution that offers satisfactory empirical performance.

The theoretical structure of our DSGE model builds on the basic New Keynesian model of a closed economy documented in Woodford (2003) and Galí (2015), adding to it a range of nominal and real rigidities, as well as extensive macrofinancial linkages. Following Smets and Wouters (2003), the model features short run nominal price and wage rigidities generated by monopolistic competition, staggered reoptimization, and partial indexation in the output and labor markets. Building on Christiano, Eichenbaum and Evans (2005) and Iacoviello (2005), the resultant inertia in inflation and persistence in output is enhanced with real rigidities such as habit persistence in consumption, adjustment costs in residential and business investment, and variable capital utilization. Following Galí (2011), the model incorporates involuntary unemployment though a reinterpretation of the labor market. Simplifying Vitek (2018), households have access to banks where they accumulate deposits, to a real estate market where they trade houses, and to capital markets where they trade money, bond and stock market securities. Building on Gerali, Neri, Sessa and Signoretti (2010) and Hülsewig, Mayer and Wollmershäuser (2009), banks issue risky mortgage and corporate loans to households and firms at infrequently adjusted predetermined 
mortgage and corporate loan rates, accumulating bank capital out of retained earnings given credit losses to satisfy a capital requirement. Motivated by Kiyotaki and Moore (1997), this borrowing by households and firms is collateralized against the values of the housing and capital stocks. The government implements monetary and macroprudential policy according to instrument rules.

Augmenting the approximate multivariate linear rational expectations representation of our DSGE model with state dependent conditional heteroskedasticity makes the conditional means and variances of its endogenous variables state dependent, allowing their conditional distributions to exhibit both location and scale shifts in response to shocks. We show that the rational expectations equilibrium of a linearized DSGE model is invariant to the presence of state dependent conditional heteroskedasticity, of the form under consideration where the conditional variances of structural shocks are driven by stationary predetermined endogenous variables. This implies that standard linear perturbation based solution algorithms remain applicable, and that the conditional mean function of its augmented linear state space representation is unchanged. It follows that the mean impulse responses of the nested homoskedastic linearized DSGE model are preserved, allowing simulation results established within that conventional empirical framework to be replicated. But unlike for its nested homoskedastic counterpart, the quantile impulse responses of the heteroskedastic linearized DSGE model differ from its mean impulse responses, because the conditional variance function is state dependent. We derive an analytical extension of the filter due to Kalman (1960) that allows for the form of state dependent conditional heteroskedasticity under consideration. This recursive multivariate nonlinear filter facilitates estimation of the augmented linear state space representation of our heteroskedastic linearized DSGE model by Bayesian maximum likelihood, without resorting to simulation methods.

Our heteroskedastic linearized DSGE model shares many features in common with the homoskedastic linearized DSGE models currently in use at many central banks, inheriting their satisfactory simulation and forecasting performance for conditional means. Based on macrofinancial time series data sets for Japan and the United States, we find that augmenting our linearized DSGE model with a parsimonious form of state dependent conditional heteroskedasticity yields a substantial improvement in its goodness of fit to the conditional distributions of its observed endogenous variables. These economies are considered because they experienced the combined bursting of credit fueled property and stock market bubbles in recent decades, and can be reasonably approximated as closed. In particular, we show that our heteroskedastic linearized DSGE model matches the key stylized facts from the growth at risk literature introduced by Adrian, Boyarchenko and Giannone (2019). This enhances its ability to jointly analyze monetary and macroprudential policy, where macrofinancial risk management considerations call for looking beyond how alternative instrument rules affect the conditional first and unconditional second moments of the distributions of target variables, to how they also affect their conditional second and potentially higher moments. Indeed, we find that our state dependent conditional heteroskedasticity mechanism substantially alters the jointly optimized response coefficients of monetary and macroprudential policy rules under quadratic loss. In particular, accounting for state dependent conditional heteroskedasticity makes it optimal for monetary policy to respond more aggressively to the business cycle, and for macroprudential policy to manage the resilience of the banking sector more actively over the financial cycle. 
Our novel approach to augmenting a linearized DSGE model to allow for variation in conditional second moments parallels some established alternatives. One is to add stochastic volatility to the structural shocks driving a linearized DSGE model, following Justiniano and Primiceri (2008). Another is to add Markov regime switching variances to them, following Liu, Waggoner and Zha (2011). From a policymaking perspective, the advantage of our approach over these alternatives is that it endogenizes the variation in conditional second moments, implying that the conditional quantiles of target variables depend nonuniformly on the levels of policy instruments. Nevertheless, our approach is computationally inexpensive, as simulation methods are not needed to estimate conditional means and variances, or to evaluate the loglikelihood function. Of course, not deriving the specification of the conditional variance function from microeconomic foundations exposes our approach to the critique due to Lucas (1976), and its slope coefficients may not be invariant to policy interventions. But a state dependent conditional heteroskedasticity mechanism can readily be bolted onto existing linearized DSGE models in use at central banks to enhance their macrofinancial risk management capabilities, while more complex nonlinear DSGE models with satisfactory simulation and forecasting performance are being developed. A step in this direction was taken by Adrian and Duarte (2017), who derive a fully microfounded extension of the basic New Keynesian model of a closed economy with financial vulnerabilities in continuous time that features endogenous variation in conditional second moments and matches the key stylized facts of growth at risk.

The organization of this paper is as follows. The next section documents the key stylized facts of growth at risk. Section three develops the theoretical framework, while section four describes the corresponding empirical framework. Estimation of this empirical framework, and examination of its goodness of fit, is the subject of section five. The measurement of growth at risk, and inference on its sources, is conducted in section six. The implications of our state dependent conditional heteroskedasticity mechanism for monetary and macroprudential policy are assessed in section seven. Finally, section eight offers conclusions and recommendations for further research.

\section{The STYLIZEd FACTS}

Our structural analysis of growth at risk matches stylized facts derived from a corresponding reduced form analysis. These key stylized facts are robust properties of the distribution of output growth, conditional on the lagged change in and level of the financial gap. They are consistent with the findings of Adrian, Boyarchenko and Giannone (2019), as well as many related empirical analyses. The change in the financial gap reflects financial conditions, while its level measures financial vulnerability. Following convention, we refer to the conditional lower quantile of output growth as growth at risk.

We estimate the financial gap by aggregating a set of financial vulnerability indicators $\left\{x_{k, i, t}\right\}_{k=1}^{K}$ using a panel regression with indicator and economy specific fixed effects,

$$
\Delta_{S} \frac{x_{k, i, t}-\hat{\mu}_{k, i}}{\hat{\sigma}_{k, i}}=\beta_{0, k, i}+\sum_{k=1}^{K} \beta_{1, k} x_{k, i, t-h}+\varepsilon_{k, i, t},
$$


where $\Delta_{S}$ denotes the seasonal difference operator. For each economy $i$, the change in each standardized financial vulnerability indicator at time $t$ depends on a linear combination of the set of lagged financial vulnerability indicators. We estimate this panel regression by pooled quantile regression with dummy variables at the 0.05 quantile using a two year lag order, and generate the financial gap as $x_{i, t}=\sum_{k=1}^{K} \hat{\beta}_{1, k} x_{k, i, t} / \sum_{k=1}^{K} \hat{\beta}_{1, k}$. This financial gap is that weighted average of financial vulnerability indicators which predicts a severe broad based unwinding of financial vulnerabilities when elevated.

To align our structural and reduced form analyses of growth at risk, we restrict the set of financial vulnerability indicators under consideration to consist of credit, house price and equity price gaps, estimated using the same data observed for Japan and the United States over the sample period 1980Q1 to 2019Q3. These financial vulnerability indicators are found to be key determinants of business and financial cycle interactions by Claessens, Kose and Terrones (2012). Credit is measured by total credit to the nonfinancial private sector, the price of housing is proxied by a broad residential property price index, and the price of equity is proxied by a broad stock price index. These nominal variables are deflated by the price level, measured by the seasonally adjusted gross domestic product price deflator. We estimate the credit, house price and equity price gaps by passing the logarithms of these real variables through the filter described in Hodrick and Prescott (1997), setting the smoothing parameter to a relatively high value of 16,000, given that financial cycles tend to be longer than business cycles. We then generate the financial gap by aggregating these financial vulnerability indicators following our panel quantile regression based methodology. The estimated weight on the credit gap is 0.72 , while that on the house price gap is 0.23 , and that on the equity price gap is 0.05 . Our estimated financial gap peaks prior to the combined bursting of the credit fueled property and stock market bubbles in Japan in the early 1990s, and in the United States in the late 2000s. 
Figure 1. Financial Gap
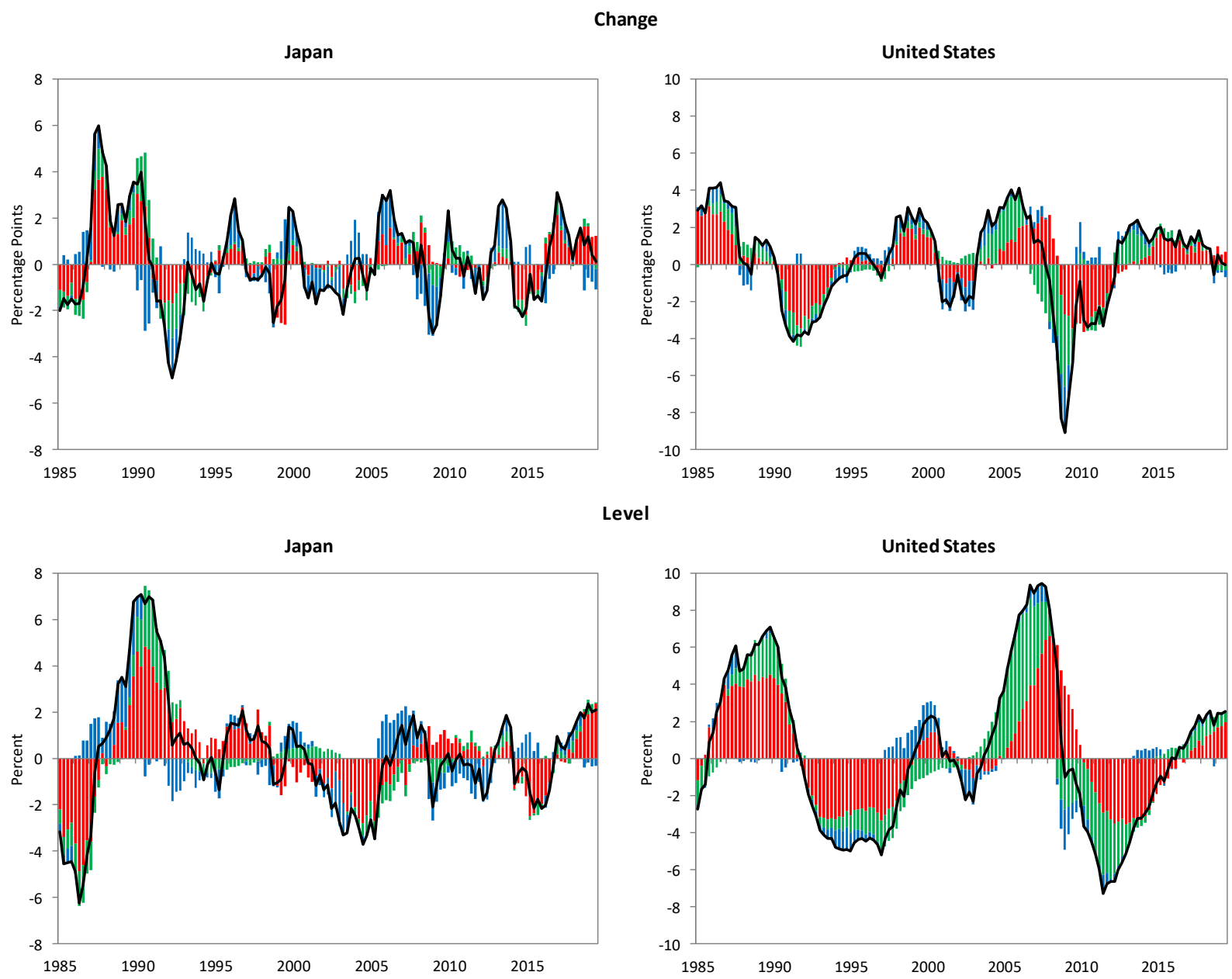

Note: Decomposes the seasonal difference and level of the estimated financial gap $\boldsymbol{m}$ into contributions from the credit $\square$, house price $\square$ and equity price $\square$ gaps.

Our first stylized fact is that the conditional lower quantile of output growth is more volatile than its conditional mean, which in turn is more volatile than its conditional upper quantile. This result is based on a panel regression of output growth $\Delta_{S} y_{i, t}$ on the lagged change in and level of the financial gap with economy specific fixed effects,

$$
\Delta_{S} y_{i, t}=\beta_{0, i}+\beta_{1} \Delta_{S} x_{i, t-h}+\beta_{2} x_{i, t-h}+\varepsilon_{i, t},
$$

where output is detrended by passing its logarithm through the filter described in Hodrick and Prescott (1997), setting the smoothing parameter to 16,000 . We generate the conditional mean of output growth as fitted values from this panel regression, estimated by pooled ordinary least squares with dummy variables. We also generate the conditional lower and upper quantiles of output growth as fitted values from this panel regression, estimated by pooled quantile regression with dummy variables at the 0.05 and 0.95 quantiles. We consider short and medium run projection horizons, corresponding to one and three year lag orders. Our short and medium run growth at risk estimates closely track the business cycle contractions that were associated with financial cycle downturns in Japan in the early 1990s, and in the United States in the early 1990s, early 2000s and 
late 2000s. In contrast, they do not fully track the sharp business cycle contraction that occurred in Japan in the late 2000 s, because it did not coincide with a sharp domestic financial cycle downturn. Across both economies and horizons, the sample variance of the estimated conditional lower quantile exceeds that of the estimated conditional mean, which in turn exceeds that of the estimated conditional upper quantile.

Figure 2. Conditional Quantiles of Output Growth
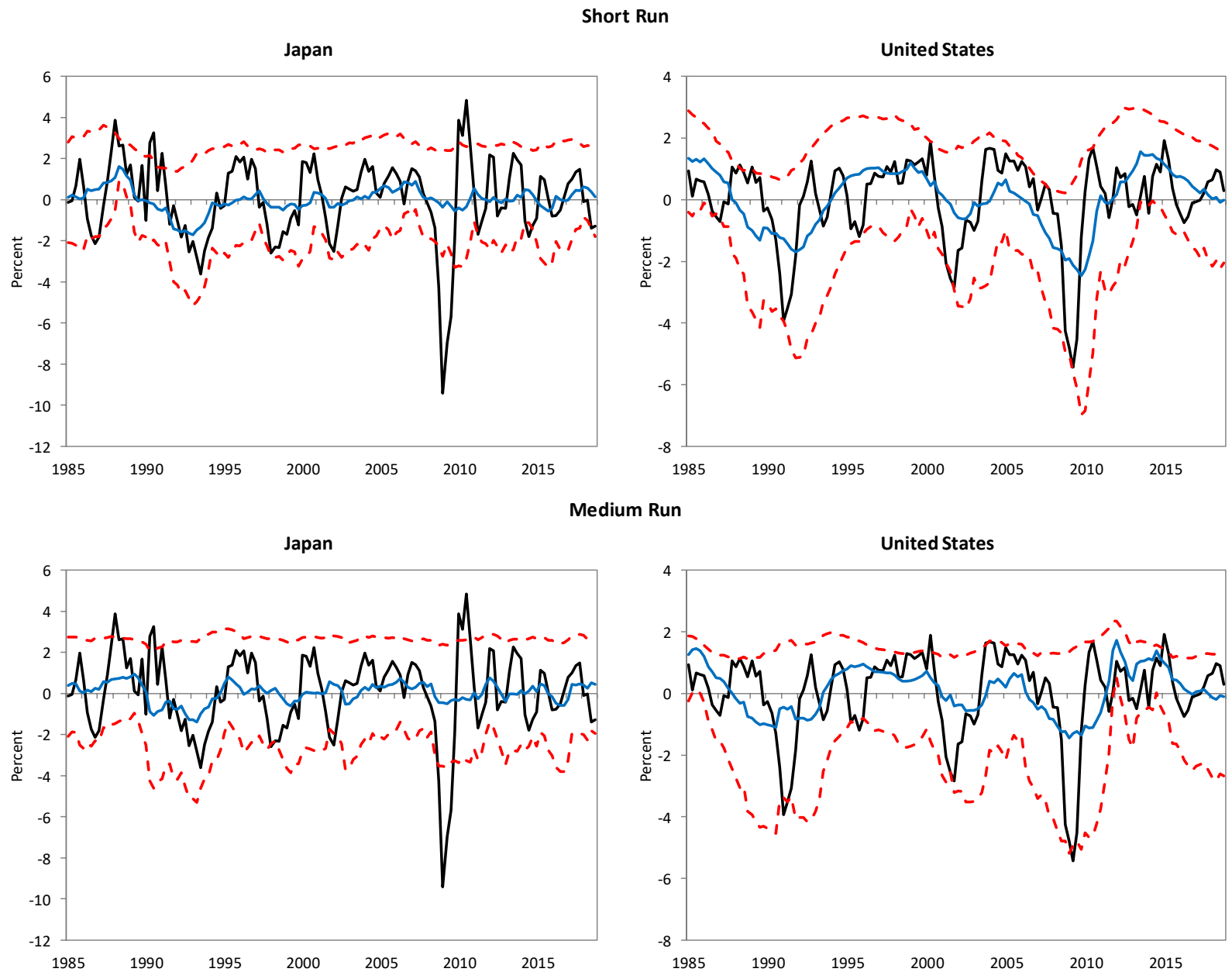

Note: Depicts the cyclical component of observed output growth $\mathbf{m}$ as measured by the seasonal difference of the cyclical component of the logarithm of output versus the one and three year ahead predicted mean $\square$ and 0.05 and 0.95 quantiles $\boldsymbol{~}$.

Our second stylized fact is that the conditional mean and variance of output growth are strongly negatively correlated. This result is based on a panel regression of the logarithm of the squared residuals $\hat{\varepsilon}_{i, t}$ from estimating the conditional mean of output growth on the lagged change in and level of the financial gap with economy specific fixed effects:

$$
\ln \hat{\varepsilon}_{i, t}^{2}=\gamma_{0, i}+\gamma_{1} \Delta_{S} x_{i, t-h}+\gamma_{2} x_{i, t-h}+v_{i, t} .
$$

We generate the conditional variance of output growth as exponentiated fitted values from this panel regression, estimated by pooled ordinary least squares with dummy variables for short and 
medium run projection horizons. Across both economies and horizons, the sample correlation between the conditional mean and variance is negative, ranging from -0.71 to -0.94 .

Figure 3. Conditional Mean versus Variance of Output Growth

Short Run
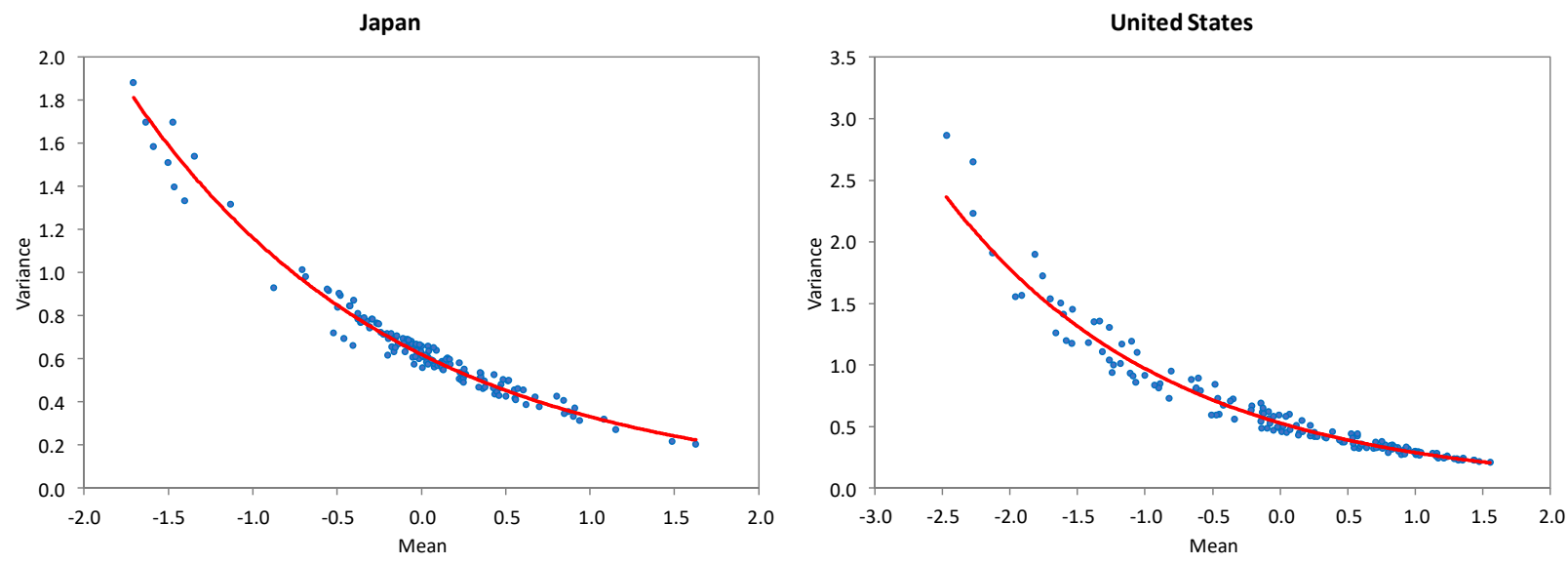

Medium Run
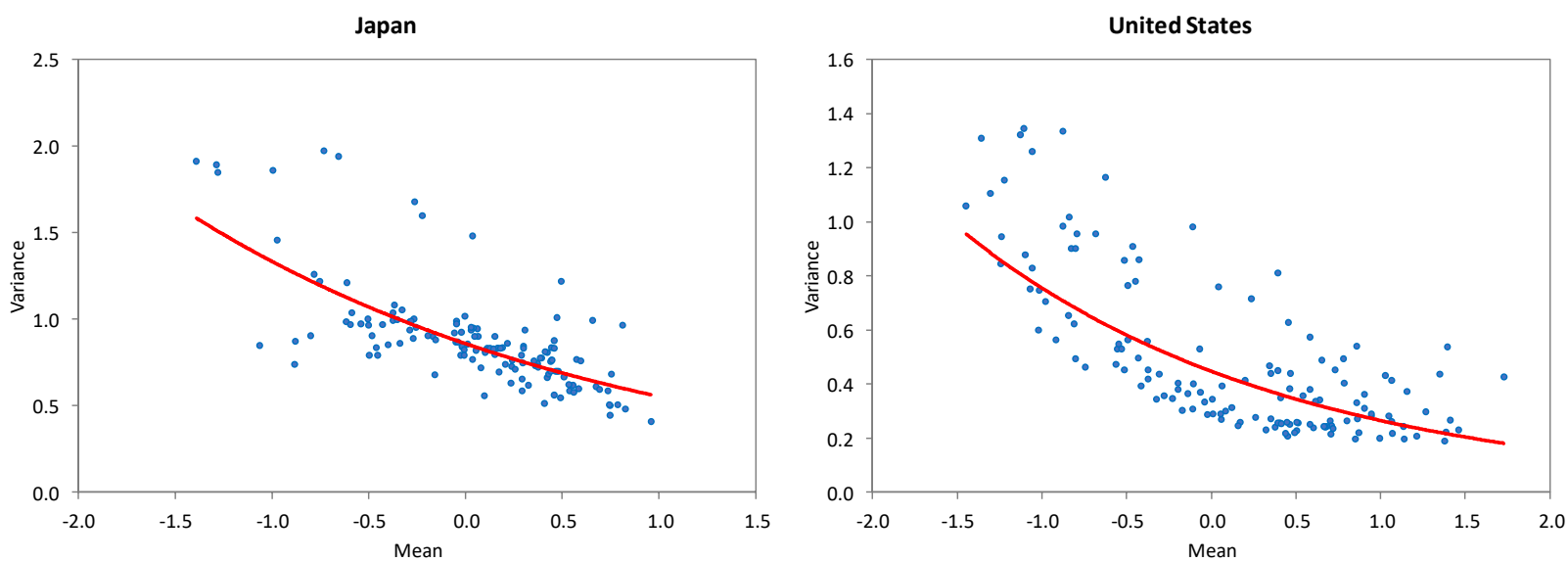

Note: Depicts the one and three year ahead predicted mean versus variance of the cyclical component of output growth $\square$, together with exponentiated ordinary least squares fitted values from a simple loglinear regression $\mathbf{\square}$.

These stylized facts are closely related but not equivalent. ${ }^{2}$ Intuitively, if the conditional mean and variance of output growth are negatively correlated, then a fall in the conditional mean is associated with a rise in the conditional variance, which amplifies the fall in the conditional lower quantile. Conversely, a rise in the conditional mean is associated with a fall in the conditional variance, which mitigates the rise in the conditional upper quantile.

\footnotetext{
${ }^{2}$ If output growth is conditionally normally distributed, then its conditional $\alpha$ quantile $q_{i, t}^{\alpha}$ depends on its conditional mean $\mu_{i, t}$ and standard deviation $\sigma_{i, t}$ according to $q_{i, t}^{\alpha}=\mu_{i, t}+z_{\alpha} \sigma_{i, t}$, where $z_{\alpha}$ denotes the $\alpha$ quantile of the standard normal distribution. Since $z_{\alpha}$ is increasing in $\alpha$, if $\operatorname{Cov}\left(\mu_{i, t}, \sigma_{i, t}\right)<0$ then $\operatorname{Var}\left(q_{i, t}^{\alpha}\right)=$ $\operatorname{Var}\left(\mu_{i, t}\right)+z_{\alpha}^{2} \operatorname{Var}\left(\sigma_{i, t}\right)+2 z_{\alpha} \operatorname{Cov}\left(\mu_{i, t}, \sigma_{i, t}\right)$ is decreasing in $\alpha$ for $z_{\alpha}<-\operatorname{Cov}\left(\mu_{i, t}, \sigma_{i, t}\right) / \operatorname{Var}\left(\sigma_{i, t}\right)$.
} 


\section{THE THEORETICAL FRAMEWORK}

Consider a closed economy consisting of households, firms, banks and a government, which in turn consists of a monetary authority, a fiscal authority and a macroprudential authority. Households, firms and banks optimize intertemporally, interacting with the government in an uncertain environment to determine equilibrium prices and quantities under rational expectations in output, housing, labor and financial markets.

\section{A. The Household Sector}

There exists a continuum of identical households indexed by $i \in[0,1]$. In a reinterpretation of the labor market in the model of nominal wage rigidity proposed by Erceg, Henderson and Levin (2000) to incorporate involuntary unemployment along the lines of Galí (2011), each household consists of a continuum of members represented by the unit square and indexed by $(g, h) \in[0,1] \times[0,1]$. There is full risk sharing among household members, who supply indivisible differentiated intermediate labor services indexed by $g \in[0,1]$, incurring disutility from work determined by $h \in[0,1]$ if they are employed and zero otherwise.

The set of assets under consideration consists of bank deposits, houses, short term bonds, long term bonds and stocks. Houses are in fixed supply at one per household. Short term bonds are discount bonds, while long term bonds are perpetual bonds with coupon payments that decay exponentially at rate $\omega^{B}$ where $0<\omega^{B}<1$, following Woodford (2001).

\section{Consumption, Saving, and Residential Investment}

Each infinitely lived household $i$ has preferences defined over consumption $C_{i, s}$, housing $S_{i, s}^{H} H_{i, s}$, labor supply $\left\{L_{i, g, s}\right\}_{g=0}^{1}$, houses $S_{i, s+1}^{H}$, long term bonds $\left\{B_{i, j, s+1}^{L}\right\}_{j=1}^{s}$ and stocks $\left\{S_{i, k, s+1}^{F}\right\}_{k=0}^{1}$ represented by intertemporal utility function

$$
U_{i, t}=\mathrm{E}_{t} \sum_{s=t}^{\infty} \beta^{s-t} u\left(C_{i, s}, S_{i, s}^{H} H_{i, s},\left\{L_{i, g, s}\right\}_{g=0}^{1}, S_{i, s+1}^{H},\left\{B_{i, j, s+1}^{L}\right\}_{j=1}^{s},\left\{S_{i, k, s+1}^{F}\right\}_{k=0}^{1}\right),
$$

where $\mathrm{E}_{t}$ denotes the expectations operator conditional on information available in period $t$, and $0<\beta<1$. The intratemporal utility function is additively separable and represents external habit formation preferences in consumption,

$$
\begin{aligned}
& u\left(C_{i, s}, S_{i, s}^{H} H_{i, s},\left\{L_{i, g, s}\right\}_{g=0}^{1}, S_{i, s+1}^{H},\left\{B_{i, j, s+1}^{L}\right\}_{j=1}^{s},\left\{S_{i, k, s+1}^{F}\right\}_{k=0}^{1}\right)=v_{s}^{C}\left[\frac{\left(C_{i, s}-\alpha C_{s-1}\right)^{1-1 / \sigma}}{1-1 / \sigma}\right. \\
& \left.\quad+v_{s}^{D} \frac{\left(S_{i, s}^{H} H_{i, s}\right)^{1-1 / \varsigma}}{1-1 / \varsigma}-v_{s}^{N} \int_{0}^{1} \int_{0}^{L_{i, s, s}} h^{1 / n} d h d g-v_{s}^{H} \frac{V_{i, s}^{H} S_{i, s+1}^{H}}{P_{s}}-v_{s}^{B} \sum_{j=1}^{s} \frac{V_{j, s}^{B} B_{i, j, s+1}^{L}}{P_{s}}-v_{s}^{s} \int_{0}^{1} \frac{V_{k, s}^{F} S_{i, k, s+1}^{F}}{P_{s}} d k\right],
\end{aligned}
$$

where $0 \leq \alpha<1$. To introduce exogenous asset risk premia that affect intertemporal substitution, we specify preference shifters $v_{s}^{C}, v_{s}^{H}, v_{s}^{B}$ and $v_{s}^{S}$ as functions of aggregate endogenous variables or structural shocks, 


$$
\begin{gathered}
v_{t}^{C}=v_{t}^{C}-\frac{\phi_{H}^{C}}{1-\rho_{H}} v_{t}^{H}-\frac{\phi_{B}^{C}}{1-\rho_{B}} v_{t}^{B}-\frac{\phi_{S}^{C}}{1-\rho_{S}} v_{t}^{S}, \\
v_{s}^{H}=\frac{v_{s}^{B}+v_{s}^{H}}{\left(C_{s}-\alpha C_{s-1}\right)^{1 / \sigma}}, v_{s}^{B}=\frac{v_{s}^{B}}{\left(C_{s}-\alpha C_{s-1}\right)^{1 / \sigma}}, v_{s}^{S}=\frac{v_{s}^{B}+v_{s}^{S}}{\left(C_{s}-\alpha C_{s-1}\right)^{1 / \sigma}},
\end{gathered}
$$

where $\phi_{H}^{C}>0, \phi_{B}^{C}>0$ and $\phi_{S}^{C}>0$. To support the existence of a long run balanced growth path, we also specify preference shifters $v_{s}^{D}$ and $v_{s}^{N}$ as functions of aggregate endogenous variables or structural shocks,

$$
v_{s}^{D}=v^{D} \frac{\left(C_{s}\right)^{1 / \varsigma}}{\left(C_{s}-\alpha C_{s-1}\right)^{1 / \sigma}}, v_{s}^{N}=A_{s}^{T} \frac{\left(\left(v_{s}^{N}\right)^{\mu}\left(L_{s}\right)^{1-\mu}\right)^{-1 / \eta}}{\left(C_{s}-\alpha C_{s-1}\right)^{1 / \sigma}},
$$

where $\mu>0$. We assume that the intratemporal utility function is strictly increasing with respect to consumption and housing, and is strictly decreasing with respect to labor supply. This implies restrictions on serially correlated consumption demand shock $v_{s}^{C}$ and labor supply shock $v_{s}^{N}$, given mean zero and serially correlated housing risk premium shock $v_{s}^{H}$, duration risk premium shock $v_{s}^{B}$ and equity risk premium shock $v_{s}^{S}$. Given these and other restrictions, this intratemporal utility function is strictly concave with respect to consumption, housing and labor supply if $\sigma>0$ , $\varsigma>0$ and $\eta>0$.

The household enters period $s$ in possession of previously accumulated wealth, which it allocates across the values of bank deposits and short term bonds, as well as portfolios of houses, long term bonds and stocks. Bank deposits $B_{i, s}^{D}$ and short term bonds $B_{i, s}^{S}$ pay interest at risk free rates $i_{s-1}^{D}$ and $i_{s-1}^{S}$, respectively. The household distributes the value of its house portfolio across the values of $S_{i, s}^{H}$ houses, where $\Pi_{i, s}^{H}=P_{s}^{H} H_{i, s}+\left(B_{i, s+1}^{H}-\left(1-\delta_{s}^{H}\right)\left(1+i_{s-1}^{H}\right) B_{i, s}^{H}\right)-P_{s} I_{i, s}^{H}$ denotes the user cost of its house and $V_{i, s}^{H}$ denotes the price of its house, while $P_{s}^{H}$ denotes the implicit rental price of housing. It also distributes the value of its long term bond portfolio across the values of $\left\{B_{i, j, s}^{L}\right\}_{j=1}^{s-1}$ vintage specific long term bonds, where $\Pi_{j, s}^{B}=\left(1+i_{j}^{L}-\omega^{B}\right)\left(\omega^{B}\right)^{s-j} V_{j, j}^{B}$ denotes the coupon payment per long term bond and $V_{j, s}^{B}$ denotes the price per long term bond, while $i_{j}^{L}$ denotes the vintage specific yield to maturity on long term bonds at issuance when $V_{j, j}^{B}=1$. Furthermore, it distributes the value of its stock portfolio across the values of $\left\{S_{i, k, s}^{F}\right\}_{k=0}^{1}$ firm specific shares, where $\Pi_{k, s}^{F}$ denotes the dividend payment per share and $V_{k, s}^{F}$ denotes the price per share. During period $s$, the household receives profit income $\Pi_{s}^{B}$ from banks, and supplies differentiated intermediate labor services $\left\{L_{i, g, s}\right\}_{g=0}^{1}$, earning labor income at trade specific wages $\left\{W_{g, s}\right\}_{g=0}^{1}$. These sources of wealth are summed in household dynamic budget constraint:

$$
\begin{aligned}
B_{i, s+1}^{D}- & S_{i, s}^{H} B_{i, s+1}^{H}+V_{i, s}^{H} S_{i, s+1}^{H}+B_{i, s+1}^{S}+\sum_{j=1}^{s} V_{j, s}^{B} B_{i, j, s+1}^{L}+\int_{0}^{1} V_{k, s}^{F} S_{i, k, s+1}^{F} d k=\left(1+i_{s-1}^{D}\right) B_{i, s}^{D}-\left(1-\delta_{s}^{H}\right)\left(1+i_{s-1}^{H}\right) S_{i, s}^{H} B_{i, s}^{H} \\
& \quad+V_{i, s}^{H} S_{i, s}^{H}+\left(1+i_{s-1}^{S}\right) B_{i, s}^{S}+\sum_{j=1}^{s-1}\left(\Pi_{j, s}^{B}+V_{j, s}^{B}\right) B_{i, j, s}^{L}+\int_{0}^{1}\left(\Pi_{k, s}^{F}+V_{k, s}^{F}\right) S_{i, k, s}^{F} d k+\Pi_{s}^{B}+\int_{0}^{1} W_{g, s} L_{i, g, s} d g-T_{s}-P_{s} C_{i, s}-P_{s} S_{i, s}^{H} I_{i, s}^{H} .
\end{aligned}
$$

According to this dynamic budget constraint, at the end of period $s$ the household allocates its wealth across the values of bank deposits and short term bonds, as well as portfolios of houses, long term bonds and stocks. It distributes the value of its house portfolio across the values of $S_{i, s+1}^{H}$ houses, the value of its long term bond portfolio across the values of $\left\{B_{i, j, s+1}^{L}\right\}_{j=1}^{s}$ vintage specific long term bonds, and the value of its stock portfolio across the values of $\left\{S_{i, k, s+1}^{F}\right\}_{k=0}^{1}$ firm specific 
shares. Finally, the household pays lump sum tax $T_{s}$ to the government, and purchases final private consumption good $C_{i, s}$ and final residential investment good $I_{i, s}^{H}$ at price $P_{s}$.

Motivated by the collateralized borrowing variant of the financial accelerator mechanism due to Kiyotaki and Moore (1997), the household maintains mortgage debt equal to a fraction of the value of the housing stock,

$$
\frac{B_{i, s+1}^{H}}{P_{s} H_{i, s+1}}=\phi^{H},
$$

where $0<\phi^{H}<1$. Net borrowing is defined as the increase in $S_{i, s}^{H}$ mortgage loans $B_{i, s+1}^{H}$ from banks net of writedowns at mortgage loan default rate $\delta_{s}^{H}$ and interest payments at mortgage loan rate $i_{s-1}^{H}$.

The household enters period $s$ with housing of previously accumulated quality $H_{i, s}$, which subsequently evolves according to accumulation function

$$
H_{i, s+1}=\left(1-\delta^{H}\right) H_{i, s}+\mathcal{H}^{H}\left(I_{i, s}^{H}, I_{i, s-1}^{H}\right)
$$

where $0 \leq \delta^{H} \leq 1$. Effective residential investment function $\mathcal{H}^{H}\left(I_{i, s}^{H}, I_{i, s-1}^{H}\right)$ incorporates convex adjustment costs,

$$
\mathcal{H}^{H}\left(I_{i, s}^{H}, I_{i, s-1}^{H}\right)=v_{s}^{I^{H}}\left[1-\frac{\chi^{H}}{2}\left(\frac{I_{i, s}^{H}}{I_{i, s-1}^{H}}-1\right)^{2}\right] I_{i, s}^{H},
$$

where serially correlated residential investment demand shock $v_{s}^{I^{H}}$ satisfies $v_{s}^{I^{H}}>0$, while $\chi^{H}>0$. In steady state equilibrium, these adjustment costs equal zero, and effective residential investment equals actual residential investment.

In period $t$, the household chooses state contingent sequences for consumption $\left\{C_{i, s}\right\}_{s=t}^{\infty}$, residential investment $\left\{I_{i, s}^{H}\right\}_{s=t}^{\infty}$, housing quality $\left\{H_{i, s+1}\right\}_{s=t}^{\infty}$, labor force participation $\left\{\left\{N_{i, g, s}\right\}_{g=0}^{1}\right\}_{s=t}^{\infty}$ , bank deposits $\left\{B_{i, s+1}^{D}\right\}_{s=t}^{\infty}$, houses $\left\{S_{i, s+1}^{H}\right\}_{s=t}^{\infty}$, short term bonds $\left\{B_{i, s+1}^{S}\right\}_{s=t}^{\infty}$, long term bonds $\left\{\left\{B_{i, j, s+1}^{L}\right\}_{j=1}^{s}\right\}_{s=t}^{\infty}$ and stocks $\left\{\left\{S_{i, k, s+1}^{F}\right\}_{k=0}^{1}\right\}_{s=t}^{\infty}$ to maximize intertemporal utility function (4) subject to dynamic budget constraint (8), housing quality accumulation function (10), and terminal nonnegativity constraints $H_{i, T+1} \geq 0, B_{i, T+1}^{D} \geq 0, S_{i, T+1}^{H} \geq 0, B_{i, T+1}^{S} \geq 0, B_{i, j, T+1}^{L} \geq 0$ and $S_{i, k, T+1}^{F} \geq 0$ for $T \rightarrow \infty$. In equilibrium, the solutions to this utility maximization problem satisfy intertemporal optimality condition

$$
\mathrm{E}_{t} \frac{\beta u_{C}(i, t+1)}{u_{C}(i, t)} \frac{P_{t}}{P_{t+1}}\left(1+i_{t}^{S}\right)=1,
$$

which equates the expected discounted value of the gross real return on short term bonds to one. They also satisfy intertemporal optimality condition

$$
\frac{Q_{i, t}^{H}}{P_{t}} \mathcal{H}_{1}^{H}(i, t)+\mathrm{E}_{t} \frac{\beta u_{C}(i, t+1)}{u_{C}(i, t)} \frac{Q_{i, t+1}^{H}}{P_{t+1}} \mathcal{H}_{2}^{H}(i, t+1)=1,
$$

which equates the expected discounted value of an additional unit of residential investment to its price, where $Q_{i, s}^{H}$ denotes the shadow price of housing, which is proportional to the Lagrange 
multiplier on the period $s$ housing quality accumulation function. In addition, they satisfy intertemporal optimality condition

$$
\frac{Q_{i, t}^{H}}{P_{t}}=\mathrm{E}_{t} \frac{\beta u_{C}(i, t+1)}{u_{C}(i, t)}\left\{\frac{P_{t+1}^{H}}{P_{t+1}}-\phi^{H} \frac{P_{t}}{P_{t+1}}\left[\left(1-\delta_{t+1}^{H}\right)\left(1+i_{t}^{H}\right)-\frac{u_{C}(i, t)}{\beta u_{C}(i, t+1)} \frac{P_{t+1}}{P_{t}}\right]+\left(1-\delta^{H}\right) \frac{Q_{i, t+1}^{H}}{P_{t+1}}\right\},
$$

which equates the relative shadow price of housing to the expected discounted value of the relative implicit rental price of housing, minus the product of the mortgage loan to value ratio with the spread of the effective cost of bank over own funds, plus the future relative shadow price of housing net of depreciation. Furthermore, they satisfy intratemporal optimality condition

$$
\frac{u_{S^{H} H}(i, t)}{u_{C}(i, t)}=\frac{P_{t}^{H}}{P_{t}}
$$

which equates the marginal rate of substitution between housing and consumption to the relative implicit rental price of housing. Moreover, they satisfy intratemporal optimality condition

$$
-\frac{u_{L_{g}}(i, g, t)}{u_{C}(i, t)}=\frac{W_{g, t}}{P_{t}}
$$

which equates the marginal rate of substitution between leisure and consumption for the marginal trade specific labor force participant to the corresponding real wage. They also satisfy intratemporal optimality condition

$$
1+i_{t}^{D}=1+i_{t}^{S}
$$

which equates the deposit rate to the return on short term bonds. In addition, they satisfy intratemporal optimality condition

$$
\mathrm{E}_{t} \frac{\beta u_{C}(i, t+1)}{u_{C}(i, t)} \frac{P_{t}}{P_{t+1}}\left[\frac{\Pi_{i, t+1}^{H}+V_{i, t+1}^{H}}{V_{i, t}^{H}}-\left(1+i_{t}^{S}\right)\right]=\frac{u_{C}(t)}{u_{C}(i, t)}\left(v_{t}^{B}+v_{t}^{H}\right),
$$

which equates the expected discounted values of the gross real risk adjusted returns on houses and short term bonds. Furthermore, they satisfy intratemporal optimality condition

$$
\mathrm{E}_{t} \frac{\beta u_{C}(i, t+1)}{u_{C}(i, t)} \frac{P_{t}}{P_{t+1}}\left[\frac{\Pi_{j, t+1}^{B}+V_{j, t+1}^{B}}{V_{j, t}^{B}}-\left(1+i_{t}^{S}\right)\right]=\frac{u_{C}(t)}{u_{C}(i, t)} v_{t}^{B},
$$

which equates the expected discounted values of the gross real risk adjusted returns on long and short term bonds. Finally, they satisfy intratemporal optimality condition

$$
\mathrm{E}_{t} \frac{\beta u_{C}(i, t+1)}{u_{C}(i, t)} \frac{P_{t}}{P_{t+1}}\left[\frac{\Pi_{k, t+1}^{F}+V_{k, t+1}^{F}}{V_{k, t}^{F}}-\left(1+i_{t}^{S}\right)\right]=\frac{u_{C}(t)}{u_{C}(i, t)}\left(v_{t}^{B}+v_{t}^{S}\right),
$$

which equates the expected discounted values of the gross real risk adjusted returns on stocks and short term bonds. 


\section{Labor Supply}

The unemployment rate $u_{t}^{L}$ measures the share of the labor force $N_{t}$ in unemployment $U_{t}$, that is $u_{t}^{L}=U_{t} / N_{t}$, where unemployment equals the labor force less employment $L_{t}$, that is $U_{t}=N_{t}-L_{t}$. The labor force satisfies $N_{t}=\int_{0}^{1} N_{g, t} d g$.

There exist a large number of perfectly competitive firms which combine differentiated intermediate labor services $\left\{L_{g, t}\right\}_{g=0}^{1}$ supplied by trade unions of workers to produce final labor service $L_{t}$ according to constant elasticity of substitution production function:

$$
L_{t}=\left[\int_{0}^{1}\left(L_{g, t}\right)^{\frac{\theta_{t}^{W}-1}{\theta_{t}^{W}}} d g\right]^{\frac{\theta_{t}^{W}}{\theta_{t}^{W}-1}} .
$$

The representative final labor service firm maximizes profits from production of the final labor service with respect to inputs of intermediate labor services, implying demand functions:

$$
L_{g, t}=\left(\frac{W_{g, t}}{W_{t}}\right)^{-\theta_{t}^{W}} L_{t} .
$$

Since the production function exhibits constant returns to scale, in equilibrium the final labor service firm generates zero profit, implying aggregate wage index:

$$
W_{t}=\left[\int_{0}^{1}\left(W_{g, t}\right)^{1-\theta_{t}^{W}} d g\right]^{\frac{1}{1-\theta_{t}^{W}}}
$$

Serially uncorrelated wage markup shock $\vartheta_{t}^{W}$ satisfies $\vartheta_{t}^{W}=\theta_{t}^{W} /\left(\theta_{t}^{W}-1\right)$, where the wage elasticity of demand for intermediate labor services $\theta_{t}^{W}$ satisfies $\theta_{t}^{W}>1$.

In an extension of the model of nominal wage rigidity proposed by Erceg, Henderson and Levin (2000) along the lines of Smets and Wouters (2003), each period a randomly selected fraction $1-\omega^{W}$ of trade unions adjust their wage optimally, where $0 \leq \omega^{W}<1$. The remaining fraction $\omega^{W}$ of trade unions adjust their wage to account for past inflation and trend productivity growth according to partial indexation rule

$$
W_{g, t}=\left(\frac{P_{t-1} A_{t-1}^{T}}{P_{t-2} A_{t-2}^{T}}\right)^{\gamma^{W}}\left(\frac{\bar{P}_{t-1} \bar{A}_{t-1}}{\bar{P}_{t-2} \bar{A}_{t-2}}\right)^{1-\gamma^{W}} W_{g, t-1},
$$

where $0 \leq \gamma^{W} \leq 1$. Under this specification, although trade unions adjust their wage every period, they infrequently do so optimally, and the interval between optimal wage adjustments is a random variable.

If trade union $g$ can adjust its wage optimally in period $t$, then it does so to maximize intertemporal utility function (4) subject to dynamic budget constraint (8), intermediate labor service demand function (22), and the assumed form of nominal wage rigidity. Since all trade unions that adjust their wage optimally in period $t$ solve an identical utility maximization problem, in equilibrium they all choose a common wage $W_{t}^{*}$ given by necessary first order condition: 


$$
\frac{W_{t}^{*}}{W_{t}}=-\frac{\mathrm{E}_{t} \sum_{s=t}^{\infty}\left(\omega^{W}\right)^{s-t} \frac{\beta^{s-t} u_{C}(i, s)}{u_{C}(i, t)} \theta_{s}^{W} \frac{u_{L_{g}}(i, g, s)}{u_{C}(i, s)}\left[\left(\frac{P_{t-1} A_{t-1}^{T}}{P_{s-1} A_{s-1}^{T}}\right)^{\gamma^{W}}\left(\frac{\bar{P}_{t-1} \bar{A}_{t-1}}{\bar{P}_{s-1} \bar{A}_{s-1}}\right)^{1-\gamma^{W}} \frac{W_{s}}{W_{t}}\right]^{\theta_{s}^{W}}\left(\frac{W_{t}^{*}}{W_{t}}\right)^{-\theta_{s}^{W}} L_{i, s}}{\mathrm{E}_{t} \sum_{s=t}^{\infty}\left(\omega^{W}\right)^{s-t} \frac{\beta^{s-t} u_{C}(i, s)}{u_{C}(i, t)}\left(\theta_{s}^{W}-1\right) \frac{W_{s}}{P_{s}}\left[\left(\frac{P_{t-1} A_{t-1}^{T}}{P_{s-1} A_{s-1}^{T}}\right)^{\gamma^{W}}\left(\frac{\bar{P}_{t-1} \bar{A}_{t-1}}{\bar{P}_{s-1} \bar{A}_{s-1}}\right)^{1-\gamma^{W}} \frac{W_{s}}{W_{t}}\right]^{\theta_{s}^{W}-1}\left(\frac{W_{t}^{*}}{W_{t}}\right)^{-\theta_{s}^{W}} L_{i, s}} .
$$

This necessary first order condition equates the expected discounted value of the marginal utility of consumption gained from labor supply to the expected discounted value of the marginal utility cost incurred from leisure foregone. Aggregate wage index (23) equals an average of the wage set by the fraction $1-\omega^{W}$ of trade unions that adjust their wage optimally in period $t$, and the average of the wages set by the remaining fraction $\omega^{W}$ of trade unions that adjust their wage according to partial indexation rule (24):

$$
W_{t}=\left\{\left(1-\omega^{W}\right)\left(W_{t}^{*}\right)^{1-\theta_{t}^{W}}+\omega^{W}\left[\left(\frac{P_{t-1} A_{t-1}^{T}}{P_{t-2} A_{t-2}^{T}}\right)^{\gamma^{W}}\left(\frac{\bar{P}_{t-1} \bar{A}_{t-1}}{\bar{P}_{t-2} \bar{A}_{t-2}}\right)^{1-\gamma^{W}} W_{t-1}\right]^{1-\theta_{t}^{W}}\right\}^{\frac{1}{1-\theta_{t}^{W}}} .
$$

Since those trade unions able to adjust their wage optimally in period $t$ are selected randomly from among all trade unions, the average wage set by the remaining trade unions equals the value of the aggregate wage index that prevailed during period $t-1$, rescaled to account for past inflation and trend productivity growth.

\section{B. The Production Sector}

The production sector supplies a final output good for absorption by households, firms and the government. In doing so, firms demand the final labor service from households, obtain corporate loans from banks, and accumulate capital through business investment.

\section{Output Demand}

There exist a large number of perfectly competitive firms which combine differentiated intermediate output goods $\left\{Y_{k, t}\right\}_{k=0}^{1}$ supplied by intermediate good firms to produce final output good $Y_{t}$ according to constant elasticity of substitution production function:

$$
Y_{t}=\left[\int_{0}^{1}\left(Y_{k, t}\right)^{\frac{\theta_{t}^{P}-1}{\theta_{t}^{P}}} d k\right]^{\frac{\theta_{t}^{P}}{\theta_{t}^{P}-1}}
$$

The representative final good firm maximizes profits from production of the final output good with respect to inputs of intermediate output goods, implying demand functions: 


$$
Y_{k, t}=\left(\frac{P_{k, t}}{P_{t}}\right)^{-\theta_{t}^{P}} Y_{t} .
$$

Since the production function exhibits constant returns to scale, in equilibrium the final good firm generates zero profit, implying aggregate price index:

$$
P_{t}=\left[\int_{0}^{1}\left(P_{k, t}\right)^{1-\theta_{t}^{P}} d k\right]^{\frac{1}{1-\theta_{t}^{P}}} .
$$

Serially uncorrelated price markup shock $\vartheta_{t}^{P}$ satisfies $\vartheta_{t}^{P}=\theta_{t}^{P} /\left(\theta_{t}^{P}-1\right)$, where the price elasticity of demand for intermediate output goods $\theta_{t}^{P}$ satisfies $\theta_{t}^{P}>1$.

\section{Labor Demand and Business Investment}

There exists a continuum of monopolistically competitive intermediate good firms indexed by $k \in[0,1]$. Intermediate good firms supply differentiated intermediate output goods, but are otherwise identical.

Each intermediate good firm $k$ sells shares to households at price $V_{k, t}^{F}$. Acting in the interests of its shareholders, it maximizes its pre-dividend stock market value, which in equilibrium equals the expected discounted value of current and future dividend payments

$$
\Pi_{k, t}^{F}+V_{k, t}^{F}=\mathrm{E}_{t} \sum_{s=t}^{\infty} \frac{\beta^{s-t} \lambda_{s}^{F}}{\lambda_{t}^{F}} \Pi_{k, s}^{F},
$$

where $\lambda_{s}^{F}=\lambda_{s} \prod_{r=1}^{s-1}\left(1+v_{r}^{B}+v_{r}^{S}\right)^{-1}$, while $\lambda_{i, s}$ denotes the Lagrange multiplier on the period $s$ household dynamic budget constraint. The derivation of this result imposes a transversality condition that rules out self-fulfilling speculative asset price bubbles.

Shares entitle households to dividend payments equal to profits $\Pi_{k, s}^{F}$, defined as earnings plus net borrowing minus business investment expenditures,

$$
\Pi_{k, s}^{F}=\left(P_{k, s} Y_{k, s}-W_{s} L_{k, s}-\Phi_{k, s}\right)+\left(B_{k, s+1}^{F}-\left(1-\delta_{s}^{F}\right)\left(1+i_{s-1}^{F}\right) B_{k, s}^{F}\right)-P_{s} I_{k, s}^{K},
$$

where $Y_{k, s}=\mathcal{F}\left(u_{k, s}^{K} K_{k, s}, A_{s} L_{k, s}\right)$. Earnings are defined as revenues from sales of differentiated intermediate output good $Y_{k, s}$ at price $P_{k, s}$ less expenditures on final labor service $L_{k, s}$, and other variable costs $\Phi_{k, s}$.

Motivated by the collateralized borrowing variant of the financial accelerator mechanism due to Kiyotaki and Moore (1997), the intermediate good firm maintains corporate debt equal to a fraction of the value of the capital stock,

$$
\frac{B_{k, s+1}^{F}}{P_{s} K_{k, s+1}}=\phi^{F},
$$

where $0<\phi^{F}<1$. Net borrowing is defined as the increase in corporate loans $B_{k, s+1}^{F}$ from banks net of writedowns at corporate loan default rate $\delta_{s}^{F}$ and interest payments at corporate loan rate $i_{s-1}^{F}$. 
The intermediate good firm utilizes capital $K_{k, s}$ at rate $u_{k, s}^{K}$ and rents final labor service $L_{k, s}$ to produce differentiated intermediate output good $Y_{k, s}$ according to production function:

$$
\mathcal{F}\left(u_{k, s}^{K} K_{k, s}, A_{s} L_{k, s}\right)=\left(u_{k, s}^{K} K_{k, s}\right)^{\phi^{\gamma}}\left(A_{s} L_{k, s}\right)^{1-\phi^{Y}} .
$$

This production function exhibits constant returns to scale, with $0 \leq \phi^{Y} \leq 1$. Trend productivity $A_{s}^{T}$ exhibits partial adjustment dynamics $A_{s}^{T}=\left(A_{s-1}^{T}\right)^{\rho^{A}}\left(A_{s}\right)^{1-\rho^{A}}$ where $0 \leq \rho^{A}<1$, while serially correlated productivity shock $A_{s}$ satisfies $A_{s}>0$.

In utilizing capital to produce output, the intermediate good firm incurs a cost $\mathcal{G}^{K}\left(u_{k, s}^{K}, K_{k, s}\right)$ denominated in terms of output,

$$
\Phi_{k, s}=P_{s} \mathcal{G}^{K}\left(u_{k, s}^{K}, K_{k, s}\right)+F_{s}^{F},
$$

where fixed cost $F_{s}^{F}$ ensures that $\Phi_{s}=0$. Following Christiano, Eichenbaum and Evans (2005), this capital utilization cost is increasing in the capital utilization rate at an increasing rate,

$$
\mathcal{G}^{K}\left(u_{k, s}^{K}, K_{k, s}\right)=\mu^{K}\left[e^{\eta^{K}\left(u_{k, s}^{K}-1\right)}-1\right] K_{k, s},
$$

where $\mu^{K}>0$ and $\eta^{K}>0$. In steady state equilibrium, the capital utilization rate equals one, and the cost of utilizing capital equals zero.

The intermediate good firm enters period $s$ with previously accumulated capital stock $K_{k, s}$, which subsequently evolves according to accumulation function

$$
K_{k, s+1}=\left(1-\delta^{K}\right) K_{k, s}+\mathcal{H}^{K}\left(I_{k, s}^{K}, I_{k, s-1}^{K}\right),
$$

where $0 \leq \delta^{K} \leq 1$. Motivated by Christiano, Eichenbaum and Evans (2005), effective business investment function $\mathcal{H}^{K}\left(I_{k, s}^{K}, I_{k, s-1}^{K}\right)$ incorporates convex adjustment costs,

$$
\mathcal{H}^{K}\left(I_{k, s}^{K}, I_{k, s-1}^{K}\right)=v_{s}^{I^{K}}\left[1-\frac{\chi^{K}}{2}\left(\frac{I_{k, s}^{K}}{I_{k, s-1}^{K}}-1\right)^{2}\right] I_{k, s}^{K},
$$

where serially correlated business investment demand shock $v_{s}^{I^{K}}$ satisfies $v_{s}^{I^{K}}>0$, while $\chi^{K}>0$ . In steady state equilibrium, these adjustment costs equal zero, and effective business investment equals actual business investment.

In period $t$, the intermediate good firm chooses state contingent sequences for employment $\left\{L_{k, s}\right\}_{s=t}^{\infty}$, the capital utilization rate $\left\{u_{k, s}^{K}\right\}_{s=t}^{\infty}$, business investment $\left\{I_{k, s}^{K}\right\}_{s=t}^{\infty}$ and the capital stock $\left\{K_{k, s+1}\right\}_{s=t}^{\infty}$ to maximize pre-dividend stock market value (30) subject to production function (33), capital accumulation function (36), and terminal nonnegativity constraint $K_{k, T+1} \geq 0$ for $T \rightarrow \infty$. In equilibrium, the solutions to this value maximization problem satisfy necessary first order condition

$$
\mathcal{F}_{A L}(k, t) \Psi_{k, t}=\frac{W_{t}}{P_{t} A_{t}},
$$

which equates real marginal cost $\Psi_{k, s}$ to the ratio of the real wage to the marginal product of labor, where $\Psi_{k, s}$ is proportional to the Lagrange multiplier on the period $s$ production technology constraint. In addition, they satisfy necessary first order condition 


$$
\mathcal{F}_{u^{K} K}(k, t) \Psi_{k, t}=\frac{\mathcal{G}_{u^{K}}^{K}(k, t)}{K_{k, t}},
$$

which equates the marginal revenue product of utilized capital to its marginal cost. Furthermore, they satisfy necessary first order condition

$$
\frac{Q_{k, t}^{K}}{P_{t}} \mathcal{H}_{1}^{K}(k, t)+\mathrm{E}_{t} \frac{\beta \lambda_{t+1}^{F}}{\lambda_{t}^{F}} \frac{P_{t+1}}{P_{t}} \frac{Q_{k, t+1}^{K}}{P_{t+1}} \mathcal{H}_{2}^{K}(k, t+1)=1,
$$

which equates the expected discounted value of an additional unit of business investment to its price, where $Q_{k, s}^{K}$ denotes the shadow price of capital, which is the Lagrange multiplier on the period $s$ capital accumulation function. Finally, they satisfy necessary first order condition

$$
\frac{Q_{k, t}^{K}}{P_{t}}=\mathrm{E}_{t} \frac{\beta \lambda_{t+1}^{F}}{\lambda_{t}^{F}} \frac{P_{t+1}}{P_{t}}\left\{u_{k, t+1}^{K} \mathcal{F}_{u^{K} K}(k, t+1) \Psi_{k, t+1}-\mathcal{G}_{K}^{K}(k, t+1)-\phi^{F} \frac{P_{t}}{P_{t+1}}\left[\left(1-\delta_{t+1}^{F}\right)\left(1+i_{t}^{F}\right)-\frac{\lambda_{t}^{F}}{\beta \lambda_{t+1}^{F}}\right]+\left(1-\delta^{K}\right) \frac{Q_{k, t+1}^{K}}{P_{t+1}}\right\}
$$

which equates the relative shadow price of capital to the expected discounted value of the future marginal product of capital net of its real marginal utilization cost, minus the product of the corporate loan to value ratio with the spread of the effective cost of bank over capital market funds, plus the future relative shadow price of capital net of depreciation.

\section{Output Supply}

In an extension of the model of nominal price rigidity proposed by Calvo (1983) along the lines of Smets and Wouters (2003), each period a randomly selected fraction $1-\omega^{P}$ of intermediate good firms adjust their price optimally, where $0 \leq \omega^{P}<1$. The remaining fraction $\omega^{P}$ of intermediate good firms adjust their price to account for past inflation according to partial indexation rule

$$
P_{k, t}=\left(\frac{P_{t-1}}{P_{t-2}}\right)^{\gamma^{P}}\left(\frac{\bar{P}_{t-1}}{\bar{P}_{t-2}}\right)^{1-\gamma^{P}} P_{k, t-1}
$$

where $0 \leq \gamma^{P} \leq 1$. Under this specification, optimal price adjustment opportunities arrive randomly, and the interval between optimal price adjustments is a random variable.

If the intermediate good firm can adjust its price optimally in period $t$, then it does so to maximize pre-dividend stock market value (30) subject to production function (33), intermediate output good demand function (28), and the assumed form of nominal price rigidity. We consider a symmetric equilibrium under which all firm specific endogenous state variables are restricted to equal their aggregate counterparts. It follows that all intermediate good firms that adjust their price optimally in period $t$ solve an identical value maximization problem, which implies that they all choose a common price $P_{t}^{*}$ given by necessary first order condition: 


$$
\frac{P_{t}^{*}}{P_{t}}=\frac{\mathrm{E}_{t} \sum_{s=t}^{\infty}\left(\omega^{P}\right)^{s-t} \frac{\beta^{s-t} \lambda_{s}^{F}}{\lambda_{t}^{F}} \theta_{s}^{P} \Psi_{k, s}\left[\left(\frac{P_{t-1}}{P_{s-1}}\right)^{\gamma^{P}}\left(\frac{\bar{P}_{t-1}}{\bar{P}_{s-1}}\right)^{1-\gamma^{P}} \frac{P_{s}}{P_{t}}\right]^{\theta_{s}^{P}}\left(\frac{P_{t}^{*}}{P_{t}}\right)^{-\theta_{s}^{P}} P_{s} Y_{s} \sum_{s=t}^{\infty}\left(\omega^{P}\right)^{s-t} \frac{\beta^{s-t} \lambda_{s}^{F}}{\lambda_{t}^{F}}\left(\theta_{s}^{P}-1\right)\left[\left(\frac{P_{t-1}}{P_{s-1}}\right)^{\gamma^{P}}\left(\frac{\bar{P}_{t-1}}{\bar{P}_{s-1}}\right)^{1-\gamma^{P}} \frac{P_{s}}{P_{t}}\right]^{\theta_{s}^{P}-1}\left(\frac{P_{t}^{*}}{P_{t}}\right)^{-\theta_{s}^{P}} P_{s} Y_{s}}{.}
$$

This necessary first order condition equates the expected discounted value of the marginal revenue gained from output supply to the expected discounted value of the marginal cost incurred from production. Aggregate price index (29) equals an average of the price set by the fraction $1-\omega^{P}$ of intermediate good firms that adjust their price optimally in period $t$, and the average of the prices set by the remaining fraction $\omega^{P}$ of intermediate good firms that adjust their price according to partial indexation rule (42):

$$
P_{t}=\left\{\left(1-\omega^{P}\right)\left(P_{t}^{*}\right)^{1-\theta_{t}^{P}}+\omega^{P}\left[\left(\frac{P_{t-1}}{P_{t-2}}\right)^{\gamma^{P}}\left(\frac{\bar{P}_{t-1}}{\bar{P}_{t-2}}\right)^{1-\gamma^{P}} P_{t-1}\right]^{1-\theta_{t}^{P}}\right\}^{\frac{1}{1-\theta_{t}^{P}}} .
$$

Since those intermediate good firms able to adjust their price optimally in period $t$ are selected randomly from among all intermediate good firms, the average price set by the remaining intermediate good firms equals the value of the aggregate price index that prevailed during period $t-1$, rescaled to account for past inflation.

\section{The Banking Sector}

The banking sector supplies financial intermediation services subject to a financial friction and a regulatory constraint. In particular, banks issue risky mortgage and corporate loans to households and firms at infrequently adjusted predetermined mortgage and corporate loan rates. They obtain funding from households via deposits and from the interbank market via loans, accumulating bank capital out of retained earnings given credit losses to satisfy a capital requirement.

\section{Credit Demand}

There exist a large number of perfectly competitive banks which combine differentiated intermediate mortgage or corporate loans $\left\{B_{l, t+1}^{Z}\right\}_{l=0}^{1}$ supplied by intermediate banks to produce final mortgage or corporate loan $B_{t+1}^{Z}$ according to constant elasticity of substitution portfolio aggregator

$$
B_{t+1}^{Z}=\left[\int_{0}^{1}\left(B_{l, t+1}^{Z}\right)^{\frac{\theta_{t+1}^{i^{Z}}-1}{\theta_{t+1}^{Z}}} d l\right]^{\frac{\theta_{t+1}^{i^{Z}}}{\theta_{t+1}^{Z}-1}}
$$


where $Z \in\{H, F\}$. The representative final bank maximizes profits from intermediation of the final mortgage or corporate loan with respect to inputs of intermediate mortgage or corporate loans, implying demand functions:

$$
B_{l, t+1}^{Z}=\left(\frac{1+i_{l, t}^{Z}}{1+i_{t}^{Z}}\right)^{-\theta_{t+1}^{Z}} B_{t+1}^{Z} .
$$

Since the portfolio aggregator exhibits constant returns to scale, in equilibrium the final bank generates zero profit, implying aggregate gross mortgage or corporate loan rate index:

$$
1+i_{t}^{Z}=\left[\int_{0}^{1}\left(1+i_{l, t}^{Z}\right)^{1-\theta_{t+1}^{Z}} d l\right]^{\frac{1}{1-\theta_{t+1}^{Z}}}
$$

Serially correlated mortgage or corporate loan markup shock $\vartheta_{t+1}^{i^{2}}$ satisfies $\vartheta_{t+1}^{i^{2}}=\theta_{t+1}^{i^{Z}} /\left(\theta_{t+1}^{i^{z}}-1\right)$, where the rate elasticity of demand for intermediate mortgage or corporate loans $\theta_{t+1}^{i^{2}}$ satisfies $\theta_{t+1}^{i^{Z}}>1$ and $\theta^{i^{Z}}=\theta^{i^{C}}$.

\section{Funding Demand and Bank Capital Accumulation}

There exists a continuum of monopolistically competitive intermediate banks indexed by $l \in[0,1]$. Intermediate banks supply differentiated intermediate mortgage and corporate loans, but are otherwise identical.

Each intermediate bank $l$ sells shares to households at price $V_{l, t}^{B}$. Acting in the interests of its shareholders, it maximizes its pre-dividend stock market value, which equals the expected discounted value of current and future dividend payments:

$$
\Pi_{l, t}^{B}+V_{l, t}^{B}=\mathrm{E}_{t} \sum_{s=t}^{\infty} \frac{\beta^{s-t} \lambda_{s}}{\lambda_{t}} \Pi_{l, s}^{B} .
$$

The derivation of this result imposes a transversality condition that rules out self-fulfilling speculative asset price bubbles.

Shares entitle households to dividend payments $\Pi_{l, s}^{B}$, defined as profits from providing financial intermediation services less retained earnings $I_{l, s}^{B}$ :

$$
\begin{aligned}
\Pi_{l, s}^{B}= & \left(B_{l, s+1}^{D}-\left(1+i_{s-1}^{D}\right) B_{l, s}^{D}\right)+\left(B_{l, s+1}^{B}-\left(1+i_{s-1}^{B}\right) B_{l, s}^{B}\right) \\
& -\left(B_{l, s+1}^{H}-\left(1-\delta_{s}^{H}\right)\left(1+i_{l, s-1}^{H}\right) B_{l, s}^{H}\right)-\left(B_{l, s+1}^{F}-\left(1-\delta_{s}^{F}\right)\left(1+i_{l, s-1}^{F}\right) B_{l, s}^{F}\right)-\Phi_{l, s}^{B}-I_{l, s}^{B} .
\end{aligned}
$$

Profits are defined as the increase in deposits $B_{l, s+1}^{D}$ from households net of interest payments at the deposit rate $i_{s-1}^{D}$, plus the increase in net loans $B_{l, s+1}^{B}$ from the interbank market net of interest payments at the interbank rate $i_{s-1}^{B}$, minus the increase in differentiated intermediate mortgage loans $B_{l, s+1}^{H}$ to households net of writedowns at mortgage loan default rate $\delta_{s}^{H}$ and interest receipts at mortgage loan rate $i_{l, s-1}^{H}$, minus the increase in differentiated intermediate corporate loans $B_{l, s+1}^{F}$ to firms net of writedowns at corporate loan default rate $\delta_{s}^{F}$ and interest receipts at corporate loan rate $i_{l, s-1}^{F}$, minus a cost of satisfying the capital requirement $\Phi_{l, s}^{B}$. 
The intermediate bank transforms deposit and money market funding into risky differentiated intermediate mortgage and corporate loans according to balance sheet identity:

$$
B_{l, s+1}^{H}+B_{l, s+1}^{F}=B_{l, s+1}^{D}+B_{l, s+1}^{B}+K_{l, s+1}^{B} .
$$

The bank credit stock $B_{s+1}^{C}$ measures aggregate bank assets, that is $B_{s+1}^{C}=B_{s+1}^{H}+B_{s+1}^{F}$, while the money stock $M_{s+1}$ measures aggregate bank funding, that is $M_{s+1}=B_{s+1}^{D}+B_{s+1}^{B}$ where $B_{s+1}^{B}=0$. The bank capital ratio $\kappa_{s+1}$ equals the ratio of aggregate bank capital to assets, that is $\kappa_{s+1}=K_{s+1}^{B} / B_{s+1}^{C}$.

In transforming deposit and money market funding into risky mortgage and corporate loans, the intermediate bank incurs a cost of satisfying the capital requirement,

$$
\Phi_{l, s}^{B}=\mathcal{G}^{B}\left(B_{l, s}^{H}, B_{l, s}^{F}, K_{l, s}^{B}\right)+F_{s}^{B},
$$

where fixed cost $F_{s}^{B}$ ensures that $\Phi_{s}^{B}=-I_{s}^{B}$. Motivated by Gerali, Neri, Sessa and Signoretti (2010), this regulation cost is decreasing in the ratio of bank capital to assets at a decreasing rate,

$$
\mathcal{G}^{B}\left(B_{l, s}^{H}, B_{l, s}^{F}, K_{l, s}^{B}\right)=\mu^{C}\left[e^{\left(2+\eta^{C}\right)\left(1-\frac{1}{\kappa_{s}^{R}} \frac{K_{l, s}^{B}}{B_{l, s}^{H}+B_{l, s}^{F}}\right)}-1\right] K_{l, s}^{B},
$$

given capital requirement $\kappa_{s}^{R}$, where $\mu^{C}>0$ and $\eta^{C}>0$. In steady state equilibrium, the bank capital ratio equals its required value, and the cost of regulation is constant.

The intermediate bank smooths retained earnings intertemporally, given credit losses. It enters period $s$ with previously accumulated bank capital stock $K_{l, s}^{B}$, which subsequently evolves according to accumulation function

$$
K_{l, s+1}^{B}=\left(1-\delta_{s}^{B}\right) K_{l, s}^{B}+\mathcal{H}^{B}\left(I_{l, s}^{B}, I_{l, s-1}^{B}\right),
$$

where bank capital destruction rate $\delta_{s}^{B}$ satisfies $\delta_{s}^{B}=\chi^{C} \delta_{s}^{C}$ with $\chi^{C}>0$, while credit loss rate $\delta_{s}^{C}$ satisfies $\delta_{s}^{C}=\phi_{H}^{B} \delta_{s}^{H}+\phi_{F}^{B} \delta_{s}^{F}$ with $\phi_{H}^{B}=\bar{B}_{s+1}^{H} / \bar{B}_{s+1}^{C}$ and $\phi_{F}^{B}=\bar{B}_{s+1}^{F} / \bar{B}_{s+1}^{C}$. Effective retained earnings function $\mathcal{H}^{B}\left(I_{l, s}^{B}, I_{l, s-1}^{B}\right)$ incorporates convex adjustment costs,

$$
\mathcal{H}^{B}\left(I_{l, s}^{B}, I_{l, s-1}^{B}\right)=\left[1-\frac{\chi^{B}}{2}\left(\frac{I_{l, s}^{B}}{I_{l, s-1}^{B}}-1\right)^{2}\right] I_{l, s}^{B},
$$

where $\chi^{B}>0$. In steady state equilibrium, these adjustment costs equal zero, and effective retained earnings equals actual retained earnings.

In period $t$, the intermediate bank chooses state contingent sequences for deposit funding $\left\{B_{l, s+1}^{D}\right\}_{s=t}^{\infty}$, net interbank market funding $\left\{B_{l, s+1}^{B}\right\}_{s=t}^{\infty}$, retained earnings $\left\{I_{l, s}^{B}\right\}_{s=t}^{\infty}$ and the bank capital stock $\left\{K_{l, s+1}^{B}\right\}_{s=t}^{\infty}$ to maximize pre-dividend stock market value (48) subject to balance sheet identity (50), bank capital accumulation function (53), and terminal nonnegativity constraint $K_{l, T+1}^{B} \geq 0$ for $T \rightarrow \infty$. In equilibrium, the solutions to this value maximization problem satisfy necessary first order condition

$$
1+i_{t}^{B}=1+i_{t}^{D}
$$


which equates the interbank rate to the deposit rate. Furthermore, they satisfy necessary first order condition

$$
\frac{Q_{l, t}^{B}}{P_{t}} \mathcal{H}_{1}^{B}(l, t)+\mathrm{E}_{t} \frac{\beta \lambda_{t+1}}{\lambda_{t}} \frac{Q_{l, t+1}^{B}}{P_{t+1}} \mathcal{H}_{2}^{B}(l, t+1)=1,
$$

which equates the expected discounted value of an additional unit of retained earnings to its price, where $Q_{l, s}^{B}$ denotes the shadow price of bank capital, which is proportional to the Lagrange multiplier on the period $s$ bank capital accumulation function. Finally, they satisfy necessary first order condition

$$
\frac{Q_{l, t}^{B}}{P_{t}}=\mathrm{E}_{t} \frac{\beta \lambda_{t+1}}{\lambda_{t}}\left\{\left(1-\delta_{t+1}^{B}\right) \frac{Q_{l, t+1}^{B}}{P_{t+1}}-\left[\frac{\lambda_{t}}{\beta \lambda_{t+1}}-\left(1+i_{t}^{B}\right)\right]-\mathcal{G}_{K^{B}}^{B}(l, t+1)\right\},
$$

which equates the relative shadow price of bank capital to the expected discounted value of the future relative shadow price of bank capital net of credit losses, minus the spread of the cost of capital over interbank market funds, minus the real marginal regulation cost of bank capital.

\section{Credit Supply}

In an adaptation of the model of nominal price rigidity proposed by Calvo (1983) to the banking sector along the lines of Hülsewig, Mayer and Wollmershäuser (2009), each period a randomly selected fraction $1-\omega^{C}$ of intermediate banks adjust their gross mortgage and corporate loan rates optimally, where $0 \leq \omega^{C}<1$. The remaining fraction $\omega^{C}$ of intermediate banks do not adjust their loan rates,

$$
1+i_{l, t}^{Z}=1+i_{l, t-1}^{Z}
$$

where $Z \in\{H, F\}$. Under this financial friction, intermediate banks infrequently adjust their loan rates, mimicking the effect of maturity transformation on the spreads between the loan and deposit rates.

If the intermediate bank can adjust its gross mortgage and corporate loan rates in period $t$, then it does so to maximize pre-dividend stock market value (48) subject to balance sheet identity (50), intermediate loan demand function (46), and the assumed financial friction. We consider a symmetric equilibrium under which all bank specific endogenous state variables are restricted to equal their aggregate counterparts. It follows that all intermediate banks that adjust their loan rates in period $t$ solve an identical value maximization problem, which implies that they all choose common loan rates $i_{t}^{Z, *}$ given by necessary first order conditions:

$$
\frac{1+i_{t}^{Z, *}}{1+i_{t}^{Z}}=\frac{\mathrm{E}_{t} \sum_{s=t}^{\infty}\left(\omega^{C}\right)^{s-t} \frac{\beta^{s-t} \lambda_{s}}{\lambda_{t}} \theta_{s}^{i^{Z}} \frac{\left(1+i_{s-1}^{B}\right)+\mathcal{G}_{B^{Z}}^{B}(l, s)}{1+i_{s-1}^{Z}}\left(\frac{1+i_{s-1}^{Z}}{1+i_{t}^{Z}}\right)^{\theta_{s}^{Z^{Z}}}\left(\frac{1+i_{t}^{Z, *}}{1+i_{t}^{Z}}\right)^{-\theta_{s}^{i^{Z}}}\left(1+i_{s-1}^{Z}\right) B_{s}^{Z}}{\mathrm{E}_{t} \sum_{s=t}^{\infty}\left(\omega^{C}\right)^{s-t} \frac{\beta^{s-t} \lambda_{s}}{\lambda_{t}}\left(\theta_{s}^{i^{Z}}-1\right)\left(1-\delta_{s}^{Z}\right)\left(\frac{1+i_{s-1}^{Z}}{1+i_{t}^{Z}}\right)^{\theta_{s}^{i^{Z}}-1}\left(\frac{1+i_{t}^{Z, *}}{1+i_{t}^{Z}}\right)^{-\theta_{s}^{i^{Z}}}\left(1+i_{s-1}^{Z}\right) B_{s}^{Z}} .
$$


These necessary first order conditions equate the expected discounted value of the marginal revenue gained from mortgage or corporate loan supply to the expected discounted value of the marginal cost incurred from intermediation. Aggregate gross mortgage or corporate loan rate index (47) equals an average of the gross mortgage or corporate loan rate set by the fraction $1-\omega^{C}$ of intermediate banks that adjust their loan rates in period $t$, and the average of the gross mortgage or corporate loan rates set by the remaining fraction $\omega^{C}$ of intermediate banks that do not adjust their loan rates:

$$
1+i_{t}^{Z}=\left[\left(1-\omega^{C}\right)\left(1+i_{t}^{Z, *}\right)^{1-\theta_{t+1}^{i^{Z}}}+\omega^{C}\left(1+i_{t-1}^{Z}\right)^{1-\theta_{t+1}^{i^{Z}}}\right]^{\frac{1}{1-\theta_{t+1}^{Z}}} .
$$

Since those intermediate banks able to adjust their loan rates in period $t$ are selected randomly from among all intermediate banks, the average gross mortgage or corporate loan rate set by the remaining intermediate banks equals the value of the aggregate gross mortgage or corporate loan rate index that prevailed during period $t-1$.

\section{Monetary, Fiscal, and Macroprudential Policy}

The government consists of a monetary authority that conducts monetary policy, a fiscal authority that conducts fiscal policy, and a macroprudential authority that conducts macroprudential policy.

\section{Monetary Policy}

The monetary authority implements monetary policy through control of the short term interest rate according to a monetary policy rule exhibiting partial adjustment dynamics of the form

$$
i_{t}^{S}-\bar{i}_{t}^{S}=\rho^{i^{S}}\left(i_{t-1}^{S}-\bar{i}_{t-1}^{S}\right)+\left(1-\rho^{i^{S}}\right)\left[\xi^{\pi} \mathrm{E}_{t}\left(\pi_{t+1}-\bar{\pi}_{t+1}\right)+\xi^{Y^{G}}\left(\ln Y_{t}-\ln Y_{t}^{P}\right)+\xi^{\Delta F}\left(\Delta \ln F_{t}-\Delta \ln \bar{F}_{t}\right)\right]+v_{t}^{i^{S}},
$$

where $0 \leq \rho^{i^{S}}<1, \xi^{\pi}>1, \xi^{Y^{G}} \geq 0$ and $\xi^{\Delta F} \geq 0$. As specified, the deviation of the short term interest rate from its steady state equilibrium value depends on a weighted average of its past deviation and its desired deviation, which in turn is increasing in the expected future deviation of inflation from its target value, the contemporaneous output gap, and the contemporaneous change in the financial gap. We define the output gap as the deviation of output from its potential value, which we define as that output level consistent with full utilization of capital and effective labor, given the capital stock and effective labor force. Deviations from this monetary policy rule are captured by mean zero and serially uncorrelated monetary policy shock $v_{t}^{i^{S}}$.

We define the financial gap as a weighted average of the contemporaneous deviations of real bank credit and the relative prices of housing and equity from their steady state equilibrium values,

$$
\ln F_{t}-\ln \bar{F}_{t}=\phi_{C}^{F}\left(\ln \frac{B_{t+1}^{C}}{P_{t}}-\ln \frac{\bar{B}_{t+1}^{C}}{\bar{P}_{t}}\right)+\phi_{H}^{F}\left(\ln \frac{V_{t}^{H}}{P_{t}}-\ln \frac{\bar{V}_{t}^{H}}{\bar{P}_{t}}\right)+\phi_{F}^{F}\left(\ln \frac{V_{t}^{F}}{P_{t}}-\ln \frac{\bar{V}_{t}^{F}}{\bar{P}_{t}}\right),
$$


where $\phi_{C}^{F}>0, \phi_{H}^{F}>0, \phi_{F}^{F}>0$ and $\phi_{C}^{F}+\phi_{H}^{F}+\phi_{F}^{F}=1$. The change in the financial gap reflects financial conditions, as well as other drivers of the financial cycle, while its level measures financial vulnerability.

\section{Fiscal Policy}

The fiscal authority implements fiscal policy through control of public demand according to a fiscal policy rule exhibiting partial adjustment dynamics of the form

$$
\ln \frac{G_{t}}{\bar{G}_{t}}=\rho^{G} \ln \frac{G_{t-1}}{\bar{G}_{t-1}}+\left(1-\rho^{G}\right) \ln \frac{Y_{t}^{P}}{\bar{Y}_{t}}+v_{t}^{G},
$$

where $0 \leq \rho^{G}<1$. As specified, the deviation of public demand from its steady state equilibrium value depends on a weighted average of its past deviation and its desired deviation, which in turn equals the contemporaneous deviation of potential output from its steady state equilibrium value. Deviations from this fiscal policy rule are captured by mean zero and serially uncorrelated public demand shock $v_{t}^{G}$.

The fiscal authority runs a balanced budget. At the end of period $t$, it levies a lump sum tax $T_{t}$ on households, which it uses to finance the purchase of final public demand good $G_{t}$ at price $P_{t}$ according to government budget constraint:

$$
P_{t} G_{t}=T_{t} \text {. }
$$

As specified, fiscal policy is nondistortionary as taxes are lump sum, and automatically stabilizing as public demand is invariant to the output gap.

\section{Macroprudential Policy}

The macroprudential authority implements macroprudential policy through control of the capital requirement according to a macroprudential policy rule exhibiting partial adjustment dynamics of the form

$$
\kappa_{t+1}^{R}-\kappa^{R}=\rho^{\kappa^{R}}\left(\kappa_{t}^{R}-\kappa^{R}\right)+\left(1-\rho^{\kappa^{R}}\right) \xi^{\kappa^{R}}\left(\ln F_{t}-\ln \bar{F}_{t}\right)+v_{t}^{\kappa^{R}}
$$

where $0<\kappa^{R}<1,0 \leq \rho^{\kappa^{R}}<1$ and $\xi^{\kappa^{R}} \geq 0$. As specified, the deviation of the capital requirement from its steady state equilibrium value depends on a weighted average of its past deviation and its desired deviation, which in turn is increasing in the contemporaneous financial gap. Deviations from this macroprudential policy rule are captured by mean zero and serially correlated macroprudential policy shock $v_{t}^{\kappa^{R}}$.

The default rates applicable to borrowing by households and firms from banks satisfy mortgage and corporate loan default rate relationships exhibiting partial adjustment dynamics of the form

$$
\delta_{t}^{Z}-\delta^{C}=\rho^{\delta^{C}}\left(\delta_{t-1}^{Z}-\delta^{C}\right)-\left(1-\rho^{\delta^{C}}\right) \zeta^{\delta^{Z}}\left[\left(\ln Y_{t}-\ln Y_{t}^{P}\right)+\zeta^{F}\left(\ln F_{t}-\ln \bar{F}_{t}\right)\right]+v_{t}^{\delta^{Z}},
$$

where $Z \in\{H, F\}$, while $0<\delta^{C}<1,0 \leq \rho^{\delta^{C}}<1, \quad \zeta^{\delta^{Z}}>0$ and $\zeta^{F}>0$. As specified, the deviation of the mortgage or corporate loan default rate from its steady state equilibrium value is 
inertially decreasing in the contemporaneous output and financial gaps. Deviations from these default rate relationships are captured by mean zero and serially correlated mortgage or corporate loan default shock $v_{t}^{\delta^{Z}}$.

\section{E. Market Clearing Conditions}

A rational expectations equilibrium in this DSGE model of a closed economy consists of state contingent sequences of allocations for households, firms and banks that solve their constrained optimization problems given prices and policies, together with state contingent sequences of allocations for the government that satisfy its policy rules and constraint given prices, with supporting prices such that all markets clear.

Clearing of the final output good market requires that final output good supply equal demand from households, firms and the government,

$$
Y_{t}=C_{t}+I_{t}+G_{t},
$$

where investment $I_{t}$ satisfies $I_{t}=I_{t}^{H}+I_{t}^{K}$. Clearing of the housing market requires that $S_{i, t+1}^{H}=1$ for all $i \in[0,1]$, of the short term bond market requires that $B_{t+1}^{S}=0$, of the long term bond market requires that $B_{j, t+1}^{L}=0$ for all $j=1, \ldots, t$, and of the stock market requires that $S_{k, t+1}^{F}=1$ for all $k \in[0,1]$.

\section{THE EMPIRICAL FRAMEWORK}

Estimation, inference and forecasting are based on an augmented linear state space representation of an approximate multivariate linear rational expectations representation of this DSGE model of a closed economy, expressed as a function of its potentially heteroskedastic structural shocks. This multivariate linear rational expectations representation is derived by analytically linearizing the equilibrium conditions of the DSGE model around a stationary deterministic steady state equilibrium that abstracts from long run balanced growth, and consolidating them by substituting out intermediate variables. ${ }^{3}$ Its linear state space representation is augmented with empirically flexible trend component specifications for observed endogenous variables that account for long run balanced growth, and state dependent conditional heteroskedasticity specifications for structural shocks that generate endogenous risk.

\section{A. Endogenous Variables}

In what follows, $\hat{x}_{t}$ denotes the cyclical component of variable $x_{t}$, while $\bar{x}_{t}$ denotes its trend component. Cyclical and trend components are additively separable, that is $x_{t}=\hat{x}_{t}+\bar{x}_{t}$.

\footnotetext{
${ }^{3}$ In steady state equilibrium $v^{C}=v^{I^{H}}=v^{I^{K}}=1$ and $v^{G}=v^{i^{S}}=v^{H}=v^{B}=v^{S}=v^{\kappa^{R}}=v^{\delta^{H}}=v^{\delta^{F}}=0$.
} 


\section{Cyclical Components}

Inflation depends on a linear combination of its past and expected future values driven by contemporaneous real unit labor cost according to price Phillips curve

$$
\hat{\pi}_{t}=\frac{\gamma^{P}}{1+\gamma^{P} \beta} \hat{\pi}_{t-1}+\frac{\beta}{1+\gamma^{P} \beta} \mathrm{E}_{t} \hat{\pi}_{t+1}+\frac{\left(1-\omega^{P}\right)\left(1-\omega^{P} \beta\right)}{\omega^{P}\left(1+\gamma^{P} \beta\right)}\left(\ln \frac{\hat{W}_{t} \hat{L}_{t}}{\hat{P}_{t} \hat{Y}_{t}}+\ln \hat{\vartheta}_{t}^{P}\right),
$$

which determines the price level $\ln \hat{P}_{t}$. Inflation $\hat{\pi}_{t}$ also satisfies $\hat{\pi}_{t}=\ln \hat{P}_{t}-\ln \hat{P}_{t-1}$.

Consumption $\ln \hat{C}_{t}$ depends on a weighted average of its past and expected future values driven by a contemporaneous financial conditions index according to consumption demand relationship:

$$
\ln \hat{C}_{t}=\frac{\alpha}{1+\alpha} \ln \hat{C}_{t-1}+\frac{1}{1+\alpha} \mathrm{E}_{t} \ln \hat{C}_{t+1}-\sigma \frac{1-\alpha}{1+\alpha} \mathrm{E}_{t}\left(\hat{r}_{t}^{C}-\ln \frac{\hat{v}_{t}^{C}}{\hat{v}_{t+1}^{C}}\right)
$$

This consumption based financial conditions index $\hat{r}_{t}^{C}$ satisfies $\hat{r}_{t}^{C}=\hat{i}_{t}^{S}-\mathrm{E}_{t} \hat{\pi}_{t+1}+\phi_{H}^{C} \hat{v}_{t}^{H}+\phi_{B}^{C} \hat{v}_{t}^{B}+\phi_{S}^{C} \hat{v}_{t}^{S}$.

Residential investment $\ln \hat{I}_{t}^{H}$ depends on a weighted average of its past and expected future values driven by the contemporaneous relative shadow price of housing according to residential investment demand relationship:

$$
\ln \hat{I}_{t}^{H}=\frac{1}{1+\beta} \ln \hat{I}_{t-1}^{H}+\frac{\beta}{1+\beta} \mathrm{E}_{t} \ln \hat{I}_{t+1}^{H}+\frac{1}{\chi^{H}(1+\beta)} \ln \left(\hat{v}_{t}^{I^{H}} \frac{\hat{Q}_{t}^{H}}{\hat{P}_{t}}\right) .
$$

The relative shadow price of housing depends on its expected future value, as well as a contemporaneous financial conditions index and the expected future relative implicit rental price of housing, according to residential investment Euler equation

$$
\ln \frac{\hat{Q}_{t}^{H}}{\hat{P}_{t}}=\mathrm{E}_{t}\left\{\beta\left(1-\delta^{H}\right) \ln \frac{\hat{Q}_{t+1}^{H}}{\hat{P}_{t+1}}-\hat{r}_{t}^{I^{H}}+\left[\left(1-\beta\left(1-\delta^{H}\right)\right)+\phi^{H} \beta\left(\left(1-\delta^{C}\right)\left(1+i^{C}\right)-\frac{1}{\beta}\right)\right] \ln \frac{\hat{P}_{t+1}^{H}}{\hat{P}_{t+1}}\right\},
$$

which determines the shadow price of housing $\ln \hat{Q}_{t}^{H}$. This residential investment based financial conditions index $\hat{r}_{t}^{I^{H}} \quad$ satisfies $\quad \hat{r}_{t}^{I^{H}}=\left(1-\phi^{H}\right)\left(\hat{i}_{t}^{S}-\mathrm{E}_{t} \hat{\pi}_{t+1}+\hat{v}_{t}^{B}+\hat{v}_{t}^{H}\right)+\phi^{H} \beta\left(1-\delta^{C}\right)\left(1+i^{C}\right)$ $\left(\hat{i}_{t}^{H}-\mathrm{E}_{t} \hat{\pi}_{t+1}-\mathrm{E}_{t} \hat{\delta}_{t+1}^{H}\right) .^{4}$ The implicit rental price of housing $\ln \hat{P}_{t}^{H}$ depends on the contemporaneous price level, as well as the deviation of the past housing stock from contemporaneous consumption, according to implicit rental price of housing relationship:

$$
\ln \hat{P}_{t}^{H}=\ln \hat{P}_{t}-\frac{1}{\varsigma} \ln \frac{\hat{H}_{t}}{\hat{C}_{t}} .
$$

The housing stock $\ln \hat{H}_{t+1}$ is accumulated according to $\ln \hat{H}_{t+1}=\left(1-\delta^{H}\right) \ln \hat{H}_{t}+\delta^{H} \ln \left(\hat{v}_{t}^{I^{H}} \hat{I}_{t}^{H}\right)$.

Business investment $\ln \hat{I}_{t}^{K}$ depends on a weighted average of its past and expected future values driven by the contemporaneous relative shadow price of capital according to business investment demand relationship:

\footnotetext{
${ }^{4}$ The dependence of this residential investment based financial conditions index on asset risk premia is not microfounded.
} 


$$
\ln \hat{I}_{t}^{K}=\frac{1}{1+\beta} \ln \hat{I}_{t-1}^{K}+\frac{\beta}{1+\beta} \mathrm{E}_{t} \ln \hat{I}_{t+1}^{K}+\frac{1}{\chi^{K}(1+\beta)} \ln \left(\hat{v}_{t}^{I^{K}} \frac{\hat{Q}_{t}^{K}}{\hat{P}_{t}}\right) .
$$

The relative shadow price of capital depends on its expected future value, as well as a contemporaneous financial conditions index and the expected future capital utilization rate, according to business investment Euler equation

$$
\ln \frac{\hat{Q}_{t}^{K}}{\hat{P}_{t}}=\mathrm{E}_{t}\left\{\beta\left(1-\delta^{K}\right) \ln \frac{\hat{Q}_{t+1}^{K}}{\hat{P}_{t+1}}-\hat{r}_{t}^{I^{K}}+\left[\left(1-\beta\left(1-\delta^{K}\right)\right)+\phi^{F} \beta\left(\left(1-\delta^{C}\right)\left(1+i^{C}\right)-\frac{1}{\beta}\right)\right] \eta^{K} \ln \hat{u}_{t+1}^{K}\right\},
$$

which determines the shadow price of capital $\ln \hat{Q}_{t}^{K}$. This business investment based financial conditions index $\hat{r}_{t}^{I^{K}} \quad$ satisfies $\hat{r}_{t}^{I^{K}}=\left(1-\phi^{F}\right)\left(\hat{i}_{t}^{S}-\mathrm{E}_{t} \hat{\pi}_{t+1}+\hat{v}_{t}^{B}+\hat{v}_{t}^{S}\right)+\phi^{F} \beta\left(1-\delta^{C}\right)\left(1+i^{C}\right)$ $\left(\hat{i}_{t}^{F}-\mathrm{E}_{t} \hat{\pi}_{t+1}-\mathrm{E}_{t} \hat{\delta}_{t+1}^{F}\right)$. The capital utilization rate $\ln \hat{u}_{t}^{K}$ depends on the contemporaneous real wage, as well as the deviation of the past capital stock from contemporaneous employment, according to capital utilization relationship:

$$
\ln \hat{u}_{t}^{K}=\frac{1}{1+\eta^{K}}\left(\ln \frac{\hat{W}_{t}}{\hat{P}_{t}}-\ln \frac{\hat{K}_{t}}{\hat{L}_{t}}\right)
$$

The capital stock $\ln \hat{K}_{t+1}$ is accumulated according to $\ln \hat{K}_{t+1}=\left(1-\delta^{K}\right) \ln \hat{K}_{t}+\delta^{K} \ln \left(\hat{v}_{t}^{I^{K}} \hat{I}_{t}^{K}\right)$.

The price of housing $\ln \hat{V}_{t}^{H}$ depends on its expected future value driven by the expected future user cost of housing, and the contemporaneous short term interest rate adjusted by the duration and housing risk premia, according to housing market relationship:

$$
\ln \hat{V}_{t}^{H}=\beta \mathrm{E}_{t} \ln \hat{V}_{t+1}^{H}+(1-\beta) \mathrm{E}_{t} \ln \hat{\Pi}_{t+1}^{H}-\left(\hat{i}_{t}^{S}+\hat{v}_{t}^{B}+\hat{v}_{t}^{H}\right) .
$$

The user cost of housing $\ln \hat{\Pi}_{t}^{H}$ depends on contemporaneous implicit rental income, net mortgage borrowing and nominal residential investment according to

$$
\frac{\Pi^{H}}{P Y} \ln \hat{\Pi}_{t}^{H}=\frac{H}{Y} \ln \left(\hat{P}_{t}^{H} \hat{H}_{t}\right)+\frac{B^{H}}{P Y}\left[\ln \hat{B}_{t+1}^{H}-\left(1-\delta^{C}\right)\left(1+i^{C}\right)\left(\hat{i}_{t-1}^{H}-\hat{\delta}_{t}^{H}+\ln \hat{B}_{t}^{H}\right)\right]-\frac{I^{H}}{Y} \ln \left(\hat{P}_{t} \hat{I}_{t}^{H}\right),
$$

where $\frac{\Pi^{H}}{P Y}=\frac{H}{Y}+\left(1-\left(1-\delta^{C}\right)\left(1+i^{C}\right)\right) \frac{B^{H}}{P Y}-\frac{I^{H}}{Y}$ with $\frac{B^{H}}{P Y}=\phi^{H} \frac{H}{Y}$ and $\frac{H}{Y}=\frac{1}{\delta^{H}} \frac{I^{H}}{Y}$.

The long term bond yield $\hat{i}_{t}^{L}$ depends on its expected future value, driven by the contemporaneous short term interest rate adjusted by the duration risk premium, according to bond market relationship:

$$
\hat{i}_{t}^{L}=\omega^{B} \beta \mathrm{E}_{t} \hat{i}_{t+1}^{L}+\frac{1-\omega^{B} \beta}{\omega^{B} \beta}\left(\omega^{B}+\frac{1-\omega^{B} \beta}{\omega^{B} \beta}\right)^{-1}\left(\hat{i}_{t}^{S}+\hat{v}_{t}^{B}\right) .
$$

The term premium $\hat{\mu}_{t}^{B}$ depends on its expected future value driven by the contemporaneous duration risk premium according to:

$$
\hat{\mu}_{t}^{B}=\omega^{B} \beta \mathrm{E}_{t} \hat{\mu}_{t+1}^{B}+\frac{1-\omega^{B} \beta}{\omega^{B} \beta}\left(\omega^{B}+\frac{1-\omega^{B} \beta}{\omega^{B} \beta}\right)^{-1} \hat{v}_{t}^{B}
$$


The price of equity $\ln \hat{V}_{t}^{F}$ depends on its expected future value driven by expected future nonfinancial corporate profits, and the contemporaneous short term interest rate adjusted by the duration and equity risk premia, according to stock market relationship:

$$
\ln \hat{V}_{t}^{F}=\beta \mathrm{E}_{t} \ln \hat{V}_{t+1}^{F}+(1-\beta) \mathrm{E}_{t} \ln \hat{\Pi}_{t+1}^{F}-\left(\hat{i}_{t}^{S}+\hat{v}_{t}^{B}+\hat{v}_{t}^{S}\right) .
$$

Nonfinancial corporate profits $\ln \hat{\Pi}_{t}^{F}$ depends on contemporaneous nominal output, labor income, net nonfinancial corporate borrowing and nominal business investment according to

$$
\frac{\Pi^{F}}{P Y} \ln \hat{\Pi}_{t}^{F}=\ln \left(\hat{P}_{t} \hat{Y}_{t}\right)-\frac{W L}{P Y} \ln \left(\hat{W}_{t} \hat{L}_{t}\right)+\frac{B^{F}}{P Y}\left[\ln \hat{B}_{t+1}^{F}-\left(1-\delta^{C}\right)\left(1+i^{C}\right)\left(\hat{i}_{t-1}^{F}-\hat{\delta}_{t}^{F}+\ln \hat{B}_{t}^{F}\right)\right]-\frac{I^{K}}{Y} \ln \left(\hat{P}_{t} \hat{I}_{t}^{K}\right),
$$

where $\frac{\Pi^{F}}{P Y}=\left(1-\frac{W L}{P Y}\right)+\left(1-\left(1-\delta^{C}\right)\left(1+i^{C}\right)\right) \frac{B^{F}}{P Y}-\frac{I^{K}}{Y}$ with $\frac{B^{F}}{P Y}=\phi^{F} \frac{K}{Y}$ and $\frac{K}{Y}=\frac{1}{\delta^{K}} \frac{I^{K}}{Y}$.

Bank credit depends on a weighted average of the contemporaneous money and bank capital stocks according to bank balance sheet identity

$$
\ln \hat{B}_{t+1}^{C}=\left(1-\kappa^{R}\right) \ln \hat{M}_{t+1}+\kappa^{R} \ln \hat{K}_{t+1}^{B},
$$

which determines the money stock $\ln \hat{M}_{t+1}$. Bank credit $\ln \hat{B}_{t+1}^{C}$ depends on a weighted average of contemporaneous mortgage and nonfinancial corporate debt according to:

$$
\ln \hat{B}_{t+1}^{C}=\phi_{H}^{B} \ln \hat{B}_{t+1}^{H}+\phi_{F}^{B} \ln \hat{B}_{t+1}^{F} .
$$

Mortgage debt $\ln \hat{B}_{t+1}^{H}$ satisfies $\ln \hat{B}_{t+1}^{H}=\ln \hat{P}_{t}+\ln \hat{H}_{t+1}$, while nonfinancial corporate debt $\ln \hat{B}_{t+1}^{F}$ satisfies $\ln \hat{B}_{t+1}^{F}=\ln \hat{P}_{t}+\ln \hat{K}_{t+1}$.

The mortgage or corporate loan rate $\hat{i}_{t}^{Z}$ depends on a weighted average of its past and expected future values, driven by the deviation of the past short term interest rate from the contemporaneous mortgage or corporate loan rate net of the mortgage or corporate default rate, according to lending rate Phillips curves

$$
\begin{aligned}
\hat{i}_{t}^{Z}=\frac{1}{1+\beta} \hat{i}_{t-1}^{Z}+\frac{\beta}{1+\beta} \mathrm{E}_{t} \hat{i}_{t+1}^{Z}+\frac{\left(1-\omega^{C}\right)\left(1-\omega^{C} \beta\right)}{\omega^{C}(1+\beta)}\left\{\left[\hat{i}_{t-1}^{S}-\left(\hat{i}_{t}^{Z}-\hat{\delta}_{t}^{Z}\right)\right]\right. \\
\left.\quad-\frac{1-\beta\left(1-\chi^{C} \delta^{C}\right)}{1+\kappa^{R}\left(1-\beta\left(1-\chi^{C} \delta^{C}\right)\right)}\left[\eta^{C}\left(\hat{\kappa}_{t}-\hat{\kappa}_{t}^{R}\right)-\left(\hat{\kappa}_{t}^{R}-\kappa^{R} \hat{i}_{t-1}^{S}\right)\right]+\ln \hat{\vartheta}_{t}^{i^{2}}\right\},
\end{aligned}
$$

where $Z \in\{H, F\}$. The mortgage or corporate loan rate also depends on the past deviation of the bank capital ratio from its required value, as well as the past deviation of the capital requirement from its funding cost.

Bank retained earnings $\ln \hat{I}_{t}^{B}$ depends on a weighted average of its past and expected future values driven by the contemporaneous relative shadow price of bank capital according to retained earnings relationship:

$$
\ln \hat{I}_{t}^{B}=\frac{1}{1+\beta} \ln \hat{I}_{t-1}^{B}+\frac{\beta}{1+\beta} \mathrm{E}_{t} \ln \hat{I}_{t+1}^{B}+\frac{1}{\chi^{B}(1+\beta)} \ln \frac{\hat{Q}_{t}^{B}}{\hat{P}_{t}} .
$$

The relative shadow price of bank capital depends on its expected future value net of the bank capital destruction rate, as well as the contemporaneous short term interest rate and deviation of the bank capital ratio from its required value, according to retained earnings Euler equation 


$$
\ln \frac{\hat{Q}_{t}^{B}}{\hat{P}_{t}}=\mathrm{E}_{t}\left\{\beta\left(1-\chi^{C} \delta^{C}\right)\left(\ln \frac{\hat{Q}_{t+1}^{B}}{\hat{P}_{t+1}}-\hat{\delta}_{t+1}^{B}\right)-\left[\hat{i}_{t}^{S}+\left(1-\beta\left(1-\chi^{C} \delta^{C}\right)\right) \frac{\eta^{C}}{\kappa^{R}}\left(\hat{\kappa}_{t+1}-\hat{\kappa}_{t+1}^{R}\right)\right]\right\}
$$

which determines the shadow price of bank capital $\ln \hat{Q}_{t}^{B}$. The bank capital ratio $\hat{\kappa}_{t+1}$ satisfies $\hat{\kappa}_{t+1}=\kappa^{R}\left(\ln \hat{K}_{t+1}^{B}-\ln \hat{B}_{t+1}^{C}\right)$, where the bank capital stock $\ln \hat{K}_{t+1}^{B}$ is accumulated according to $\ln \hat{K}_{t+1}^{B}=\left(1-\chi^{C} \delta^{C}\right)\left(\ln \hat{K}_{t}^{B}-\hat{\delta}_{t}^{B}\right)+\chi^{C} \delta^{C} \ln \hat{I}_{t}^{B}$.

The real effective wage depends on a weighted average of its past and expected future values driven by the contemporaneous unemployment rate according to wage Phillips curve

$$
\begin{aligned}
\ln \frac{\hat{W}_{t}}{\hat{P}_{t} \hat{A}_{t}^{T}} & =\frac{1}{1+\beta} \ln \frac{\hat{W}_{t-1}}{\hat{P}_{t-1} \hat{A}_{t-1}^{T}}+\frac{\beta}{1+\beta} \mathrm{E}_{t} \ln \frac{\hat{W}_{t+1}}{\hat{P}_{t+1} \hat{A}_{t+1}^{T}}-\frac{\left(1-\omega^{W}\right)\left(1-\omega^{W} \beta\right)}{\omega^{W}(1+\beta)}\left(\frac{1}{\eta} \hat{u}_{t}^{L}-\ln \hat{\vartheta}_{t}^{W}\right) \\
& -\frac{1+\gamma^{W} \beta}{1+\beta}\left[\left(\hat{\pi}_{t}+\Delta \ln \hat{A}_{t}^{T}\right)-\frac{\gamma^{W}}{1+\gamma^{W} \beta}\left(\hat{\pi}_{t-1}+\Delta \ln \hat{A}_{t-1}^{T}\right)-\frac{\beta}{1+\gamma^{W} \beta} \mathrm{E}_{t}\left(\hat{\pi}_{t+1}+\Delta \ln \hat{A}_{t+1}^{T}\right)\right],
\end{aligned}
$$

which determines the wage $\ln \hat{W}_{t}$. The real effective wage also depends on contemporaneous, past and expected future inflation and trend productivity growth. The unemployment rate depends on contemporaneous employment and the real effective wage according to labor supply relationship

$$
\hat{u}_{t}^{L}=-\mu \ln \frac{\hat{L}_{t}}{\hat{v}_{t}^{N}}+\eta \ln \frac{\hat{W}_{t}}{\hat{P}_{t} \hat{A}_{t}^{T}}
$$

which determines the labor force $\ln \hat{N}_{t}$. The unemployment rate $\hat{u}_{t}^{L}$ satisfies $\hat{u}_{t}^{L}=\ln \hat{N}_{t}-\ln \hat{L}_{t}$.

Output $\ln \hat{Y}_{t}$ depends on contemporaneous consumption, investment and public demand according to output demand relationship

$$
\ln \hat{Y}_{t}=\frac{C}{Y} \ln \hat{C}_{t}+\frac{I}{Y} \ln \hat{I}_{t}+\frac{G}{Y} \ln \hat{G}_{t}
$$

where investment $\ln \hat{I}_{t}$ satisfies $\frac{I}{Y} \ln \hat{I}_{t}=\frac{I^{H}}{Y} \ln \hat{I}_{t}^{H}+\frac{I^{K}}{Y} \ln \hat{I}_{t}^{K}$, while $\frac{C}{Y}+\frac{I}{Y}+\frac{G}{Y}=1$ and $\frac{I}{Y}=\frac{I^{H}}{Y}+\frac{I^{K}}{Y}$ . Output also depends on the contemporaneous utilized capital stock and effective employment according to production function

$$
\ln \hat{Y}_{t}=\left(1-\frac{\theta^{P}}{\theta^{P}-1} \frac{W L}{P Y}\right) \ln \left(\hat{u}_{t}^{K} \hat{K}_{t}\right)+\frac{\theta^{P}}{\theta^{P}-1} \frac{W L}{P Y} \ln \left(\hat{A}_{t} \hat{L}_{t}\right)
$$

which determines employment $\ln \hat{L}_{t}$. The output gap $\ln \hat{Y}_{t}^{G}$ satisfies $\ln \hat{Y}_{t}^{G}=\ln \hat{Y}_{t}-\ln \hat{Y}_{t}^{P}$, where potential output $\ln \hat{Y}_{t}^{P}$ depends on a weighted average of the past capital stock and contemporaneous effective labor force according to

$$
\ln \hat{Y}_{t}^{P}=\left(1-\frac{\theta^{P}}{\theta^{P}-1} \frac{W L}{P Y}\right) \ln \hat{K}_{t}+\frac{\theta^{P}}{\theta^{P}-1} \frac{W L}{P Y} \ln \left(\hat{A}_{t} \hat{N}_{t}\right)
$$

given that full utilization of capital and effective labor is defined by $\ln \hat{u}_{t}^{K}=0$ and $\hat{u}_{t}^{L}=0$, respectively. ${ }^{5}$ Trend productivity $\ln \hat{A}_{t}^{T}$ depends on its past value driven by contemporaneous productivity according to $\ln \hat{A}_{t}^{T}=\rho^{A} \ln \hat{A}_{t-1}^{T}+\left(1-\rho^{A}\right) \ln \hat{A}_{t}$.

${ }^{5}$ It follows that the output gap also satisfies $\ln \hat{Y}_{t}^{G}=\left(1-\frac{\theta^{P}}{\theta^{P}-1} \frac{W L}{P Y}\right) \ln \hat{u}_{t}^{K}-\frac{\theta^{P}}{\theta^{P}-1} \frac{W L}{P Y} \hat{u}_{t}^{L}$. 
The financial gap $\ln \hat{F}_{t}$ depends on a weighted average of contemporaneous real bank credit and the relative prices of housing and equity according to:

$$
\ln \hat{F}_{t}=\phi_{C}^{F} \ln \frac{\hat{B}_{t+1}^{C}}{\hat{P}_{t}}+\phi_{H}^{F} \ln \frac{\hat{V}_{t}^{H}}{\hat{P}_{t}}+\phi_{F}^{F} \ln \frac{\hat{V}_{t}^{F}}{\hat{P}_{t}} .
$$

The mortgage or corporate loan default rate $\hat{\delta}_{t}^{Z}$ depends inertially on the contemporaneous output and financial gaps according to default rate relationships

$$
\hat{\delta}_{t}^{Z}=\rho^{\delta^{C}} \hat{\delta}_{t-1}^{Z}-\left(1-\rho^{\delta^{C}}\right) \zeta^{\delta^{Z}}\left(\ln \hat{Y}_{t}^{G}+\zeta^{F} \ln \hat{F}_{t}\right)+\hat{v}_{t}^{\delta^{Z}}
$$

where $Z \in\{H, F\}$. The bank capital destruction rate $\hat{\delta}_{t}^{B}$ satisfies $\left(1-\chi^{C} \delta^{C}\right) \hat{\delta}_{t}^{B}=\chi^{C}\left(1-\delta^{C}\right) \hat{\delta}_{t}^{C}$, where the credit loss rate $\hat{\delta}_{t}^{C}$ satisfies $\hat{\delta}_{t}^{C}=\phi_{H}^{B} \hat{\delta}_{t}^{H}+\phi_{F}^{B} \hat{\delta}_{t}^{F}$.

The short term interest rate $\hat{i}_{t}^{S}$ depends on a weighted average of its past and desired values according to monetary policy rule:

$$
\hat{i}_{t}^{S}=\rho^{i^{S}} \hat{i}_{t-1}^{S}+\left(1-\rho^{i^{S}}\right)\left(\xi^{\pi} \mathrm{E}_{t} \hat{\pi}_{t+1}+\xi^{Y^{G}} \ln \hat{Y}_{t}^{G}+\xi^{\Delta F} \Delta \ln \hat{F}_{t}\right)+\hat{v}_{t}^{i^{S}} .
$$

The desired short term interest rate responds to expected future inflation, the contemporaneous output gap, and the contemporaneous change in the financial gap. Public demand $\ln \hat{G}_{t}$ depends on a weighted average of its past and desired values according to fiscal policy rule:

$$
\ln \hat{G}_{t}=\rho^{G} \ln \hat{G}_{t-1}+\left(1-\rho^{G}\right) \ln \hat{Y}_{t}^{P}+\hat{v}_{t}^{G} .
$$

Desired public demand tracks contemporaneous potential output one for one. The capital requirement $\hat{\kappa}_{t+1}^{R}$ depends on a weighted average of its past and desired values according to macroprudential policy rule:

$$
\hat{\kappa}_{t+1}^{R}=\rho^{\kappa^{R}} \hat{\kappa}_{t}^{R}+\left(1-\rho^{\kappa^{R}}\right) \xi^{\kappa^{R}} \ln \hat{F}_{t}+\hat{v}_{t}^{\kappa^{R}} .
$$

The desired capital requirement responds to the contemporaneous financial gap.

\section{Trend Components}

The changes in the trend components of the price level $\ln \bar{P}_{t}$, output $\ln \bar{Y}_{t}$, consumption $\ln \bar{C}_{t}$, investment $\ln \bar{I}_{t}$, the price of housing $\ln \bar{V}_{t}^{H}$, the price of equity $\ln \bar{V}_{t}^{F}$, the wage $\ln \bar{W}_{t}$ and employment $\ln \bar{L}_{t}$ follow stationary first order autoregressive processes

$$
\Delta \bar{x}_{t}=(1-\rho) \mu_{x}+\rho \Delta \bar{x}_{t-1}+\bar{\varepsilon}_{t}^{x}, \bar{\varepsilon}_{t}^{x} \mid \mathcal{I}_{t-1} \sim \mathcal{N}\left(0, \bar{h}^{x}\right),
$$

where $\bar{x}_{t} \in\left\{\ln \bar{P}_{t}, \ln \bar{Y}_{t}, \ln \bar{C}_{t}, \ln \bar{I}_{t}, \ln \bar{V}_{t}^{H}, \ln \bar{V}_{t}^{F}, \ln \bar{W}_{t}, \ln \bar{L}_{t}\right\}$, with corresponding unconditional means $\mu_{x} \in\{\pi, g+n, g+n, g+n, \pi+g, \pi+g+n, \pi+g, n\}$ and innovations $\bar{\varepsilon}_{t}^{x} \in\left\{\bar{\varepsilon}_{t}^{P}, \bar{\varepsilon}_{t}^{Y}, \bar{\varepsilon}_{t}^{C}, \bar{\varepsilon}_{t}^{I}\right.$, $\left.\bar{\varepsilon}_{t}^{V^{H}}, \bar{\varepsilon}_{t}^{V^{F}}, \bar{\varepsilon}_{t}^{W}, \bar{\varepsilon}_{t}^{L}\right\}$ having unconditional variances $\bar{h}^{x} \in\left\{\bar{\sigma}_{P}^{2}, \bar{\sigma}_{Y}^{2}, \bar{\sigma}_{C}^{2}, \bar{\sigma}_{I}^{2}, \bar{\sigma}_{V^{H}}^{2}, \bar{\sigma}_{V^{F}}^{2}, \bar{\sigma}_{W}^{2}, \bar{\sigma}_{L}^{2}\right\}$. These trend components converge asymptotically at a common speed determined by $\rho$ to a long run balanced growth path featuring constant inflation at rate $\pi$, productivity growth at rate $g$, and population growth at rate $n$. In parallel, the changes in the trend components of the short term interest rate ${\overline{i_{t}}}^{S}$, the long term bond yield ${\overline{i_{t}}}^{L}$, the corporate loan rate $\bar{i}_{t}{ }^{F}$ and the unemployment rate $\bar{u}_{t}^{L}$ follow stationary first order autoregressive processes with unconditional means of zero 


$$
\Delta \bar{x}_{t}=\rho \Delta \bar{x}_{t-1}+\bar{\varepsilon}_{t}^{x}, \bar{\varepsilon}_{t}^{x} \mid \mathcal{I}_{t-1} \sim \mathcal{N}\left(0, \bar{h}^{x}\right),
$$

where $\bar{x}_{t} \in\left\{\bar{i}_{t}^{S}, \bar{i}_{t}^{L}, \bar{i}_{t}^{F}, \bar{u}_{t}^{L}\right\}$, with corresponding innovations $\bar{\varepsilon}_{t}^{x} \in\left\{\bar{\varepsilon}_{t}^{i^{s}}, \bar{\varepsilon}_{t}^{i^{L}}, \bar{\varepsilon}_{t}^{i^{F}}, \bar{\varepsilon}_{t}^{u^{L}}\right\}$ having unconditional variances $\bar{h}^{x} \in\left\{\bar{\sigma}_{i^{s}}^{2}, \bar{\sigma}_{i^{L}}^{2}, \bar{\sigma}_{i^{F}}^{2}, \bar{\sigma}_{u^{L}}^{2}\right\}$. These trend components converge asymptotically at the same speed to a long run balanced growth path featuring constant interest and unemployment rates. As an identifying restriction, all innovations are assumed to be contemporaneously uncorrelated.

\section{B. Exogenous Variables}

All structural shocks follow stationary first order autoregressive or serially uncorrelated processes, generally driven by conditionally normally distributed heteroskedastic innovations.

\section{Conditional Means}

The productivity $\ln \hat{A}_{t}$, labor supply $\ln \hat{v}_{t}^{N}$, consumption demand $\ln \hat{v}_{t}^{C}$, residential investment demand $\ln \hat{v}_{t}^{I^{H}}$, business investment demand $\ln \hat{v}_{t}^{I^{K}}$, housing risk premium $\hat{v}_{t}^{H}$, duration risk premium $\hat{v}_{t}^{B}$, equity risk premium $\hat{v}_{t}^{S}$, mortgage loan markup $\ln \hat{\vartheta}_{t}^{H^{H}}$ and corporate loan markup $\ln \hat{\vartheta}_{t}^{i^{F}}$ shocks follow stationary first order autoregressive processes driven by conditionally normally distributed heteroskedastic innovations

$$
\hat{v}_{t}^{Z}=\rho_{Z} \hat{v}_{t-1}^{Z}+\hat{\varepsilon}_{t}^{Z}, \hat{\varepsilon}_{t}^{Z} \mid \mathcal{I}_{t-1} \sim \mathcal{N}\left(0, \hat{h}_{t}^{Z}\right),
$$

where $\quad \hat{v}_{t}^{Z} \in\left\{\ln \hat{A}_{t}, \ln \hat{v}_{t}^{N}, \ln \hat{v}_{t}^{C}, \ln \hat{v}_{t}^{H}, \ln \hat{v}_{t}^{I^{K}}, \hat{v}_{t}^{H}, \hat{v}_{t}^{B}, \hat{v}_{t}^{S}, \ln \hat{\vartheta}_{t}^{i^{H}}, \ln \hat{\vartheta}_{t}^{F^{F}}\right\}, \quad$ with $\quad$ corresponding autoregressive coefficients $\rho_{Z} \in\left\{\rho_{A}, \rho_{N}, \rho_{C}, \rho_{I}, \rho_{I}, \rho_{H}, \rho_{B}, \rho_{S}, \rho_{i c}, \rho_{i^{c}}\right\}$ and innovations $\hat{\varepsilon}_{t}^{Z} \in\left\{\hat{\varepsilon}_{t}^{A}\right.$, $\left.\hat{\varepsilon}_{t}^{N}, \hat{\varepsilon}_{t c}^{C}, \hat{\varepsilon}_{t}^{H^{H}}, \hat{\varepsilon}_{t}^{I^{K}}, \hat{\varepsilon}_{t}^{H}, \hat{\varepsilon}_{t}^{B}, \hat{\varepsilon}_{t}^{S}, \hat{\varepsilon}_{t}^{i^{t^{*}}}, \hat{\varepsilon}_{t}^{i^{F}}\right\}$ having conditional variances $h_{t}^{Z} \in\left\{h_{t}^{A}, h_{t}^{N}, h_{t}^{C}, h_{t}^{I}, h_{t}^{I}, h_{t}^{H}, h_{t}^{B}\right.$, $\left.h_{t}^{S}, h_{t}^{C}, h_{t}^{C}\right\}$. Furthermore, the public demand $\hat{v}_{t}^{G}$, price markup $\ln \hat{\vartheta}_{t}^{P}$, wage markup $\ln \hat{\vartheta}_{t}^{W}$ and monetary policy $\hat{v}_{t}^{i}$ shocks follow serially uncorrelated processes driven by conditionally normally distributed heteroskedastic innovations

$$
\hat{v}_{t}^{Z}=\hat{\varepsilon}_{t}^{Z}, \hat{\varepsilon}_{t}^{Z} \mid \mathcal{I}_{t-1} \sim \mathcal{N}\left(0, \hat{h}_{t}^{Z}\right),
$$

where $\hat{v}_{t}^{Z} \in\left\{\hat{v}_{t}^{G}, \ln \hat{\vartheta}_{t}^{P}, \ln \hat{\vartheta}_{t}^{W}, \hat{v}_{t}^{S}\right\}$, with corresponding innovations $\hat{\varepsilon}_{t}^{Z} \in\left\{\hat{\varepsilon}_{t}^{G}, \hat{\varepsilon}_{t}^{P}, \hat{\varepsilon}_{t}^{W}, \hat{\varepsilon}_{t}^{i}\right\}$ having conditional variances $h_{t}^{Z} \in\left\{h_{t}^{G}, h_{t}^{P}, h_{t}^{W}, h_{t}^{i^{S}}\right\}$. Finally, the macroprudential policy $\hat{v}_{t}^{\kappa^{R}}$, mortgage loan default $\hat{v}_{t}^{\delta^{H}}$ and corporate loan default $\hat{v}_{t}^{\delta^{F}}$ shocks follow stationary first order autoregressive processes driven by conditionally normally distributed homoskedastic innovations

$$
\hat{v}_{t}^{Z}=\rho_{Z} \hat{v}_{t-1}^{Z}+\hat{\varepsilon}_{t}^{Z}, \hat{\varepsilon}_{t}^{Z} \mid \mathcal{I}_{t-1} \sim \mathcal{N}\left(0, \hat{h}^{Z}\right),
$$

where $\hat{v}_{t}^{Z} \in\left\{\hat{v}_{t}^{\kappa^{R}}, \hat{v}_{t}^{\delta^{H}}, \hat{v}_{t}^{\delta^{F}}\right\}$, with corresponding autoregressive coefficients $\rho_{Z} \in\left\{\rho_{\kappa^{R}}, \rho_{\delta^{c}}, \rho_{\delta^{c}}\right\}$ and innovations $\hat{\varepsilon}_{t}^{Z} \in\left\{\hat{\varepsilon}_{t}^{K^{R}}, \hat{\varepsilon}_{t}^{\delta^{H}}, \hat{\varepsilon}_{t}^{\delta^{F}}\right\}$ having unconditional variances $\hat{h}^{Z} \in\left\{\sigma_{\kappa^{R}}^{2}, \sigma_{\delta^{C}}^{2}, \sigma_{\delta^{C}}^{2}\right\}$. As an identifying restriction, all innovations are assumed to be contemporaneously uncorrelated. 


\section{Conditional Variances}

The conditional variances of the productivity $\hat{h}_{t}^{A}$, labor supply $\hat{h}_{t}^{N}$, consumption demand $\hat{h}_{t}^{C}$, investment demand $\hat{h}_{t}^{I}$, public demand $\hat{h}_{t}^{G}$, price markup $\hat{h}_{t}^{P}$, wage markup $\hat{h}_{t}^{W}$ and monetary policy $\hat{h}_{t}^{i^{S}}$ shocks are loglinear functions of the past change in and level of the output gap

$$
\ln \hat{h}_{t}^{Z}=\ln \hat{\sigma}_{Z}^{2}-\psi_{\Delta Y} \Delta \ln \hat{Y}_{t-1}^{G}+\psi_{Y} \ln \hat{Y}_{t-1}^{G},
$$

where $Z \in\left\{A, N, C, I, G, P, W, i^{S}\right\}$. If $\psi_{\Delta Y}>0$ then the conditional variances of these macroeconomic shocks are higher during a business cycle contraction than during an expansion, while if $\psi_{Y}>0$ then they are higher when capacity pressures are elevated than when they are subdued. In parallel, the conditional variances of the housing risk premium $\hat{h}_{t}^{H}$, duration risk premium $\hat{h}_{t}^{B}$, equity risk premium $\hat{h}_{t}^{S}$ and loan markup $\hat{h}_{t}^{i}$ shocks are loglinear functions of the past change in and level of the financial gap

$$
\ln \hat{h}_{t}^{Z}=\ln \hat{\sigma}_{Z}^{2}-\psi_{\Delta F} \Delta \ln \hat{F}_{t-1}+\psi_{F} \ln \hat{F}_{t-1},
$$

where $Z \in\left\{H, B, S, i^{C}\right\}$. If $\psi_{\Delta F}>0$ then the conditional variances of these financial shocks are higher during a financial cycle downturn than during an upturn, while if $\psi_{F}>0$ then they are higher when financial vulnerabilities are elevated than when they are subdued. These loglinear functional forms ensure positive conditional variances $\hat{h}_{t}^{Z}$, which converge asymptotically to unconditional variances of $\hat{\sigma}_{Z}^{2}$, given that the lagged output and financial gaps are stationary predetermined endogenous variables with unconditional means of zero.

\section{ESTIMATION}

We interpret our linearized DSGE model with state dependent conditional heteroskedasticity as a representation of the joint probability distribution of the data, and estimate a restricted version of it by Bayesian maximum likelihood. Following Harvey, Ruiz and Sentana (1992), we treat its augmented linear state space representation as though it were conditionally Gaussian, and maximize the implied posterior density function with respect to the parameters, facilitated by the implied extension of the filter due to Kalman (1960). This approximate Bayesian maximum likelihood estimation procedure would be exact if our state dependent conditional heteroskedasticity mechanism were driven by observed predetermined endogenous variables - or unobserved predetermined endogenous or exogenous variables that could be filtered without noise - as the augmented linear state space representation of the model would then be conditionally Gaussian.

The restricted version of our heteroskedastic linearized DSGE model consolidates or eliminates those structural shocks that are weakly identified by our macrofinancial time series data sets. In particular, the residential and business investment demand shocks are consolidated into an investment demand shock, while the mortgage and corporate loan markup shocks are consolidated into a loan markup shock. Furthermore, the macroprudential policy, and mortgage and corporate loan default shocks, are eliminated. Of those parameters that enter into the conditional mean function of its augmented linear state space representation, the strongly identified ones are 
estimated conditional on informative independent priors, while the weakly identified ones are calibrated. In contrast, those parameters that only enter into the conditional variance function are estimated conditional on diffuse priors.

\section{A. Estimation Procedure}

Let $\left\{\boldsymbol{x}_{t}\right\}_{t=1}^{T}$ denote a vector stochastic process consisting of the levels of $N$ nonpredetermined endogenous variables, of which $M$ are observed. The cyclical components of this vector stochastic process satisfy second order stochastic linear difference equation

$$
\boldsymbol{A}_{0} \hat{\boldsymbol{x}}_{t}=\boldsymbol{A}_{1} \hat{\boldsymbol{x}}_{t-1}+\boldsymbol{A}_{2} \mathrm{E}_{t} \hat{\boldsymbol{x}}_{t+1}+\boldsymbol{A}_{3} \hat{\boldsymbol{v}}_{t},
$$

where vector stochastic process $\left\{\hat{\boldsymbol{v}}_{t}\right\}_{t=1}^{T}$ consists of $K$ exogenous variables. This vector stochastic process satisfies stationary first order stochastic linear difference equation

$$
\hat{\boldsymbol{v}}_{t}=\boldsymbol{B}_{1} \hat{\boldsymbol{v}}_{t-1}+\hat{\boldsymbol{\varepsilon}}_{t},
$$

where $\hat{\boldsymbol{H}}_{t}^{-1 / 2} \hat{\boldsymbol{\varepsilon}}_{t} \mid \mathcal{I}_{t-1} \sim$ iid $\mathcal{N}\left(\mathbf{0}, \boldsymbol{I}_{K}\right)$ with $\mathcal{I}_{t}=\left\{\boldsymbol{y}_{s}\right\}_{s=1}^{t}$, which implies that $\hat{\boldsymbol{\varepsilon}}_{t} \mid \mathcal{I}_{t-1} \sim \mathcal{N}\left(\mathbf{0}, \hat{\boldsymbol{H}}_{t}\right)$. The conditional variances of these exogenous variables may depend loglinearly on predetermined endogenous or exogenous variables:

$$
\operatorname{diag}\left(\boldsymbol{H}_{t}\right)=\exp \left(\boldsymbol{C}_{0}+\boldsymbol{C}_{1} \hat{\boldsymbol{x}}_{t-1}+\boldsymbol{C}_{2} \hat{\boldsymbol{v}}_{t-1}\right)
$$

To ensure finite conditional variances, all linear combinations $\boldsymbol{C}_{1} \hat{\boldsymbol{x}}_{t-1}$ are stationary, which admits the possibility that the relevant predetermined endogenous variables are nonstationary but cointegrated. If there exists a unique stationary solution to this heteroskedastic multivariate linear rational expectations model, then it may be expressed as:

$$
\hat{\boldsymbol{x}}_{t}=\boldsymbol{D}_{1} \hat{\boldsymbol{x}}_{t-1}+\boldsymbol{D}_{2} \hat{\boldsymbol{v}}_{t}
$$

We calculate this unique stationary solution with the algorithm due to Klein (2000). This solution algorithm assumes that vector stochastic process $\left\{\hat{\boldsymbol{v}}_{t}\right\}_{t=1}^{T}$ is stable. Given that first order stochastic linear difference equation (105) is stationary, this assumption is satisfied if vector stochastic process $\left\{\hat{\boldsymbol{\varepsilon}}_{t}\right\}_{t=1}^{T}$ is stable. In the absence of state dependent conditional heteroskedasticity, $\left\{\hat{\boldsymbol{\varepsilon}}_{t}\right\}_{t=1}^{T}$ would be white noise, which is stable. In the presence of state dependent conditional heteroskedasticity, of the form under consideration where the conditional variances of exogenous variables are driven by stationary linear combinations of predetermined endogenous or exogenous variables, $\left\{\hat{\boldsymbol{\varepsilon}}_{t}\right\}_{t=1}^{T}$ remains a uniformly bounded martingale difference process, which is also stable.

Let $\boldsymbol{S}$ denote a matrix which selects those nonpredetermined endogenous variables that are observed. The trend components of vector stochastic process $\left\{\boldsymbol{S} \boldsymbol{x}_{t}\right\}_{t=1}^{T}$ satisfy nonstationary second order stochastic linear difference equation

$$
\Delta \boldsymbol{S} \overline{\boldsymbol{x}}_{t}=\boldsymbol{T}_{0}+\boldsymbol{T}_{1} \Delta \boldsymbol{S} \overline{\boldsymbol{x}}_{t-1}+\overline{\boldsymbol{\varepsilon}}_{t},
$$

where $\overline{\boldsymbol{H}}_{t}^{-1 / 2} \overline{\boldsymbol{\varepsilon}}_{t} \mid \mathcal{I}_{t-1} \sim$ iid $\mathcal{N}\left(\mathbf{0}, \boldsymbol{I}_{M}\right)$, which implies that $\overline{\boldsymbol{\varepsilon}}_{t} \mid \mathcal{I}_{t-1} \sim \mathcal{N}\left(\mathbf{0}, \overline{\boldsymbol{H}}_{t}\right)$. Suppose that the trend components of the observed nonpredetermined endogenous variables $\boldsymbol{S} \overline{\boldsymbol{x}}_{t}=\Delta \boldsymbol{S} \overline{\boldsymbol{x}}_{t}+\boldsymbol{S} \overline{\boldsymbol{x}}_{t-1}$ are observed with independent measurement errors

$$
\boldsymbol{w}_{t}=\boldsymbol{S} \overline{\boldsymbol{x}}_{t}+\boldsymbol{\eta}_{t},
$$


where $\boldsymbol{R}_{t}^{-1 / 2} \boldsymbol{\eta}_{t} \mid \mathcal{I}_{t-1} \sim \operatorname{iid} \mathcal{N}\left(\mathbf{0}, \boldsymbol{I}_{M}\right)$, which implies that $\boldsymbol{\eta}_{t} \mid \mathcal{I}_{t-1} \sim \mathcal{N}\left(\mathbf{0}, \boldsymbol{R}_{t}\right)$. Following Vitek (2009), this set of stochastic linear restrictions of time dependent tightness imposes judgment on the paths of these trend components, summarized by a conditional multivariate normal distribution with mean $\boldsymbol{w}_{t}$ and variance $\boldsymbol{R}_{t}$. The cyclical and trend components of these observed nonpredetermined endogenous variables are additively separable, that is $\boldsymbol{S} \boldsymbol{x}_{t}=\boldsymbol{S} \hat{\boldsymbol{x}}_{t}+\boldsymbol{S} \overline{\boldsymbol{x}}_{t}$.

Let $\left\{\boldsymbol{y}_{t}\right\}_{t=1}^{T}$ denote a vector stochastic process consisting of the levels of $M$ observed nonpredetermined endogenous variables, as well as preliminary estimates of their trend components, where $M \leq K$ to ensure stochastic nonsingularity. Also, let $\left\{\boldsymbol{z}_{t}\right\}_{t=1}^{T}$ denote a vector stochastic process consisting of the cyclical components of $N$ nonpredetermined endogenous variables and $K$ exogenous variables, as well as the levels and differences of the trend components of $M$ observed nonpredetermined endogenous variables. Given unique stationary solution (107), these vector stochastic processes have augmented linear state space representation

$$
\begin{aligned}
& \boldsymbol{y}_{t}=\boldsymbol{E}_{1} \boldsymbol{z}_{t}+\boldsymbol{E}_{2} \boldsymbol{\eta}_{t}, \\
& \boldsymbol{z}_{t}=\boldsymbol{F}_{0}+\boldsymbol{F}_{1} \boldsymbol{z}_{t-1}+\boldsymbol{F}_{2} \boldsymbol{\varepsilon}_{t}, \\
& \operatorname{diag}\left(\boldsymbol{H}_{t}\right)=\exp \left(\boldsymbol{G}_{0}+\boldsymbol{G}_{1} \boldsymbol{z}_{t-1}\right),
\end{aligned}
$$

where $\boldsymbol{\varepsilon}_{t} \mid \mathcal{I}_{t-1} \sim \mathcal{N}\left(\mathbf{0}, \boldsymbol{H}_{t}\right)$ with $\boldsymbol{\varepsilon}_{t}=\left[\begin{array}{c}\hat{\boldsymbol{\varepsilon}}_{t} \\ \overline{\boldsymbol{\varepsilon}}_{t}\end{array}\right]$ and $\boldsymbol{H}_{t}=\left[\begin{array}{cc}\hat{\boldsymbol{H}}_{t} & \mathbf{0} \\ \mathbf{0} & \overline{\boldsymbol{H}}\end{array}\right]$, while $\boldsymbol{z}_{0} \sim \mathcal{N}\left(\boldsymbol{z}_{000}, \boldsymbol{P}_{0 \mid 0}\right)$. We assume that the signal innovation vector $\boldsymbol{\eta}_{t}$, state innovation vector $\boldsymbol{\varepsilon}_{t}$ and initial state vector $\boldsymbol{z}_{0}$ are mutually independent. The signal conditional covariance matrix $\boldsymbol{R}_{t}$ is diagonal and time dependent, whereas the state conditional covariance matrix $\boldsymbol{H}_{t}$ is diagonal and state dependent.

Given the parameters associated with this augmented linear state space model, the unobserved state vector $\boldsymbol{z}_{t}$ and its mean squared error matrix $\boldsymbol{P}_{t}$ may be estimated with the filter due to Kalman (1960), extended to allow for the form of state dependent conditional heteroskedasticity under consideration. Following Harvey, Ruiz and Sentana (1992), we treat the signal vector $\boldsymbol{y}_{t}$ and state vector $\boldsymbol{z}_{t}$ as jointly multivariate normally distributed conditional on information available at time $t-1$ - as they would be in the absence of state dependent conditional heteroskedasticity - which implies that the state vector $\boldsymbol{z}_{t}$ is multivariate normally distributed conditional on information available at time $t$. In particular, estimates of the means and variances of the signal and state vectors conditional on information available at time $t-1$ satisfy the usual prediction equations:

$$
\begin{aligned}
& \boldsymbol{z}_{t \mid t-1}=\boldsymbol{F}_{0}+\boldsymbol{F}_{1} \boldsymbol{z}_{t-1 \mid t-1}, \\
& \boldsymbol{P}_{t \mid t-1}=\boldsymbol{F}_{1} \boldsymbol{P}_{t-1 \mid t-1} \boldsymbol{F}_{1}^{\top}+\boldsymbol{F}_{2} \boldsymbol{H}_{t \mid t-1} \boldsymbol{F}_{2}^{\top}, \\
& \boldsymbol{y}_{t \mid t-1}=\boldsymbol{E}_{1} \boldsymbol{z}_{t \mid t-1}, \\
& \boldsymbol{Q}_{t \mid t-1}=\boldsymbol{E}_{1} \boldsymbol{P}_{t \mid t-1} \boldsymbol{E}_{1}^{\top}+\boldsymbol{E}_{2} \boldsymbol{R}_{t \mid t-1} \boldsymbol{E}_{2}^{\top} .
\end{aligned}
$$

Treating the state vector $\boldsymbol{z}_{t}$ as multivariate normally distributed conditional on information available at time $t$, it follows that $\operatorname{diag}\left(\boldsymbol{H}_{t}\right)$ is multivariate lognormally distributed conditional on information available at time $t-1$, which implies that an estimate of its mean conditional on information available at time $t-1$ satisfies the additional prediction equation: 


$$
\operatorname{diag}\left(\boldsymbol{H}_{t \mid t-1}\right)=\exp \left\{\boldsymbol{G}_{0}+\boldsymbol{G}_{1} \boldsymbol{z}_{t-1 \mid t-1}+\frac{1}{2} \operatorname{diag}\left(\boldsymbol{G}_{1} \boldsymbol{P}_{t-1 \mid t-1} \boldsymbol{G}_{1}^{\boldsymbol{\top}}\right)\right\} .
$$

The derivation of this result exploits the exact functional relationship between the conditional mean of a conditionally multivariate lognormally distributed vector stochastic process, and the conditional mean and variance of the underlying conditionally multivariate normally distributed vector stochastic process. ${ }^{6}$ Treating the signal vector $\boldsymbol{y}_{t}$ and state vector $\boldsymbol{z}_{t}$ as jointly multivariate normally distributed conditional on information available at time $t-1$, estimates of the mean and mean squared error of the state vector conditional on information available at time $t$ satisfy the usual updating equations

$$
\begin{aligned}
& \boldsymbol{z}_{t \mid t}=\boldsymbol{z}_{t \mid t-1}+\boldsymbol{K}_{t}\left(\boldsymbol{y}_{t}-\boldsymbol{y}_{t \mid t-1}\right), \\
& \boldsymbol{P}_{t \mid t}=\boldsymbol{P}_{t \mid t-1}-\boldsymbol{K}_{t} \boldsymbol{E}_{1} \boldsymbol{P}_{t \mid t-1},
\end{aligned}
$$

where $\boldsymbol{K}_{t}=\boldsymbol{P}_{t \mid t-1} \boldsymbol{E}_{1}^{\top} \boldsymbol{Q}_{t \mid t-1}^{-1}$. Given initial conditions $\boldsymbol{z}_{0 \mid 0}$ and $\boldsymbol{P}_{0 \mid 0}$, recursive forward evaluation of equations (113), (117), (114), (115), (116), (118) and (119) yields predicted and filtered estimates of the state vector and its mean squared error matrix.

Let $\boldsymbol{\theta} \in \boldsymbol{\Theta} \subset \mathbb{R}^{J}$ denote a $J$ dimensional vector containing the parameters associated with this augmented linear state space model. The Bayesian maximum likelihood estimator of this parameter vector has posterior density function:

$$
f\left(\boldsymbol{\theta} \mid\left\{\boldsymbol{y}_{t}\right\}_{t=1}^{T}\right) \propto f\left(\left\{\boldsymbol{y}_{t}\right\}_{t=1}^{T} \mid \boldsymbol{\theta}\right) f(\boldsymbol{\theta}) .
$$

Treating the signal vector $\boldsymbol{y}_{t}$ as multivariate normally distributed conditional on information available at time $t-1$, conditional density function $f\left(\left\{\boldsymbol{y}_{t}\right\}_{t=1}^{T} \mid \boldsymbol{\theta}\right)$ satisfies:

$$
f\left(\left\{\boldsymbol{y}_{t}\right\}_{t=1}^{T} \mid \boldsymbol{\theta}\right)=\prod_{t=1}^{T}(2 \pi)^{-\frac{M}{2}}\left|\boldsymbol{Q}_{t \mid t-1}\right|^{-\frac{1}{2}} \exp \left\{-\frac{1}{2}\left(\boldsymbol{y}_{t}-\boldsymbol{y}_{t \mid t-1}\right)^{\top} \boldsymbol{Q}_{t \mid t-1}^{-1}\left(\boldsymbol{y}_{t}-\boldsymbol{y}_{t \mid t-1}\right)\right\} .
$$

Suppose that prior information concerning parameter vector $\boldsymbol{\theta}$ is summarized by a multivariate normal distribution with mean $\boldsymbol{\theta}_{1}$ and variance $\boldsymbol{\Omega}$ :

$$
f(\boldsymbol{\theta})=(2 \pi)^{-\frac{J}{2}}|\boldsymbol{\Omega}|^{-\frac{1}{2}} \exp \left\{-\frac{1}{2}\left(\boldsymbol{\theta}-\boldsymbol{\theta}_{1}\right)^{\top} \boldsymbol{\Omega}^{-1}\left(\boldsymbol{\theta}-\boldsymbol{\theta}_{1}\right)\right\} .
$$

Independent priors are represented by a diagonal covariance matrix, under which diffuse priors are represented by unboundedly large variances.

We conduct inference on the parameters based on an asymptotic normal approximation to the posterior distribution around its mode. Under regularity conditions stated in Geweke (2005), posterior mode $\hat{\boldsymbol{\theta}}_{T}$ satisfies

$$
\sqrt{T}\left(\hat{\boldsymbol{\theta}}_{T}-\boldsymbol{\theta}_{0}\right) \stackrel{d}{\rightarrow} \mathcal{N}\left(\mathbf{0},-\mathcal{H}_{0}^{-1}\right)
$$

\footnotetext{
${ }^{6}$ The conditional variance term would drop out if the state dependent conditional heteroskedasticity were driven by observed predetermined endogenous variables, or unobserved predetermined endogenous or exogenous variables that could be filtered without noise
} 
where $\boldsymbol{\theta}_{0} \in \boldsymbol{\Theta}$ denotes the pseudotrue parameter vector. Motivated by Engle and Watson (1981), we estimate Hessian $\mathcal{H}_{0}$ by:

$$
\hat{\mathcal{H}}_{T}=-\frac{1}{T} \sum_{t=1}^{T}\left[\nabla_{\theta} \boldsymbol{y}_{t \mid t-1}^{\top} \boldsymbol{Q}_{t \mid t-1}^{-1} \nabla_{\theta} \boldsymbol{y}_{t \mid t-1}+\frac{1}{2} \nabla_{\theta} \boldsymbol{Q}_{t \mid t-1}^{\top}\left(\boldsymbol{Q}_{t \mid t-1}^{-1} \otimes \boldsymbol{Q}_{t \mid t-1}^{-1}\right) \nabla_{\theta} \boldsymbol{Q}_{t \mid t-1}\right]-\frac{1}{T} \boldsymbol{\Omega}^{-1} .
$$

This estimator of the Hessian depends only on first derivatives and is negative semidefinite.

\section{B. Estimation Results}

Estimation of our heteroskedastic linearized DSGE model of a closed economy is based on the levels of twelve endogenous variables observed for Japan or the United States over the sample period 1986Q3 to 2019Q3. The observed macroeconomic and financial market variables under consideration are the price level, output, consumption, investment, the short term interest rate, the long term bond yield, the price of housing, the price of equity, the corporate loan rate, the wage, the unemployment rate, and employment. The price level is measured by the seasonally adjusted gross domestic product price deflator, output is measured by seasonally adjusted real gross domestic product, consumption is measured by seasonally adjusted real private consumption expenditures, and investment is measured by seasonally adjusted real private investment expenditures. Furthermore, the short term interest rate is measured by the policy interest rate, the long term bond yield is measured by the ten year government bond yield, the price of housing is proxied by a broad residential property price index, the price of equity is proxied by a broad stock price index, and the corporate loan rate is proxied by a reference bank lending rate. Finally, the wage is proxied by a seasonally adjusted wage index, the unemployment rate is measured by the seasonally adjusted share of total unemployment in the total labor force, and employment is measured by seasonally adjusted total employment. This time series data was extracted from the GDS or IFS database compiled by the IMF, except for the house price data which was obtained from the BIS, and the wage data which was obtained from the OECD.

We generate judgment concerning the paths of the trend components of all observed endogenous variables with preliminary estimates of their means and variances from the extension of the filter described in Hodrick and Prescott (1997) due to Vitek (2014). This extension parameterizes the difference order associated with the penalty term determining the smoothness of the trend component, and augments the point estimates with time varying mean squared errors. These mean squared errors tend to increase with the distance from the midpoint of the sample period, reflecting the two sided nature of the filter. For those variables that exhibit long run trends, namely the price level, output, consumption, investment, the price of housing, the price of equity, the wage and employment, we set the difference order to two and the smoothing parameter to 16,000 . In contrast, for those variables that do not exhibit long run trends, namely the short term interest rate, the long term bond yield, the corporate loan rate and the unemployment rate, we set the difference order to one and the smoothing parameter to 400. Given that financial cycles tend to be longer than business cycles, these smoothing parameters are set to relatively high values.

The marginal prior distributions of the strongly identified parameters that enter into the conditional mean function are centered within the range of estimates reported in the existing 
empirical literature where available, as reported in the Appendix. For example, the prior mean of the habit persistence parameter $\alpha$ is 0.80 , while that of the intertemporal consumption elasticity parameter $\sigma$ is 1.00 , and that of the intratemporal labor supply elasticity parameter $\eta$ is 0.50 . In addition, the prior mean of the residential investment adjustment cost parameter $\chi^{H}$ is 3.00 , while that of the intratemporal housing demand elasticity parameter $\varsigma$ is 1.00 . In parallel, the prior mean of the business investment adjustment cost parameter $\chi^{K}$ is 3.25 , while that of the capital utilization cost parameter $\eta^{K}$ is 1.00 . Furthermore, the prior means of the partial indexation parameters for price $\gamma^{P}$ and wage $\gamma^{W}$ determination are 0.80 , while those of the nominal rigidity parameters for price $\omega^{P}$ and wage $\omega^{W}$ determination imply average reoptimization intervals of 8.0 quarters. In addition, the prior means of the mortgage $\phi^{H}$ and corporate $\phi^{F}$ loan to value ratio parameters are 0.80 , while that of the financial friction parameter for mortgage and corporate loan rate determination $\omega^{C}$ implies an average adjustment interval of 4.0 quarters. Finally, the prior mean of the partial adjustment parameter $\rho^{i^{S}}$ in the monetary policy rule is 0.80 , while that of the expected inflation response coefficient $\xi^{\pi}$ is 1.50 , and that of the output gap response coefficient $\xi^{Y^{G}}$ is 0.50 at the annual frequency.

The weakly identified parameters that enter into the conditional mean function are calibrated to match conventional or average observed values. For example, the subjective discount factor parameter $\beta$ is set to imply a discount rate of 4.0 percent, while the housing depreciation parameter $\delta^{H}$ is set to imply a depreciation rate of 3.0 percent, and the capital depreciation parameter $\delta^{K}$ is set to imply a depreciation rate of 9.0 percent, at the annual frequency. In addition, the price markup parameter $\theta^{P}$ is set to imply a steady state equilibrium price markup of 15.0 percent, while the steady state equilibrium labor income share is set to 0.67 . Furthermore, the steady state equilibrium bank lending rate $i^{C}$ is set to 6.0 percent, while the steady state equilibrium default rate $\delta^{C}$ is set to 1.0 percent, at the annual frequency. In the financial gap, the weight on the credit gap is set to 0.75 , while that on the house price gap is set to 0.20 , and that on the equity price gap is set to 0.05 , broadly in line with our reduced form estimation results. In addition, the long run speed of adjustment parameter $\rho$ is set to 0.99 , while the steady state equilibrium inflation rate $\pi$, productivity growth rate $g$ and population growth rate $n$ are set to their average observed values for the economy under consideration over the sample period. ${ }^{7}$ Finally, the steady state equilibrium ratios of consumption, residential investment and business investment to output are set to their average observed values for the economy under consideration over the sample period, while the steady state equilibrium ratio of public demand to output follows from the final output good market clearing condition.

Parameter estimation results based on effective sample period 1987Q1 to 2019Q3 are reported in the Appendix. The logarithm of the posterior density kernel is globally maximized numerically with the differential evolution algorithm due to Storn and Price (1997). The data is very informative regarding many of the strongly identified parameters that enter into the conditional mean function, as evidenced by substantial updates from prior to posterior. These updates tend to be in the same direction for Japan and the United States, but their magnitudes often differ

\footnotetext{
${ }^{7}$ The steady state equilibrium productivity growth rate is estimated by the sample average growth rate of output less that of employment, while the steady state equilibrium population growth rate is estimated by the sample average growth rate of employment.
} 
substantially, reflecting differences in the structural characteristics of these economies. For example, the posterior modes of the partial indexation parameters for price and wage determination are 0.55 and 0.71 for Japan, versus 0.76 and 0.78 for the United States, respectively. Furthermore, the posterior mode of the expected inflation response coefficient in the monetary policy rule is 1.28 for Japan, versus 1.50 for the United States. As for the parameters that enter into the conditional variance function, the posterior modes of the slope coefficients are all positive and generally economically significant for Japan and the United States. In particular, a one percentage point faster rate of business cycle contraction is estimated to raise the conditional variances of the macroeconomic shocks by 76 percent for Japan and by 96 percent for the United States, while a one percentage point faster rate of financial cycle downturn is estimated to raise the conditional variances of the financial shocks by 30 percent for Japan and by 68 percent for the United States. Finally, a one percent higher output gap is estimated to raise the conditional variances of the macroeconomic shocks by 10 percent for Japan and by 1 percent for the United States, while a one percent higher financial gap is estimated to raise the conditional variances of the financial shocks by 26 percent for Japan and by 7 percent for the United States.

Allowing the structural shocks that drive our linearized DSGE model to exhibit state dependent conditional heteroskedasticity yields a substantial improvement in its goodness of fit to the conditional distributions of its observed endogenous variables. In particular, on the basis of the Bayes factor — which emphasizes relative distributional predictive accuracy — we find very strong evidence against the conditionally homoskedastic specification in favor of the conditionally heteroskedastic specification for both Japan and the United States. Indeed, twice the logarithm of the Bayes factor evaluates to 29 for Japan and to 56 for the United States using a Laplace approximation, far above the threshold for very strong evidence of 10 proposed by Kass and Raftery (1995).

\section{Diagnostic Checks}

Before analyzing growth at risk with our heteroskedastic linearized DSGE model, we assess its empirical performance along conventional dimensions, focusing on inflation and output growth. In particular, we examine historical decompositions and sequential dynamic forecasts of these key macroeconomic variables. We also assess the contribution of our state dependent conditional heteroskedasticity mechanism to the confidence intervals surrounding these dynamic forecasts, focusing on times of macrofinancial stress.

Our historical decompositions of inflation and output growth yield economically plausible explanations of their evolution over time. Those of inflation attribute deviations from trend rates primarily to markup shocks, and secondarily to demand and financial shocks. In parallel, our historical decompositions of output growth attribute business cycle dynamics around trend growth rates primarily to demand and financial shocks. Consistent with conventional views, they identify adverse demand and financial shocks as the primary drivers of the business cycle contractions that occurred in Japan in the early 1990s and late 2000s, and in the United States in the early 1990s, early 2000s and late 2000s. Finally, they identify policy shocks as countercyclical mitigants of these business cycle contractions. 
Figure 4. Historical Decompositions
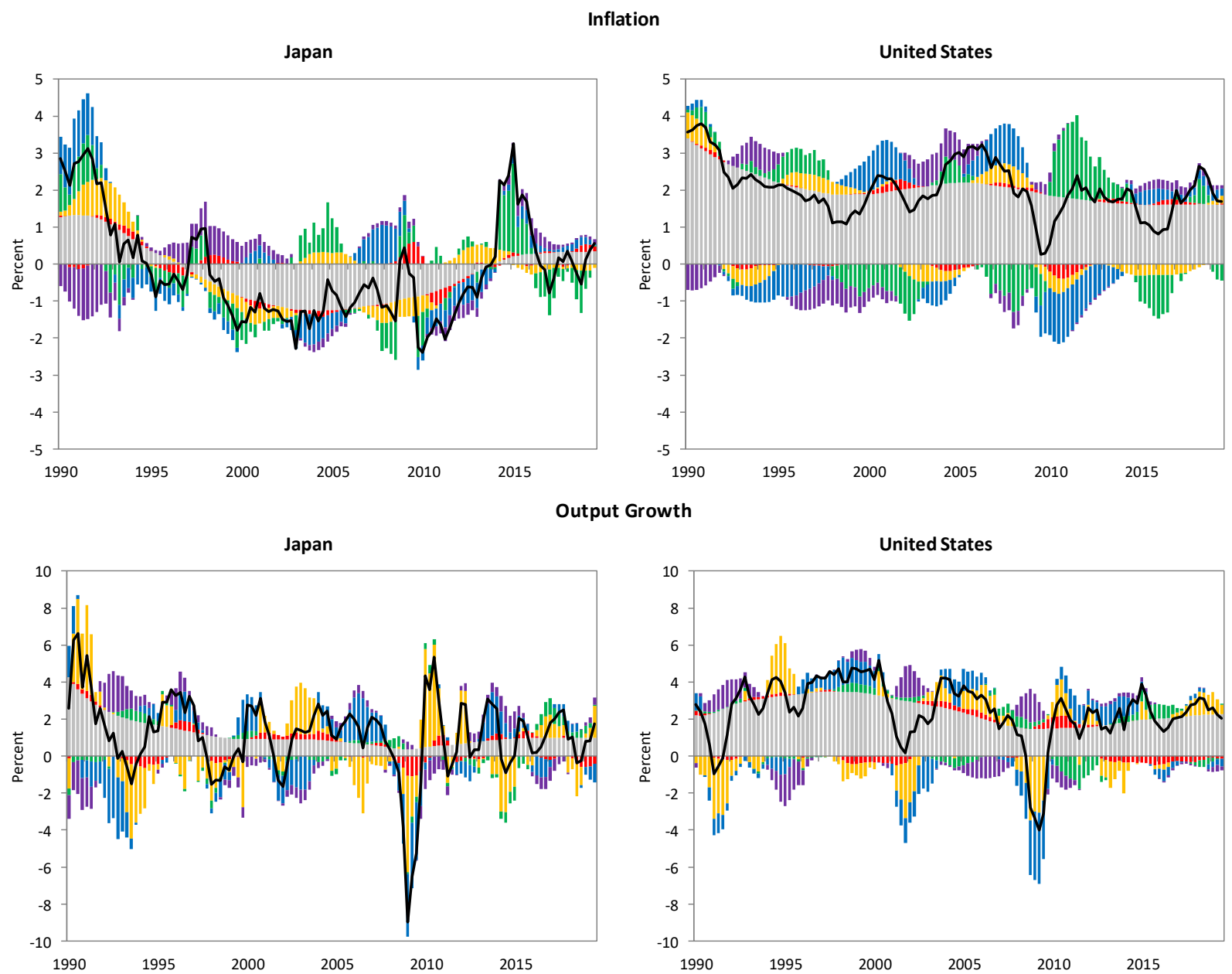

Note: Decomposes observed inflation or output growth $\mathbf{a}$ as measured by the seasonal logarithmic difference of the price level or output into the sum of a trend component $\square$ and contributions from supply $\square$, demand $\varpi$, markup $\square$, financial $\square$ and policy $\square$ shocks.

Our sequential dynamic forecasts of inflation and output growth track their observed realizations reasonably well. We measure the dynamic forecasting performance of our heteroskedastic linearized DSGE model relative to that of a random walk in sample at the one through twelve quarter horizons on the basis of the logarithm of the $U$ statistic due to Theil (1966), which equals the ratio of root mean squared prediction errors. We find that the model dominates a random walk in terms of predictive accuracy for inflation and output growth at all horizons, for both Japan and the United States. Indeed, over the holdout sample period 1990Q2 to 2019Q3, the root mean squared prediction error is 32 percent lower for inflation and 52 percent lower for output growth in Japan, as well as 22 percent lower for inflation and 59 percent lower for output growth in the United States, on average across horizons. 
Figure 5. Sequential Dynamic Forecasts
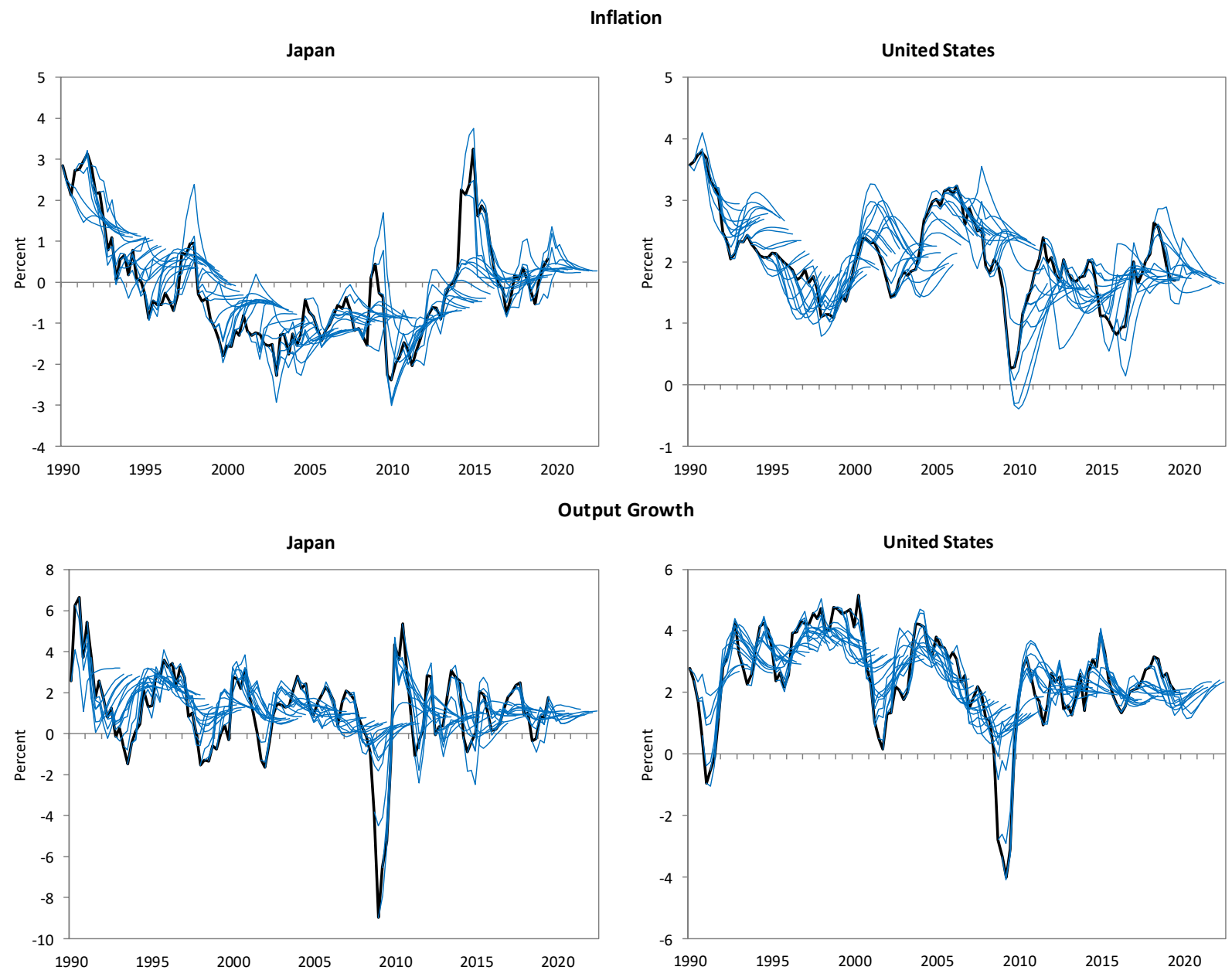

Note: Depicts observed inflation or output growth $\mathbf{~ a s ~ m e a s u r e d ~ b y ~ t h e ~ s e a s o n a l ~ d i f f e r e n c e ~ o f ~ t h e ~ l o g a r i t h m ~ o f ~ t h e ~}$ price level or output versus sequential dynamic forecasts $\boldsymbol{m}$.

Our state dependent conditional heteroskedasticity mechanism has little effect on the predicted means of inflation and output growth. Indeed, if their parameters and initial conditions are restricted to be the same, then our heteroskedastic and homoskedastic linearized DSGE models yield identical dynamic forecasts of the means of all endogenous variables. However, allowing for state dependent conditional heteroskedasticity can substantially alter the coverage of the confidence intervals surrounding the predicted means of inflation and output growth. In general, these forecast confidence intervals expand considerably at times of macrofinancial stress assigning more appropriate probabilities to tail events - and contract slightly during normal times. For example, our heteroskedastic linearized DSGE model generates considerably wider forecast confidence intervals for inflation and output growth than its nested homoskedastic counterpart for Japan originating in 1992Q4, and for the United States originating in 2008Q4. These were times of acute macrofinancial stress associated with synchronized business and financial cycle downturns. 
Figure 6. Dynamic Forecast Comparison
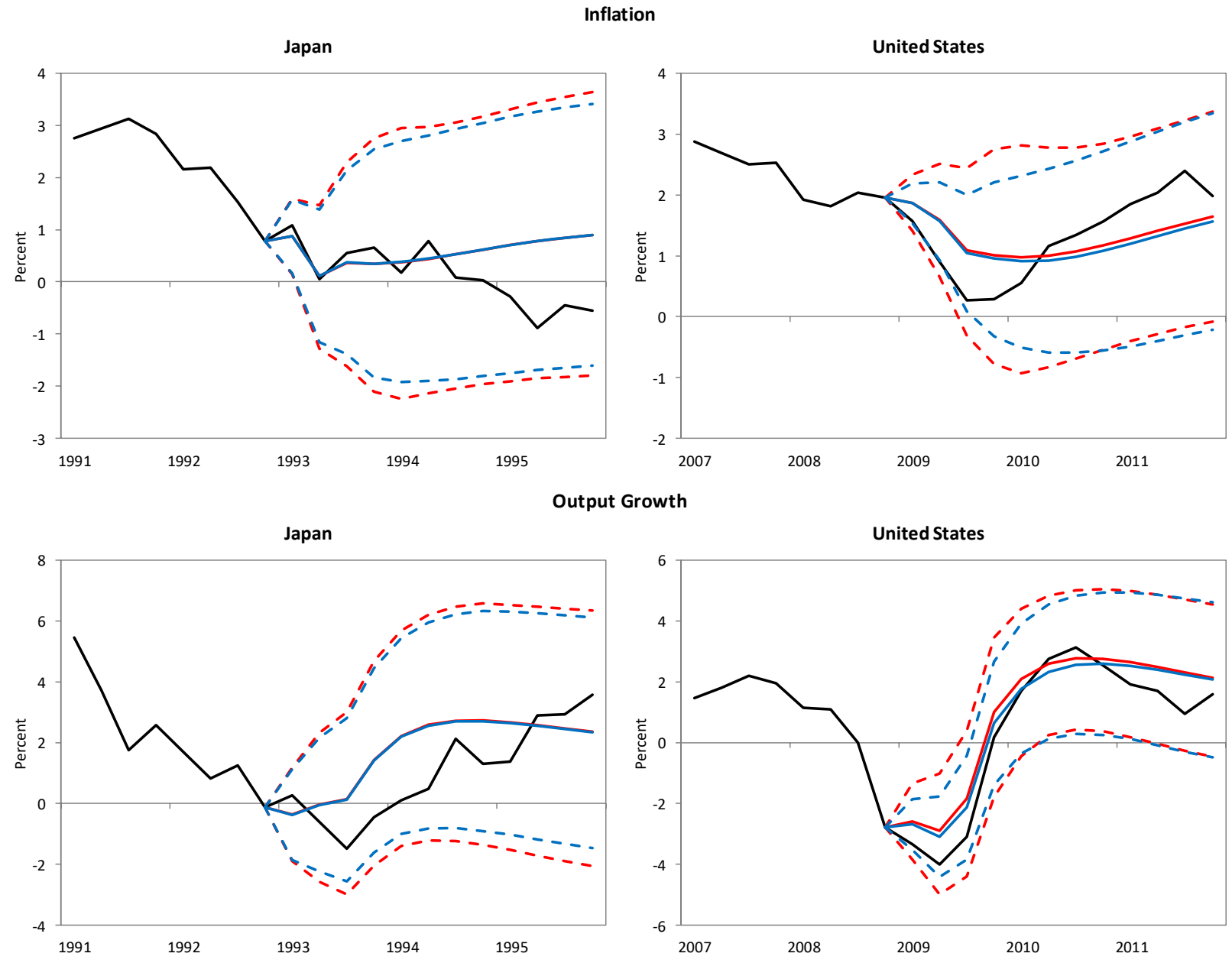

Note: Depicts observed inflation or output growth - as measured by the seasonal difference of the logarithm of the price level or output versus dynamic forecasts of means together with 0.05 and 0.95 quantiles generated with the heteroskedastic n versus homoskedastic $n$ linearized DSGE models. The quantiles are estimated based on a Monte Carlo simulation with 100,000 replications.

\section{GROWTH AT RISK}

Policymakers are often concerned with the risks surrounding the central forecast of output growth. Our heteroskedastic linearized DSGE model embodies the notion that these risks vary systematically over the business and financial cycles. Before jointly analyzing monetary and macroprudential policy using our model, we verify that it matches the key stylized facts of growth at risk.

\section{A. Measuring Growth at Risk}

In our heteroskedastic linearized DSGE model, the entire conditional distribution of output growth, and not just its central tendency, evolves over time. Indeed, both the location and scale of 
the predicted distribution of output growth shift in response to changes in macroeconomic and financial conditions and vulnerabilities, to varying degrees depending on the forecast horizon. Moreover, these shifts are negatively correlated, generating conditional distributions that are skewed to the downside, particularly at times of macrofinancial stress.

Figure 7. Conditional Distribution of Output Growth
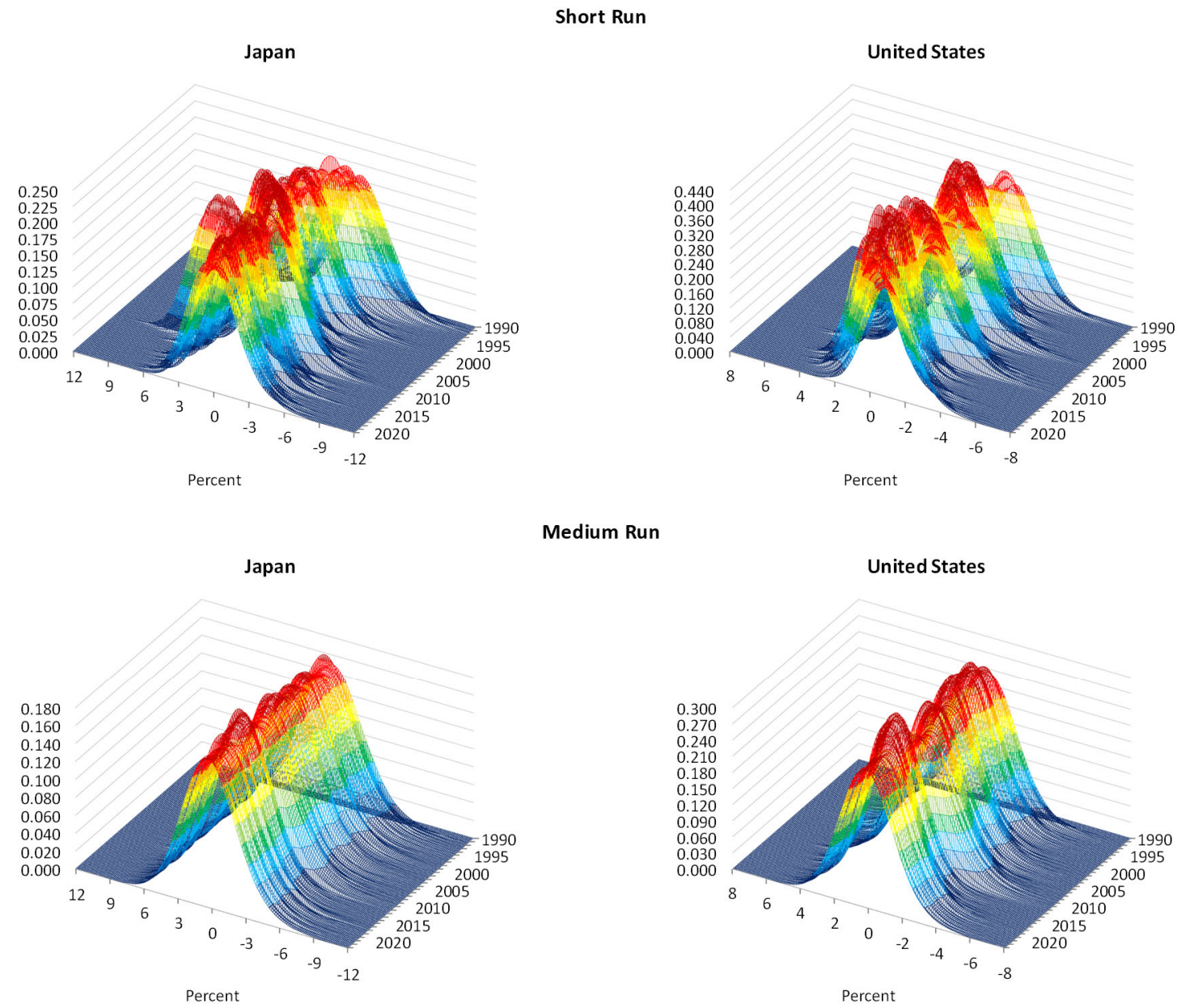

Medium Run

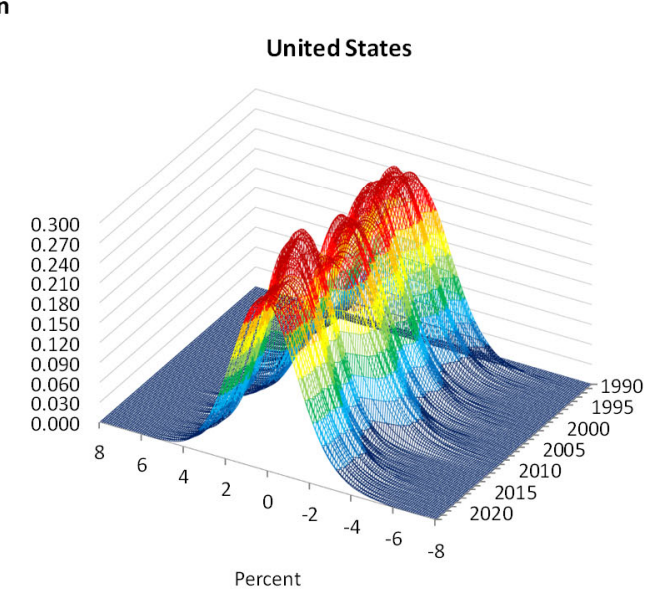

Note: Depicts the one and three year ahead predicted probability density function of the cyclical component of output growth, estimated with a normal kernel based on a Monte Carlo simulation with 100,000 replications.

Consistent with our first stylized fact of growth at risk, in our heteroskedastic linearized DSGE model the conditional lower quantile of output growth is more volatile than its conditional mean, which in turn is more volatile than its conditional upper quantile. Indeed, across both economies and horizons, the sample variance of the estimated conditional lower quantile of output growth exceeds that of the estimated conditional mean, which in turn exceeds that of the estimated conditional upper quantile. In contrast, in a homoskedastic linearized DSGE model driven by normally distributed innovations, the conditional lower and upper quantiles of all endogenous variables evolve symmetrically, shifting in parallel with their conditional means. 
Figure 8. Conditional Quantiles of Output Growth
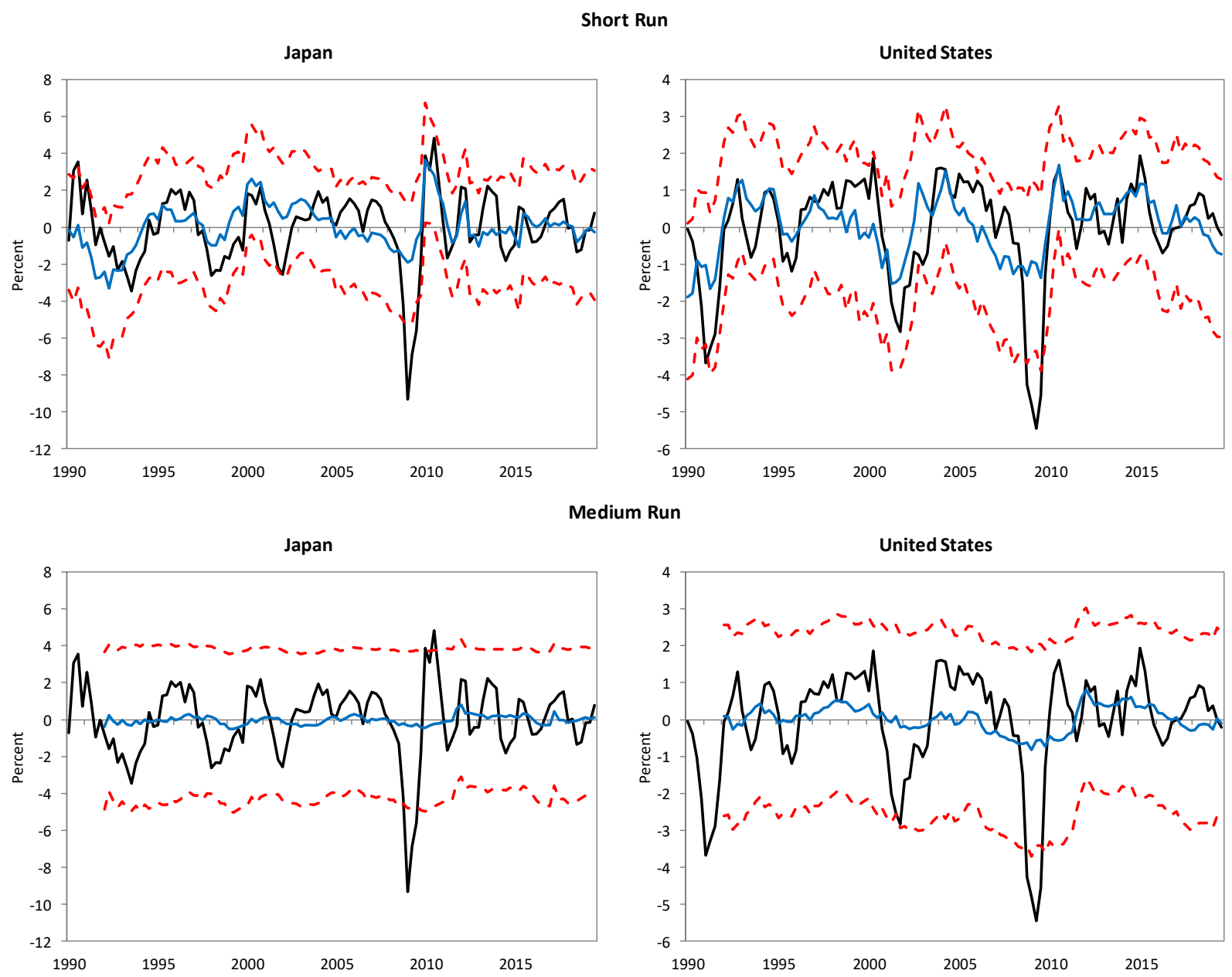

Note: Depicts the cyclical component of observed output growth $\mathbf{a}$ as measured by the seasonal difference of the cyclical component of the logarithm of output versus the one and three year ahead predicted mean $\square$ and 0.05 and 0.95 quantiles $\square$. The quantiles are estimated based on a Monte Carlo simulation with 100,000 replications.

\section{B. Explaining Growth at Risk}

In our heteroskedastic linearized DSGE model, business and financial cycle downturns are associated with a fall in the conditional mean and rise in the conditional variance of output growth. The former dependence reflects the mean impulse responses of the model to adverse macroeconomic and financial shocks, which lower the central forecast of output growth. The latter dependence reflects our state dependent conditional heteroskedasticity mechanism, which links the risks surrounding this central forecast to the phase and position of the business and financial cycles. 
Figure 9. Decomposition of Growth at Risk
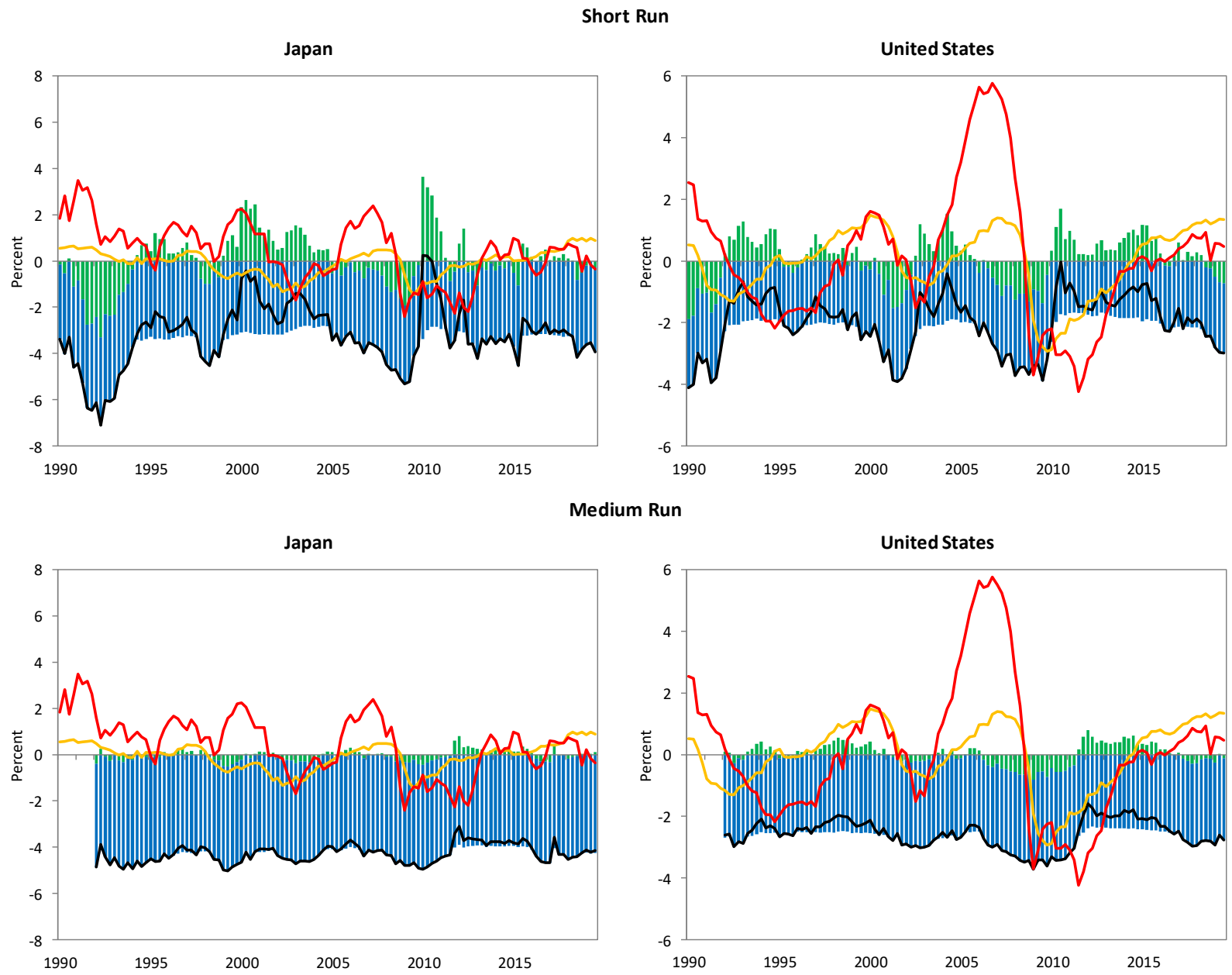

Note: Decomposes the one and three year ahead predicted 0.05 quantile of the cyclical component of output growth

- into contributions from the predicted mean $\|$ and variance $\square$ versus the output $\|$ and financial $\square$ gaps. The quantile is estimated based on a Monte Carlo simulation with 100,000 replications.

Consistent with our second stylized fact of growth at risk, in our heteroskedastic linearized DSGE model the conditional mean and variance of output growth are strongly negatively correlated. Indeed, across both economies and horizons, the sample correlation between the conditional mean and variance of output growth is negative, ranging from -0.62 to -0.84 . In contrast, in a homoskedastic linearized DSGE model driven by normally distributed innovations, the conditional means and variances of all endogenous variables are approximately uncorrelated. 
Figure 10. Conditional Mean versus Variance of Output Growth

\section{Short Run}
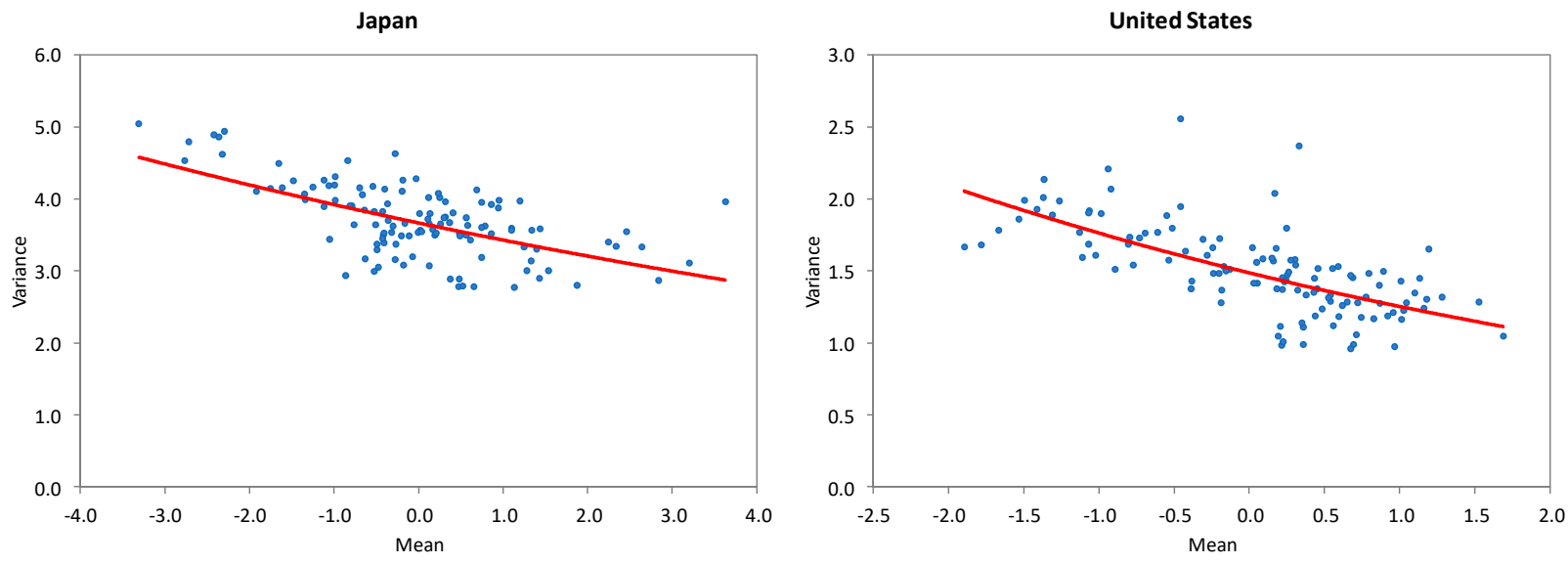

Medium Run
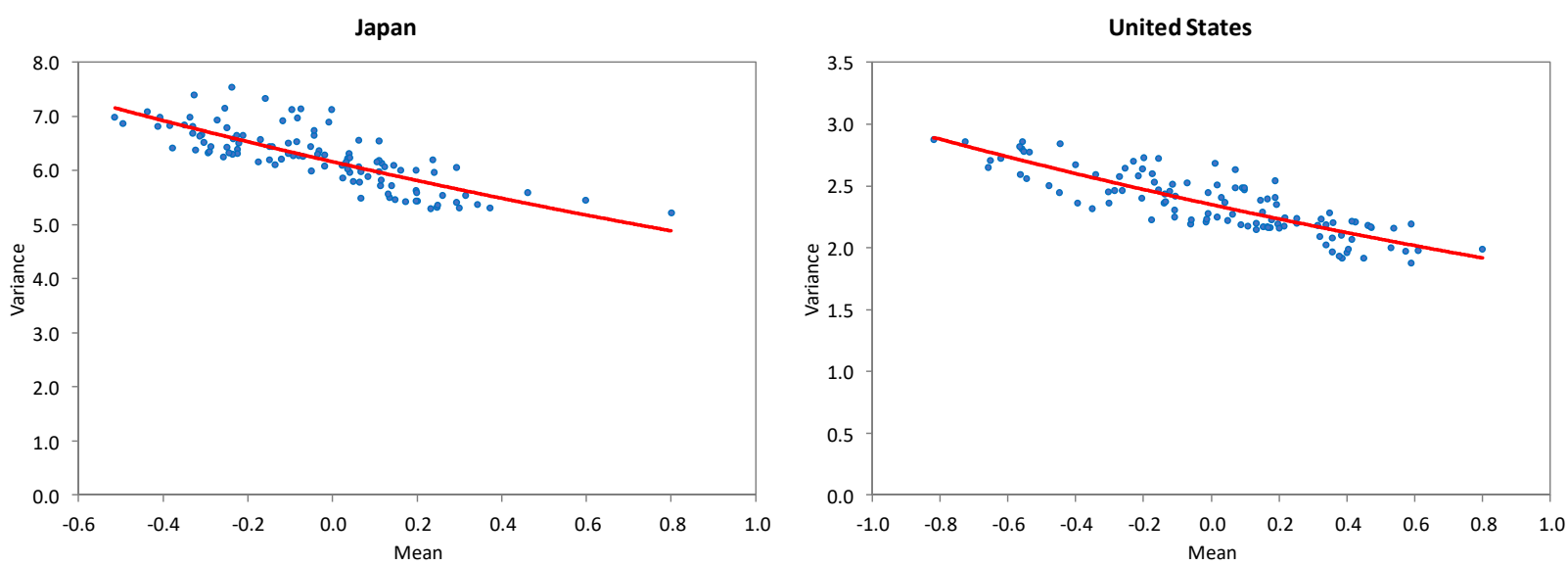

Note: Depicts the one and three year ahead predicted mean versus variance of the cyclical component of output growth $\square$, together with exponentiated ordinary least squares fitted values from a simple loglinear regression $\mathbf{m}$.

\section{Policy Analysis}

Having verified that our heteroskedastic linearized DSGE model matches the key stylized facts of growth at risk, we proceed to jointly analyze monetary and macroprudential policy using it. In particular, we quantify its monetary and macroprudential policy transmission mechanisms with quantile impulse responses. We also simulate the counterfactual distributions of output growth conditional on alternative monetary and macroprudential policy measures. Finally, we assess the implications of our state dependent conditional heteroskedasticity mechanism for the optimal conduct of monetary and macroprudential policy with jointly optimized instrument rules.

\section{A. Transmission Mechanisms}

A monetary policy shock that raises the short term interest rate reduces all of the components of private domestic demand reflecting tighter financial conditions, in particular residential and 
business investment. This tightening of financial conditions in turn reflects higher market interest rates and lower asset prices. The resultant contraction of aggregate demand reduces output more than potential, and the output gap falls while the unemployment rate rises, associated with lower price and wage inflation. The financial gap also falls, reflecting lower real bank credit and relative asset prices. The macroprudential authority responds to the fall in the financial gap by lowering the capital requirement, supporting bank credit supply. Quantitatively, a temporary but persistent 100 basis point increase in the short term interest rate induced by a monetary policy shock is estimated to reduce the conditional mean of inflation by 0.2 to 0.3 percentage points after 4 to 5 quarters, and that of output by 0.5 to 0.7 percent after 4 quarters. 
Figure 11. Quantile Impulse Responses to a Monetary Policy Shock
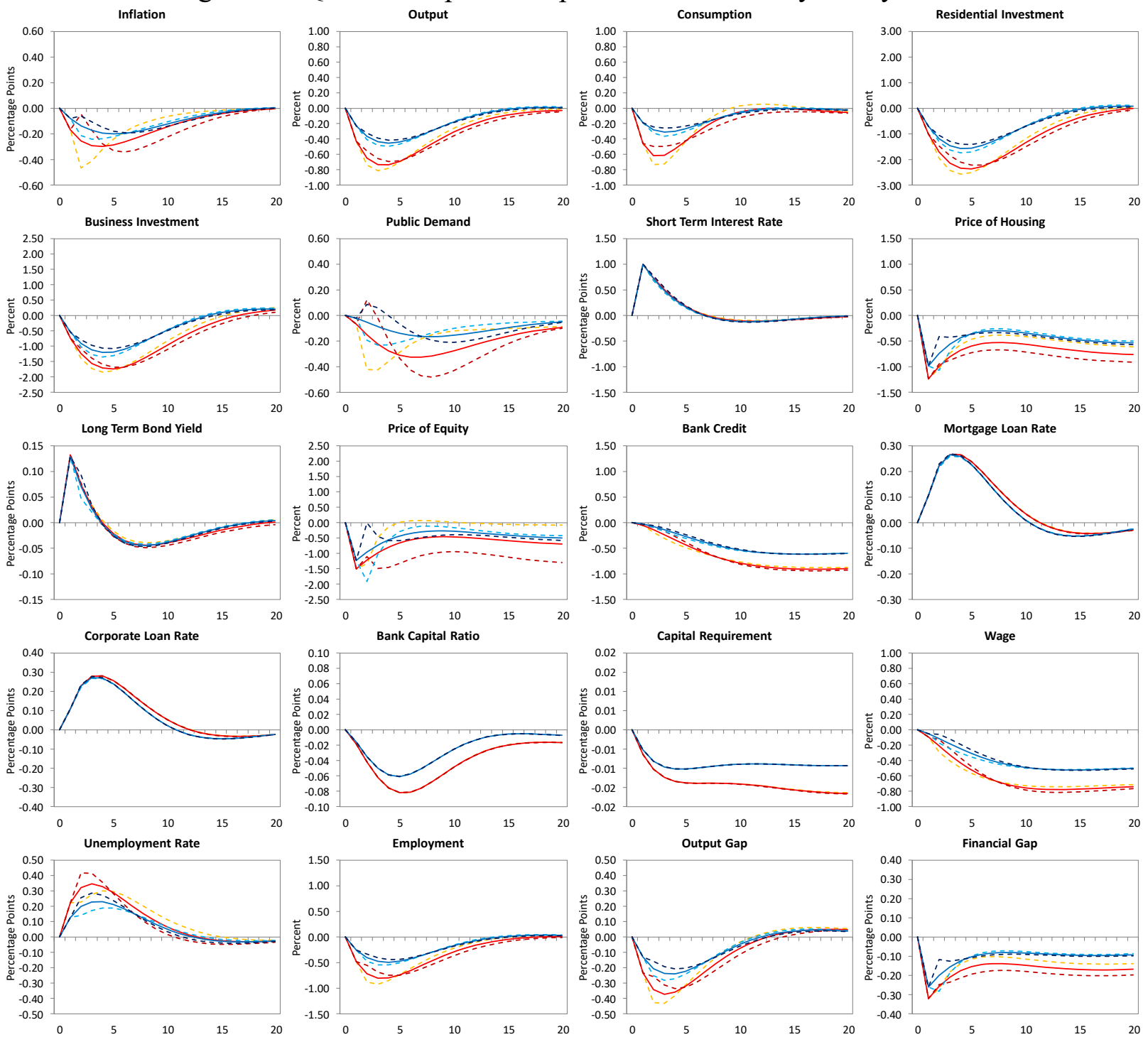

Note: Depicts impulse responses of the (0.05 quantile, mean, 0.95 quantile) for Japan $(\square, \square, \square)$ and the United States $(\square, \square, \Xi)$ to a monetary policy shock that raises the short term interest rate by 100 basis points, respectively. The quantile impulse responses are calculated with a conditional normality approximation. All variables are annualized, where applicable.

A macroprudential policy shock that raises the capital requirement reduces residential and business investment, reflecting higher mortgage and corporate loan rates set by banks to facilitate their accumulation of capital through retained earnings. The resultant contraction of aggregate demand reduces output more than potential, and the output gap falls while the unemployment rate rises, associated with lower price and wage inflation. The financial gap also falls, reflecting lower real bank credit. The monetary authority responds to the falls in inflation and the output gap by cutting the short term interest rate, supporting bank credit demand. Quantitatively, a temporary but persistent 2.5 percentage point increase in the capital requirement induced by a macroprudential 
policy shock is estimated to reduce the conditional mean of inflation by 0.1 percentage point after 4 to 5 quarters, and that of output by 0.2 to 0.3 percent after 4 to 5 quarters.

Figure 12. Quantile Impulse Responses to a Macroprudential Policy Shock
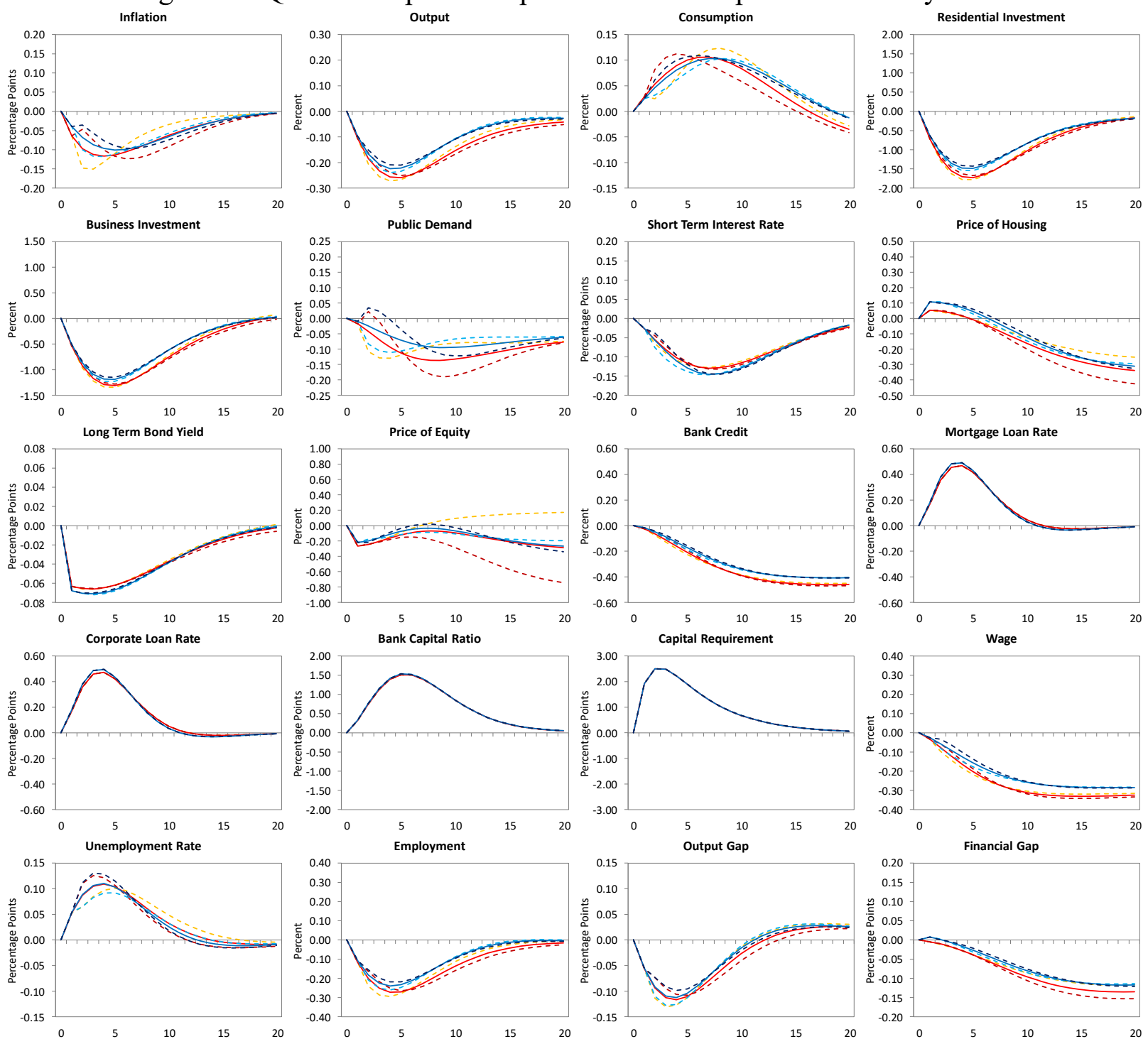

Note: Depicts impulse responses of the (0.05 quantile, mean, 0.95 quantile) for Japan $(\square, \square, \square)$ and the United States $(\square, \square, \square)$ to a macroprudential policy shock that raises the capital requirement by 2.5 percentage points, respectively. The quantile impulse responses are calculated with a conditional normality approximation. All variables are annualized, where applicable.

In response to both a contractionary monetary and macroprudential policy shock, the conditional lower quantiles of inflation and output fall more than their conditional means in the short run, reflecting higher conditional variances, but less over the medium term, reflecting lower conditional variances. The conditional upper quantiles of inflation and output exhibit opposing dynamics, for the same reasons. These conditional variance dynamics reflect the business cycle 
contraction and financial cycle downturn induced by tighter monetary or macroprudential policy in the short run, followed by a business cycle recovery over the medium term.

\section{B. Counterfactual Distributions}

The effects of monetary policy tightening and easing measures on the conditional distribution of output growth are asymmetric. In the short run, a temporary but persistent increase in the short term interest rate induced by a monetary policy shock expands the left tail of the conditional output growth distribution by more than a decrease of equal magnitude expands the right tail. This reflects our state dependent conditional heteroskedasticity mechanism, which expands the scale of the conditional output growth distribution while its location shifts to the left in response to a monetary tightening measure, reflecting the induced business cycle contraction and financial cycle downturn, and vice versa for a monetary easing measure. This asymmetry in the response of the conditional output growth distribution to monetary tightening and easing measures is reversed over the medium term, reflecting the recovery of the business cycle. 
Figure 13. Distribution of Output Growth Conditional on a Monetary Policy Shock
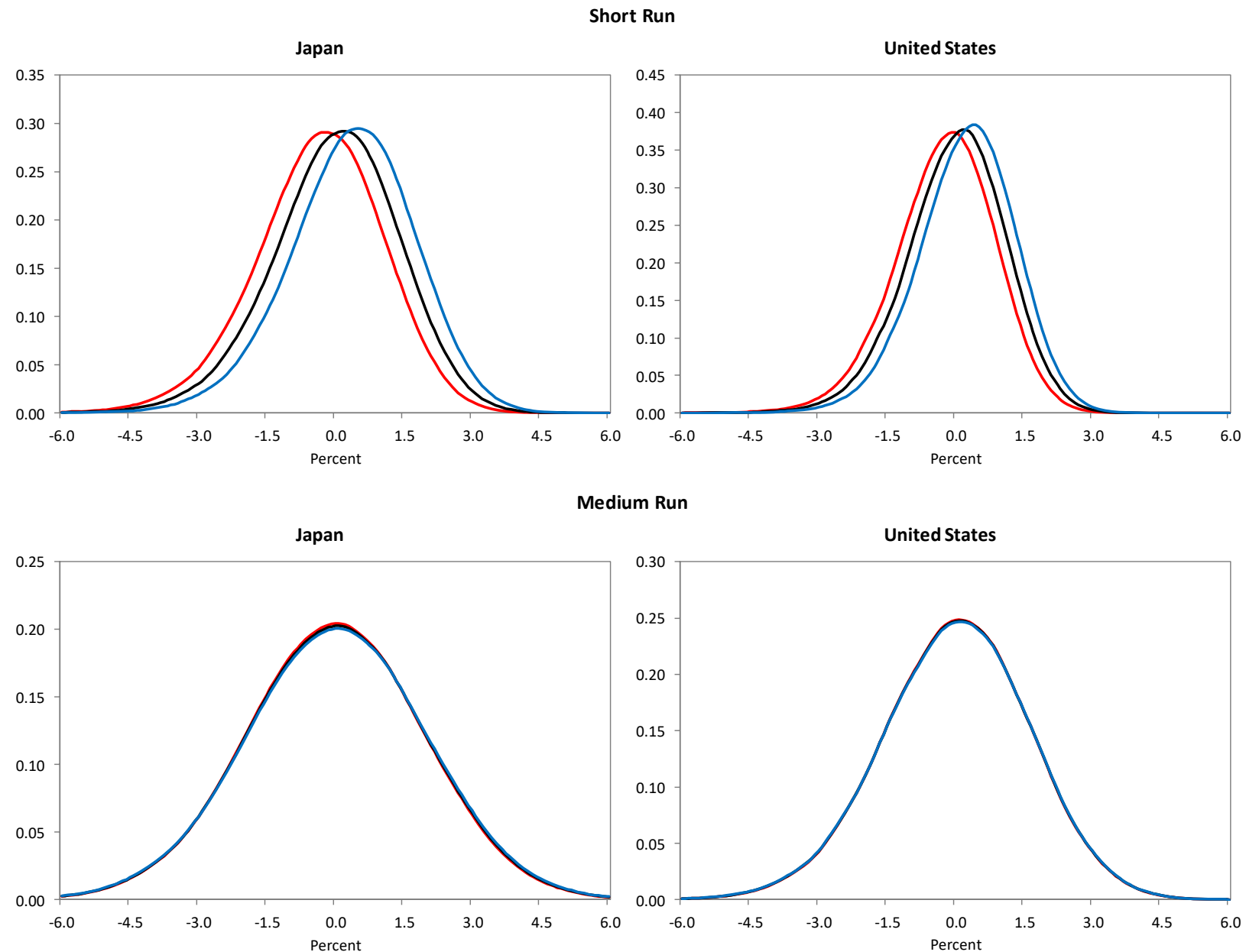

Note: Depicts the one and three year ahead predicted probability density function of the cyclical component of output growth conditional on a monetary policy shock that raises $\square$ or lowers $\boldsymbol{\|}$ the short term interest rate by 100 basis points, versus the corresponding unconditional probability density function $\mathbf{m}$. The probability density functions are estimated with a normal kernel based on a Monte Carlo simulation with 100,000 replications.

The effects of macroprudential policy tightening and easing measures on the conditional distribution of output growth are also asymmetric. In the short run, a temporary but persistent increase in the capital requirement induced by a macroprudential policy shock expands the left tail of the conditional output growth distribution by more than a decrease of equal magnitude expands the right tail, while this asymmetry is reversed over the medium term. This again reflects our state dependent conditional heteroskedasticity mechanism, which operates qualitatively identically in response to monetary and macroprudential policy shocks, given their qualitatively similar effects on the business and financial cycles. 
Figure 14. Distribution of Output Growth Conditional on a Macroprudential Policy Shock Short Run
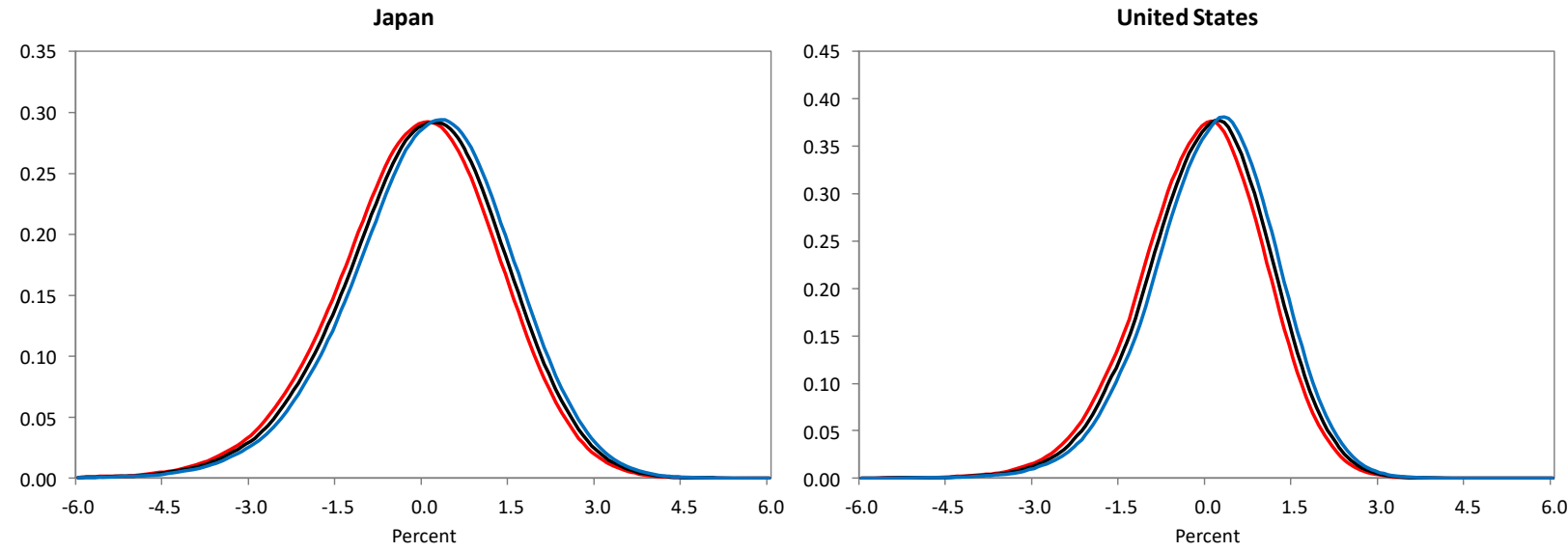

Medium Run
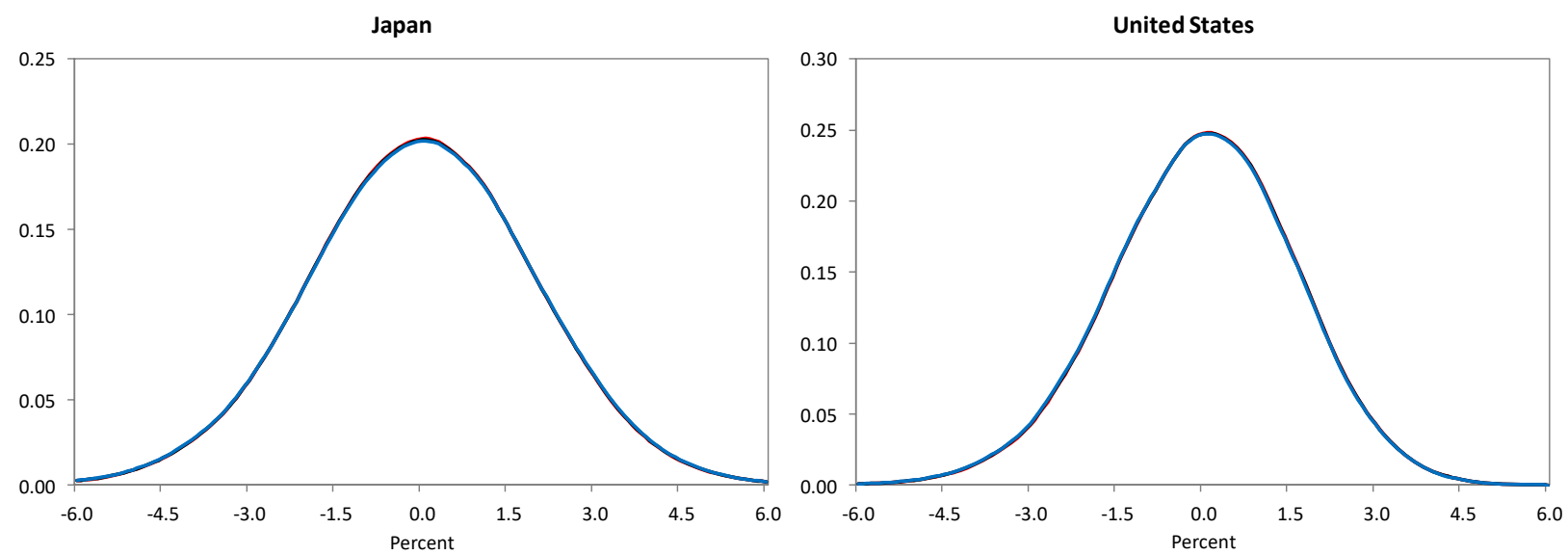

Note: Depicts the one and three year ahead predicted probability density function of the cyclical component of output

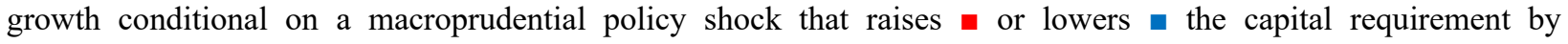
2.5 percentage points, versus the corresponding unconditional probability density function $\mathbf{m}$. The probability density functions are estimated with a normal kernel based on a Monte Carlo simulation with 100,000 replications.

\section{Optimized Rules}

Suppose that the monetary and macroprudential authorities have preferences defined over inflation and output stabilization objectives, as well as instrument smoothing objectives, represented by intertemporal loss function:

$$
\mathcal{L}_{t}=(1-\beta) \mathrm{E}_{t} \sum_{s=t}^{\infty} \beta^{s-t} l\left(\hat{\pi}_{s}, \ln \hat{Y}_{s}^{G}, \hat{i}_{s}^{S}, \hat{\kappa}_{s+1}^{R}\right) .
$$

The intratemporal loss function quadratically penalizes the deviations of inflation from target and output from potential, as well as of the short term interest rate and capital requirement from their steady state equilibrium values,

$$
l\left(\hat{\pi}_{s}, \ln \hat{Y}_{s}^{G}, \hat{i}_{s}^{S}, \hat{\kappa}_{s+1}^{R}\right)=\left(\hat{\pi}_{s}\right)^{2}+\lambda^{Y^{G}}\left(\ln \hat{Y}_{s}^{G}\right)^{2}+\lambda^{i^{s}}\left(\hat{i}_{s}^{S}\right)^{2}+\lambda^{\kappa^{R}}\left(\hat{\kappa}_{s+1}^{R}\right)^{2},
$$


where $\lambda^{Y^{G}} \geq 0, \lambda^{i^{S}} \geq 0$ and $\lambda^{\kappa^{R}} \geq 0$. As specified, this intratemporal loss function does not represent an independent financial stability objective. Note that its conditional mean depends on the conditional means and variances of its arguments:

$$
\begin{aligned}
\mathrm{E}_{t} l\left(\hat{\pi}_{s}, \ln \hat{Y}_{s}^{G}, \hat{i}_{s}^{S}, \hat{\kappa}_{s+1}^{R}\right)=\left[\left(\mathrm{E}_{t} \hat{\pi}_{s}\right)^{2}+\operatorname{Var}_{t}\left(\hat{\pi}_{s}\right)\right] \\
+\lambda^{Y^{G}}\left[\left(\mathrm{E}_{t} \ln \hat{Y}_{s}^{G}\right)^{2}+\operatorname{Var}_{t}\left(\ln \hat{Y}_{s}^{G}\right)\right]+\lambda^{i^{S}}\left[\left(\mathrm{E}_{t} \hat{i}_{s}^{S}\right)^{2}+\operatorname{Var}_{t}\left(\hat{i}_{s}^{S}\right)\right]+\lambda^{\kappa^{R}}\left[\left(\mathrm{E}_{t} \hat{\kappa}_{s+1}^{R}\right)^{2}+\operatorname{Var}_{t}\left(\hat{\kappa}_{s+1}^{R}\right)\right] .
\end{aligned}
$$

It follows that state dependent conditional heteroskedasticity has the potential to alter the optimal conduct of policy under quadratic loss.

Suppose that the monetary and macroprudential authorities jointly minimize their intertemporal loss function under long run commitment to their policy rules with respect to their response coefficients, subject to the structure of the economy as represented by the rest of our linearized DSGE model. We consider a flexible inflation targeting regime with a dual mandate, and set the weight on output fluctuations $\lambda^{Y^{G}}$ to 0.50 . To account for instrument smoothing, we set the weight on short term interest rate fluctuations $\lambda^{i^{s}}$ to 1.00 , and that on capital requirement fluctuations $\lambda^{\kappa^{R}}$ to 0.25 . We evaluate the intertemporal loss function by forecasting the means and variances of its annualized arguments out 25 years, conditional on the estimated state of the economy. Under long run commitment, this intertemporal loss function is then averaged across all historical states, to eliminate its dependence on initial conditions. Finally, this average intertemporal loss function is globally minimized numerically with the differential evolution algorithm due to Storn and Price (1997), jointly with respect to the response coefficients of the monetary and macroprudential policy rules, subject to inequality constraints on them.

Allowing the structural shocks that drive our linearized DSGE model to exhibit state dependent conditional heteroskedasticity makes it optimal for monetary policy to respond more aggressively to the business cycle, and for macroprudential policy to manage the resilience of the banking sector to systemic risk more actively over the financial cycle. Indeed, the optimized values of the relevant monetary and macroprudential policy rule response coefficients are all larger. The intuition for this result is straightforward. Our state dependent conditional heteroskedasticity mechanism amplifies the volatility of the economy substantially during business cycle contractions and financial cycle downturns, but not on average over the business and financial cycles. This makes it optimal for monetary and macroprudential policy to limit the frequency and severity of business cycle contractions and financial cycle downturns to a greater degree. This calls for tighter monetary policy during business cycle expansions, to mitigate the buildup of capacity pressures, and for looser policy when contractions do occur, to limit their amplitude and duration. It also calls for tighter macroprudential policy during financial cycle upturns, to make the banking sector more resilient to systemic risk arising from financial vulnerabilities while leaning against their buildup, and for looser policy when downturns do occur, to limit their severity.

Our linearized DSGE model robustly prescribes the separation of these monetary and macroprudential policy responses to the business and financial cycles. In particular, it is optimal for monetary policy to not lean against the buildup of financial vulnerabilities during financial cycle upturns, irrespective of whether we allow for state dependent conditional heteroskedasticity. Indeed, the optimized value of the relevant monetary policy rule response coefficient is always zero. This result is consistent with most of the extensive literature on whether monetary policy 
should be used to promote financial stability. This literature, surveyed by Adrian and Liang (2018), generally finds that macroprudential policy should be used as the first line of defense against the buildup of financial vulnerabilities, because it is better targeted. But this question remains intensely debated, and our answer is conditional on the structure and parameterization of our model, under which macroprudential policy is effective and applies to the entire financial sector.

Table 1. Optimized Rules

\begin{tabular}{lcccc}
\hline \hline & \multicolumn{2}{c}{ Japan } & \multicolumn{2}{c}{ United States } \\
& Heteroskedastic & Homoskedastic & Heteroskedastic & Homoskedastic \\
\hline$\xi^{\pi}$ & 1.6393 & 1.6064 & 1.9035 & 1.9141 \\
$\xi^{Y}$ & 0.4742 & 0.2559 & 0.2450 & 0.1363 \\
$\xi^{\Delta F}$ & 0.0000 & 0.0000 & 0.0000 & 0.0000 \\
$\xi^{\kappa^{R}}$ & 0.1596 & 0.1267 & 0.1427 & 0.1391 \\
\hline \hline
\end{tabular}

Note: Reports the optimized values of the monetary and macroprudential policy rule response coefficients at the annual frequency.

\section{CONCLUSION}

We augment a linearized DSGE model similar to those in use at central banks with a tractable endogenous risk mechanism, to support the joint analysis of monetary and macroprudential policy. This state dependent conditional heteroskedasticity mechanism specifies the conditional variances of structural shocks as functions of the predetermined phase and position of the business or financial cycle. The resultant heteroskedastic linearized DSGE model preserves the satisfactory simulation and forecasting performance of its nested homoskedastic counterpart for the conditional means of endogenous variables, while substantially improving its goodness of fit to their conditional distributions. In particular, the model matches the key stylized facts from the growth at risk literature.

We find that our state dependent conditional heteroskedasticity mechanism substantially alters the jointly optimized response coefficients of monetary and macroprudential policy rules under quadratic loss. In particular, accounting for state dependent conditional heteroskedasticity makes it optimal for monetary policy to respond more aggressively to the business cycle, and for macroprudential policy to manage the resilience of the banking sector more actively over the financial cycle.

It would be useful to analyze how well a linearized DSGE model with a state dependent conditional heteroskedasticity mechanism can approximate the corresponding nonlinear DSGE model, as the response coefficients of its monetary and macroprudential policy rules change. This could reveal the relevance of the critique due to Lucas (1976) in this context. It would also be interesting to compare the empirical performance and policy implications of alternative state dependent conditional heteroskedasticity mechanisms, within the framework of different linearized DSGE models. The parsimonious specification that we propose could be extended and refined along many dimensions, to fit additional stylized facts that emerge as the growth at risk literature expands to other variables. This could help inform the development of nonlinear DSGE models with satisfactory simulation and forecasting performance that can explain these 
phenomena, to better support the conduct of monetary and macroprudential policy under endogenous risk. 


\section{Appendix. Estimation Results}

Table 2. Conditional Mean Function Parameters

\begin{tabular}{ccccccc}
\hline \hline & & & \multicolumn{2}{c}{ Japan } & \multicolumn{2}{c}{ United States } \\
& Prior Mean & Prior SD & Posterior Mode & Posterior SE & Posterior Mode & Posterior SE \\
\hline$\alpha$ & 0.8000 & 0.0800 & 0.6067 & 0.0618 & 0.7876 & 0.0418 \\
$\chi^{H}$ & 3.0000 & 0.3000 & 2.8481 & 0.2990 & 3.0839 & 0.2982 \\
$\chi^{K}$ & 3.2500 & 0.3250 & 4.0414 & 0.3123 & 3.9868 & 0.3099 \\
$\eta$ & 0.5000 & 0.0050 & 0.4948 & 0.0050 & 0.4944 & 0.0050 \\
$\eta^{K}$ & 1.0000 & 0.1000 & 0.9660 & 0.0986 & 0.9894 & 0.0989 \\
$\eta^{C}$ & 5.0000 & 0.5000 & 4.7697 & 0.4995 & 5.0386 & 0.5000 \\
$\gamma^{P}$ & 0.8000 & 0.0400 & 0.5476 & 0.0360 & 0.7553 & 0.0378 \\
$\gamma^{W}$ & 0.8000 & 0.0400 & 0.7096 & 0.0392 & 0.7789 & 0.0398 \\
$\mu^{P}$ & 0.5000 & 0.0500 & 0.5209 & 0.0259 & 0.5674 & 0.0367 \\
$\omega^{P}$ & 0.8750 & 0.0088 & 0.8801 & 0.0083 & 0.8827 & 0.0081 \\
$\omega^{W}$ & 0.8750 & 0.0088 & 0.8600 & 0.0086 & 0.8733 & 0.0085 \\
$\omega^{C}$ & 0.7500 & 0.0075 & 0.7445 & 0.0069 & 0.7372 & 0.0074 \\
$\phi^{H}$ & 0.8000 & 0.0080 & 0.7992 & 0.0080 & 0.7987 & 0.0080 \\
$\phi^{F}$ & 0.8000 & 0.0080 & 0.8106 & 0.0079 & 0.8066 & 0.0078 \\
$\phi_{H}^{C}$ & 0.2500 & 0.0250 & 0.2935 & 0.0238 & 0.2556 & 0.0236 \\
$\phi_{B}^{C}$ & 0.3000 & 0.0300 & 0.2940 & 0.0298 & 0.3148 & 0.0295 \\
$\phi_{S}^{C}$ & 0.0500 & 0.0050 & 0.0477 & 0.0049 & 0.0539 & 0.0049 \\
$\rho^{i}$ & 0.8000 & 0.0080 & 0.8233 & 0.0074 & 0.7982 & 0.0077 \\
$\rho^{G}$ & 0.8000 & 0.0800 & 0.6545 & 0.0681 & 0.7728 & 0.0587 \\
$\rho^{A}$ & 0.8000 & 0.0080 & 0.8006 & 0.0079 & 0.7961 & 0.0080 \\
$\sigma$ & 1.0000 & 0.1000 & 0.9844 & 0.0971 & 0.9311 & 0.0969 \\
$\varsigma^{A}$ & 1.0000 & 0.1000 & 0.9839 & 0.0998 & 1.0496 & 0.0999 \\
$\xi^{\pi}$ & 1.5000 & 0.0750 & 1.2843 & 0.0707 & 1.4984 & 0.0720 \\
$\xi^{Y}$ & 0.1250 & 0.0125 & 0.1149 & 0.0120 & 0.1282 & 0.0122 \\
$\rho_{A}$ & 0.5000 & 0.0500 & 0.6345 & 0.0430 & 0.5716 & 0.0452 \\
$\rho_{N}$ & 0.5000 & 0.0500 & 0.7203 & 0.0430 & 0.7760 & 0.0398 \\
$\rho_{C}$ & 0.5000 & 0.0500 & 0.4176 & 0.0470 & 0.4561 & 0.0462 \\
$\rho_{I}$ & 0.5000 & 0.0500 & 0.5014 & 0.0436 & 0.5463 & 0.0440 \\
$\rho_{H}$ & 0.7500 & 0.0750 & 0.9415 & 0.0265 & 0.9494 & 0.0268 \\
$\rho_{B}$ & 0.7500 & 0.0750 & 0.7070 & 0.0478 & 0.7799 & 0.0461 \\
$\rho_{S}$ & 0.7500 & 0.0750 & 0.7396 & 0.0454 & 0.8230 & 0.0349 \\
$\rho_{i}$ & 0.5000 & 0.0500 & 0.4880 & 0.0427 & 0.4741 & 0.0417 \\
\hline \hline$A$ & & & & &
\end{tabular}

Note: All priors are normally distributed, while all posteriors are asymptotically normally distributed. 
Table 3. Conditional Variance Function Parameters

\begin{tabular}{|c|c|c|c|c|c|c|}
\hline & \multirow[b]{2}{*}{ Prior Mean } & \multirow[b]{2}{*}{ Prior SD } & \multicolumn{2}{|c|}{ Japan } & \multicolumn{2}{|c|}{ United States } \\
\hline & & & Posterior Mode & Posterior SE & Posterior Mode & Posterior SE \\
\hline$\hat{\sigma}_{A}$ & $\ldots$ & $\infty$ & 1.2298 & 0.1129 & 0.5941 & 0.0551 \\
\hline$\hat{\sigma}_{N}^{A}$ & $\ldots$ & $\infty$ & 0.6709 & 0.0693 & 0.6214 & 0.0685 \\
\hline$\hat{\sigma}_{C}$ & $\ldots$ & $\infty$ & 2.5951 & 0.5054 & 2.0578 & 0.4456 \\
\hline$\hat{\sigma}_{I}$ & $\ldots$ & $\infty$ & 4.8648 & 0.6185 & 3.0516 & 0.3889 \\
\hline$\hat{\sigma}_{G}$ & $\ldots$ & $\infty$ & 2.0415 & 0.1928 & 1.3121 & 0.1245 \\
\hline$\hat{\sigma}_{P}$ & $\ldots$ & $\infty$ & 26.4002 & 4.3349 & 12.7817 & 2.0705 \\
\hline$\hat{\sigma}_{W}$ & $\ldots$ & $\infty$ & 31.9409 & 4.7957 & 33.1409 & 5.2851 \\
\hline$\hat{\sigma}_{i s}$ & $\ldots$ & $\infty$ & 0.0829 & 0.0074 & 0.1137 & 0.0103 \\
\hline$\hat{\sigma}_{H}$ & $\ldots$ & $\infty$ & 0.1247 & 0.0495 & 0.1409 & 0.0615 \\
\hline$\hat{\sigma}_{B}$ & $\ldots$ & $\infty$ & 0.3402 & 0.0561 & 0.3405 & 0.0594 \\
\hline$\hat{\sigma}_{S}$ & $\ldots$ & $\infty$ & 2.6673 & 0.5246 & 1.3754 & 0.2881 \\
\hline$\hat{\sigma}_{i c}$ & $\ldots$ & $\infty$ & 0.1310 & 0.0164 & 0.5349 & 0.0615 \\
\hline$\psi_{\Delta Y}$ & $\ldots$ & $\infty$ & 0.7616 & 0.5048 & 0.9647 & 0.3258 \\
\hline$\psi_{\Delta F}$ & $\ldots$ & $\infty$ & 0.3036 & 0.1565 & 0.6830 & 0.2236 \\
\hline$\psi_{Y}$ & $\ldots$ & $\infty$ & 0.1045 & 0.1676 & 0.0100 & 0.0907 \\
\hline$\psi_{F}$ & $\ldots$ & $\infty$ & 0.2628 & 0.0910 & 0.0701 & 0.0716 \\
\hline $\bar{\sigma}_{P}^{2}$ & $\ldots$ & $\infty$ & 0.0296 & 0.0081 & 0.0245 & 0.0046 \\
\hline $\bar{\sigma}_{Y}^{2}$ & $\ldots$ & $\infty$ & 0.0344 & 0.0081 & 0.0328 & 0.0085 \\
\hline $\bar{\sigma}_{C}^{2}$ & $\ldots$ & $\infty$ & 0.0299 & 0.0062 & 0.0344 & 0.0089 \\
\hline $\bar{\sigma}_{I}^{2}$ & $\ldots$ & $\infty$ & 0.0685 & 0.0204 & 0.0756 & 0.0277 \\
\hline $\bar{\sigma}_{i s}^{2}$ & $\ldots$ & $\infty$ & 0.0024 & 0.0007 & 0.0026 & 0.0010 \\
\hline $\bar{\sigma}_{V^{H}}^{i^{3}}$ & $\ldots$ & $\infty$ & 0.0979 & 0.0264 & 0.1383 & 0.0622 \\
\hline $\bar{\sigma}_{i L}^{2}$ & $\ldots$ & $\infty$ & 0.0014 & 0.0005 & 0.0012 & 0.0004 \\
\hline $\bar{\sigma}_{V^{F}}^{2}$ & $\ldots$ & $\infty$ & 0.1630 & 0.1230 & 0.2130 & 0.0832 \\
\hline $\bar{\sigma}_{i F}^{V^{F}}$ & $\ldots$ & $\infty$ & 0.0015 & 0.0005 & 0.0022 & 0.0009 \\
\hline $\bar{\sigma}_{W}^{i t}$ & $\ldots$ & $\infty$ & 0.0427 & 0.0094 & 0.0429 & 0.0081 \\
\hline $\bar{\sigma}_{, L}^{2}$ & $\ldots$ & $\infty$ & 0.0045 & 0.0021 & 0.0087 & 0.0059 \\
\hline $\bar{\sigma}_{L}^{2}$ & $\ldots$ & $\infty$ & 0.0213 & 0.0057 & 0.0218 & 0.0101 \\
\hline
\end{tabular}

Note: All priors are diffuse, while all posteriors are asymptotically normally distributed. 


\section{References}

Adrian, T., N. Boyarchenko and D. Giannone (2019), "Vulnerable Growth", American Economic Review, Vol. 109, pp. 1263-1289.

Adrian, T. and F. Duarte (2017), "Financial Vulnerability and Monetary Policy", Federal Reserve Bank of New York Staff Reports, No. 804.

Adrian, T. and N. Liang (2018), "Monetary Policy, Financial Conditions, and Financial Stability", International Journal of Central Banking, Vol. 14, pp. 73-131.

Adrian, T. and H. Shin (2010), "Financial Intermediaries and Monetary Economics", Handbook of Monetary Economics, Vol. 3, pp. 601-650.

Borio, C. and H. Zhu (2012), "Capital Regulation, Risk-Taking and Monetary Policy: A Missing Link in the Transmission Mechanism?”, Journal of Financial Stability, Vol. 8, pp. 236-251.

Calvo, G. (1983), "Staggered Prices in a Utility-Maximizing Framework", Journal of Monetary Economics, Vol. 12, pp. 383-398.

Christiano, L., M. Eichenbaum and C. Evans (2005), "Nominal Rigidities and the Dynamic Effects of a Shock to Monetary Policy", Journal of Political Economy, Vol. 113, pp. 1-45.

Claessens, S., A. Kose and M. Terrones (2012), "How do Business and Financial Cycles Interact?", Journal of International Economics, Vol. 87, pp. 178-190.

Engle, R. and M. Watson (1981), "A One-Factor Multivariate Time Series Model of Metropolitan Wage Rates”, Journal of the American Statistical Association, Vol. 76, pp. 774-781.

Erceg, C., D. Henderson and A. Levin (2000), "Optimal Monetary Policy with Staggered Wage and Price Contracts", Journal of Monetary Economics, Vol. 46, pp. 281-313.

Galí, J. (2011), “The Return of the Wage Phillips Curve”, Journal of the European Economic Association, Vol. 9, pp. 436-461.

Galí, J. (2015), Monetary Policy, Inflation, and the Business Cycle: An Introduction to the New Keynesian Framework and Its Applications, Princeton University Press.

Gerali, A., S. Neri, L. Sessa and F. Signoretti (2010), "Credit and Banking in a DSGE Model of the Euro Area", Journal of Money, Credit and Banking, Vol. 42, pp. 107-141.

Geweke, J. (2005), Contemporary Bayesian Econometrics and Statistics, Wiley.

Harvey, A., E. Ruiz and E. Sentana (1992), "Unobserved Component Time Series Models with ARCH Disturbances", Journal of Econometrics, Vol. 52, pp. 129-157.

Hodrick, R. and E. Prescott (1997), "Post-War U.S. Business Cycles: A Descriptive Empirical Investigation”, Journal of Money, Credit and Banking, Vol. 29, pp. 1-16.

Hülsewig, O., E. Mayer and T. Wollmershäuser (2009), "Bank Behavior, Incomplete Interest Rate Pass-Through, and the Cost Channel of Monetary Policy Transmission", Economic Modelling, Vol. 26, pp. 1310-1327.

Iacoviello, M. (2005), "House Prices, Borrowing Constraints, and Monetary Policy in the Business Cycle", American Economic Review, Vol. 95, pp. 739-764.

Justiniano, A. and G. Primiceri (2008), "The Time-Varying Volatility of Macroeconomic Fluctuations", American Economic Review, Vol. 98, pp. 604-641.

Kalman, R. (1960), "A New Approach to Linear Filtering and Prediction Problems", Transactions ASME Journal of Basic Engineering, Vol. 82, pp. 35-45. 
Kass, R. and A. Raftery (1995), "Bayes Factors", Journal of the American Statistical Association, Vol. 90, pp. 773-795.

Kiyotaki, N. and J. Moore (1997), "Credit Cycles”, Journal of Political Economy, Vol. 105, pp. 211-248.

Klein, P. (2000), "Using the Generalized Schur Form to Solve a Multivariate Linear Rational Expectations Model", Journal of Economic Dynamics and Control, Vol. 24, pp. 1405-1423.

Liu, Z., D. Waggoner and T. Zha (2011), "Sources of Macroeconomic Fluctuations: A RegimeSwitching DSGE Approach", Quantitative Economics, Vol. 2, pp. 251-301.

Lucas, R. (1976), "Econometric Policy Evaluation: A Critique”, Carnegie-Rochester Conference Series on Public Policy, Vol. 1, pp. 19-46.

Smets, F. and R. Wouters (2003), “An Estimated Dynamic Stochastic General Equilibrium Model of the Euro Area", Journal of the European Economic Association, Vol. 1, pp. 1123-1175.

Storn, R. and K. Price (1997), "Differential Evolution-A Simple and Efficient Heuristic for Global Optimization over Continuous Spaces”, Journal of Global Optimization, Vol. 11, pp. 341-359.

Theil, H. (1966), Applied Economic Forecasting, North Holland Press.

Vitek, F. (2009), "Monetary Policy Analysis and Forecasting in the World Economy: A Panel Unobserved Components Approach”, International Monetary Fund Working Paper, No. 238.

Vitek, F. (2014), "Policy and Spillover Analysis in the World Economy: A Panel Dynamic Stochastic General Equilibrium Approach”, International Monetary Fund Working Paper, No. 200.

Vitek, F. (2018a), “The Global Macrofinancial Model”, International Monetary Fund Working Paper, No. 81.

Vitek, F. (2018b), “Accounting for Macrofinancial Fluctuations and Turbulence”, International Monetary Fund Working Paper, No. 238.

Woodford, M. (2001), "Fiscal Requirements for Price Stability", Journal of Money, Credit and Banking, Vol. 33, pp. 669-728.

Woodford, M. (2003), Interest and Prices: Foundations of a Theory of Monetary Policy, Princeton University Press. 